\title{
Investing in youth: Testing community-based approaches for improving adolescent sexual and reproductive health
}

\author{
Tamara Fetters \\ Fines Munkonze \\ Julie Solo
}

Follow this and additional works at: https://knowledgecommons.popcouncil.org/departments_sbsr-rh

Part of the Community-Based Research Commons, Demography, Population, and Ecology Commons, and the International Public Health Commons How does access to this work benefit you? Let us know!

\section{Recommended Citation}

Fetters, Tamara, Fines Munkonze, and Julie Solo. 1999. "Investing in youth: Testing community-based approaches for improving adolescent sexual and reproductive health." Lusaka: CARE Zambia and Population Council. 


\section{Investing in Youth:}

Testing Community based Approaches for Improving Adolescent Sexual and Reproductive Health

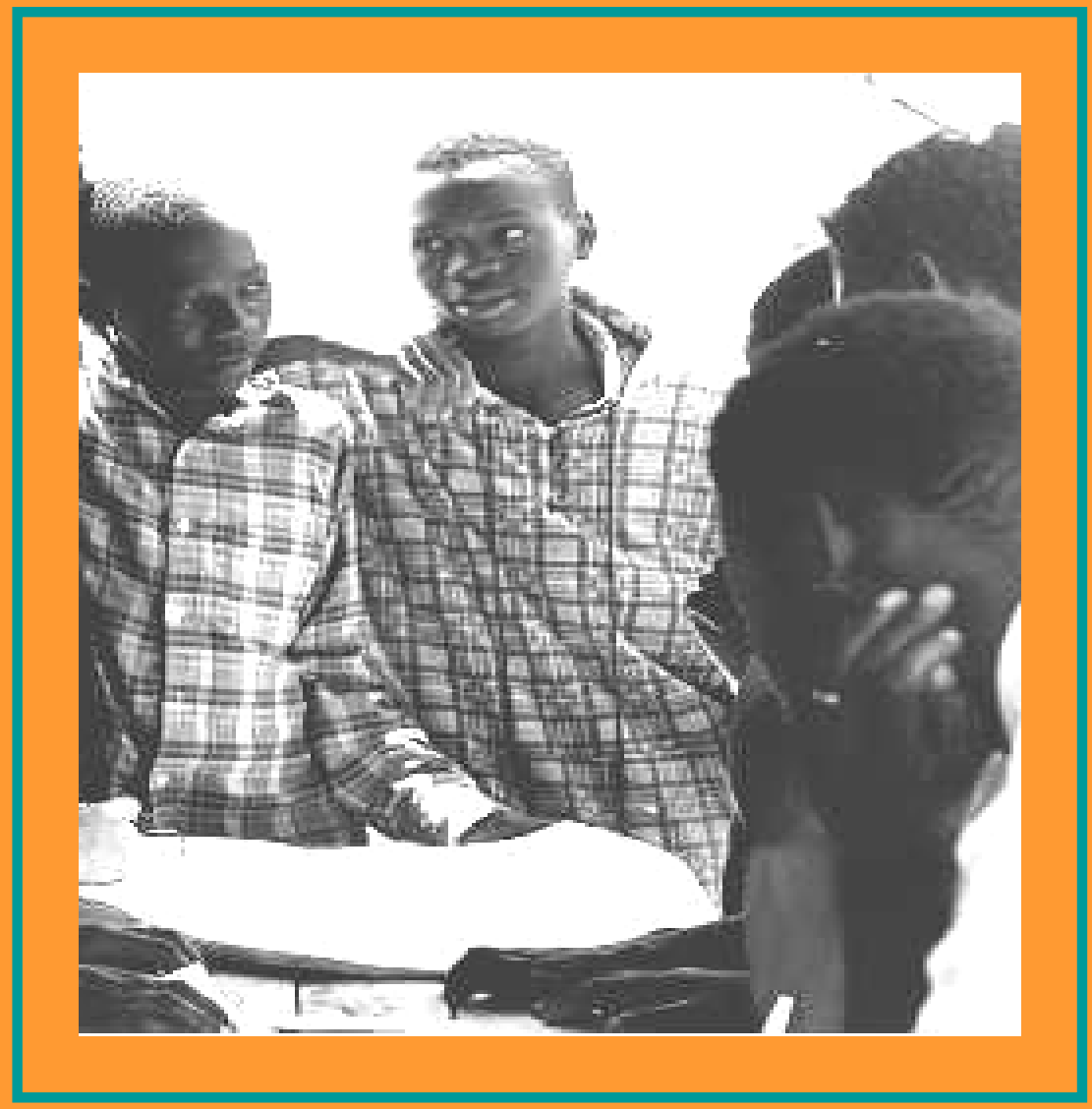

Tamara Fetters

Fines Munkonze

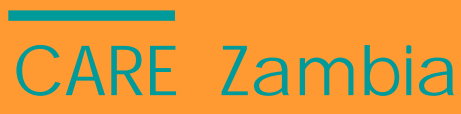

Julie Solo

Africa OR/TA Project II

The Population Council 


\section{Table of C ontents}

Acknowledgments ii

Executive summary iii

Introduction $\quad 1$

Problem statement 1

What to do? Going beyond focus group discussions 2

Study design/methodology $\quad 5$

$\begin{array}{ll}\text { Phase 1: A summary of PLA baseline findings } & 7\end{array}$

Phase 2: Implementation of the two interventions 8

Phase 3: Evaluation of the interventions 10

$\begin{array}{ll}\text { Study findings } & 11\end{array}$

The peer education/condom sales agent intervention 12

$\begin{array}{ll}\text { Recommendations for improving the peer education/ } & \\ \text { condom sales agent intervention } & 16\end{array}$

$\begin{array}{ll}\text { The micro-finance intervention } & 17\end{array}$

Recommendations for improving the micro-finance
intervention

Impact on intervention participants $\quad 27$

Peer education/condom sales agent intervention participants $\quad 27$

Micro-finance intervention participants 33

Community impact $\quad 40$

Final community based PLA assessments and
survey results

Sexual behavior among youth in Lusaka: To make
love grow

Pregnancy Prevention $\quad 46$

HIV/AIDS and sexually transmitted infections $\quad 50$

Program coverage $\quad 54$

$\begin{array}{ll}\text { Community impact conclusions } & 57\end{array}$

Comparison of the interventions: measuring success $\quad 57$

$\begin{array}{ll}\text { Policy and programmatic recommendations } & 58\end{array}$

$\begin{array}{ll}\text { Appendices } & 60\end{array}$

Listing of study outputs and presentations $\quad 60$

End of project questionnaire on sexual and reproductive
health

${ }^{*}$ Cover design and photo by Noreen Fagan - Mtendere adolescents discussing sexuality during participatory exercises 


\section{Acknowledgments}

This study would have been impossible without the enthusiastic involvement of the peer educators and the micro-finance participants in Mtendere, Ngombe and Kanyama Compounds. These young peer educators, with the support of their families, were determined to contribute something in their communities even when others told them that they were wasting their time or what they were doing was morally wrong. Many of the loan recipients spent hours preparing their business skills lessons and struggled to make loan payments even as the Zambian economy was faltering. We must also thank the providers in Mtendere and Kanyama clinics and the Residents' Development Committee in Kanyama Compound who supported our efforts throughout the study.

We thank the Planned Parenthood Association of Zambia (PPAZ) and Makeni Ecumenical Center (MEC), who, as partners in this project, deputed their representatives to take part in the research. Our special thanks go to many individuals without whom this project would surely have been impossible. First and foremost, Sarah Degnan Kambou and Naomi Rutenberg who conceptualized this project; Meera Kaul Shah and Rose Zambezi who have contributed towards refining the field methodology; the CARE PULSE Project whose members contributed their expertise and training skills in the area of micro-finance; and Wingray Michelo and Michelle Munro for their enthusiasm and comments on this paper.

Finally, we must thank the project staff who always believed in trying harder and building a better project. They worked long hours to test new ideas and approaches, document their work and meet the needs and demands of their participants. The PPAZ credit officers, Patrick Mwango and Vincent Mufwinda; the credit officer from CARE, Joseph Ndelefa, the peer educator/condom sales agent supervisors, Mutale Nkonde from CARE and J. R. Muunyu and Chrispin Simbotwe from MEC. Also, all of the Operations Research staff, Gladys Nkhama, Evans Mupela, Mangala Chambeshi and Jones Katongo, who supported this work with their efforts.

Of course, none of this would have been possible without the financial support and technical assistance of the Population Council's Africa OR/TA Project II, a project supported by The United States Agency for International Development. 


\section{Exec utive Summary}

The world is now sustaining the largest number of youth in human history; today there are nearly 900 million 10-19 year olds and their health and livelihood issues are becoming increasingly important to policy makers worldwide. In Zambia, as in many other countries, young people face severe problems, including limited access to jobs, secondary education and health care. The social, economic and peer pressures that youth face often lead to high levels of sexual activity, often with subsequent negative impacts on their sexual and reproductive health. For example, in Zambia it is estimated that more than two-thirds of adolescents are sexually active by age 18, almost onequarter of girls are mothers by age twenty, $20 \%$ of a sample of urban females aged 1519 were HIV positive, and young women in the 15-19 year age group are five times as likely to be infected with HIV as boys in that age group.

In spite of the magnitude of the reproductive health problems facing youth, they still have limited access to effective programs and services to address these problems. In an effort to address this need, CARE Zambia, in collaboration with the Planned Parenthood Association of Zambia (PPAZ) and Makeni Ecumenical Center, with technical assistance and funding from the Population Council's Africa Operations Research and Technical Assistance Project II, have conducted a study to test community based approaches for improving adolescent sexual and reproductive health $(\mathrm{SRH})$.

\section{Study Design}

The study followed a pre-post test design to assess the impact of the interventions and to make comparisons between the different interventions. The following table outlines the three phases of the project and the data that were collected during each phase. An innovative aspect of this project was its use of the Participatory Learning and Action (PLA) methodology. Using a variety and mix of verbal and visual tools, this methodology helps participants appraise their situations, identify and analyze their concerns and plan for strategies to address these concerns. It can be a particularly useful approach when dealing with a sensitive research topic, such as adolescent reproductive health, as it helps to build community involvement, support and ownership.

\section{Phases of study and sources of data}

\begin{tabular}{|c|c|c|}
\hline & Sources of data & Dates \\
\hline Phase 1: Baseline & $\begin{array}{ll} & \text { Community based PLAs } \\
\text { - } & \text { SRH surveys in each community } \\
\text { - } & \text { SRH survey with intervention } \\
& \text { participants }\end{array}$ & Nov 1996 - March 1997 \\
\hline Phase 2: Interventions & $\begin{array}{l}\text { - Process evaluation with the } \\
\text { implementation team }\end{array}$ & April 1997 - Nov 1998 \\
\hline Phase 3: Evaluation & $\begin{array}{ll}- & \text { Community based PLAs } \\
\text { - } & \text { SRH surveys in each community } \\
\text { - } & \text { SRH surveys with intervention } \\
& \text { participants }\end{array}$ & June 1998 - Dec 1998 \\
\hline
\end{tabular}

The intervention phase involved implementing two strategies aimed at improving adolescent sexual and reproductive health: 1) adolescent peer educators/ condom sales 
agents; and 2) micro-finance for youth. Each intervention was tested in one compound, while in a third compound both interventions were implemented together. A fourth compound was selected as a control site. This four cell design is depicted below, showing the compound, the implementing agency in that compound and the interventions that took place.

\section{Structure of interventions}

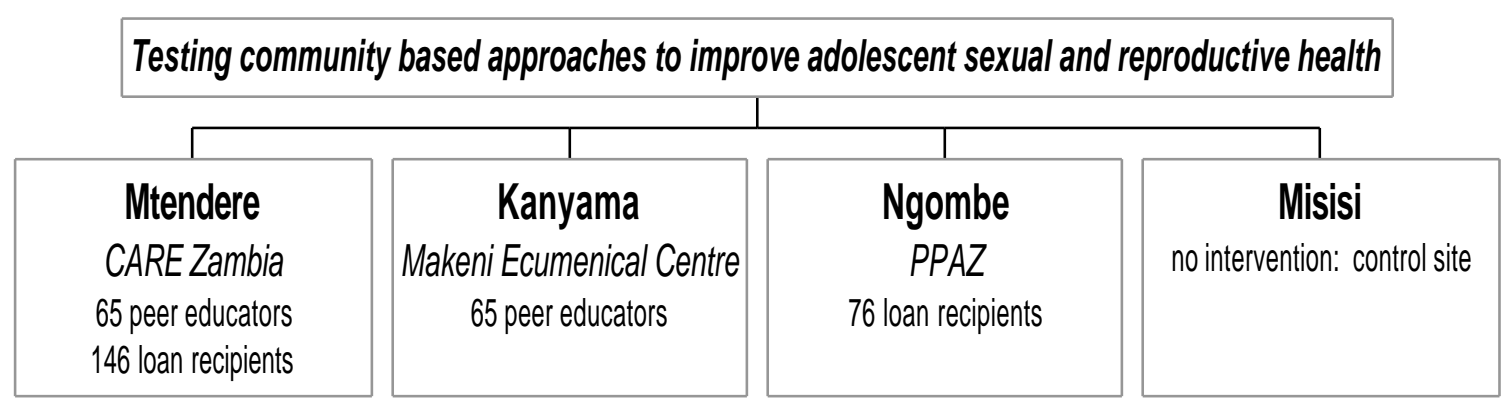

\section{Findings}

\section{The Interventions}

Based on the baseline findings and previous work by CARE in Zambia, two interventions were developed and implemented to help improve adolescents' lives, as detailed below.

\section{Peer Educators/ Condom Sales Agents}

The objective of this intervention was to promote safer sex behaviors and provide accurate sexual and reproductive health information through adolescent community counselors who also acted as condom sales agents. During the course of implementation of the intervention, 130 adolescents were trained, over 65,600 condoms were distributed and over 4,000 sexual and reproductive health counseling sessions were held in the clinic and/or in the community.

Although the peer educators were quite successful at distributing condoms, they were not successful at selling them; of the 65,600 condoms distributed, only 5,000 were sold. They gave many reasons for their difficulty in selling condoms, including the widespread availability of free condoms in the community and the ethical dilemma they faced in denying access to condoms to those who could not afford them in the face of such high rates of STIs and HIV/AIDS in the community. In the words of one peer educator, "as most clients don't have money but engage in sexual activity, it is better to give them free so they are protected." The general opinion of these sales agents was that adolescents are unlikely to spend money on condoms because their earning potential is so low.

\section{Micro-finance}

The objective of this intervention was to promote safer sex behavior through the introduction of activities that promote a more positive view of one's self and one's future by building skills needed for improving the livelihood status of out of school young 
people. Overall, 221 adolescents participated in business skills courses and received small loans.

The repayment on the loans has been disappointing. Of the total amount disbursed, $35 \%$ and $11 \%$ in Mtendere and Ngombe, respectively, has been recovered. These rates improve somewhat if we disregard those adolescents who have paid back nothing, increasing to $41 \%$ in Mtendere and $17 \%$ in Ngombe. Reasons for not paying back the loan included the generally poor state of the Zambian economy, the pressure of family responsibilities, the need to pay for funerals or theft of the money by friends, relatives or thieves. It is worth noting that the repayment pattern for girls was consistently higher than that of boys. The credit officers felt that the girls took the project and their responsibilities more seriously.

In spite of the difficulties, there was general agreement that a great deal was learned in the process and that implementing credit programs with youth is a new area that should still be pursued, learning from the efforts that have taken place.

\section{Impact on participants}

Both the peer educator and the micro-finance interventions had substantial impact on the participants. Peer educators were pleased to be able to counsel and help others and felt that they had gained self-confidence. Most credit recipients $(78 \%)$ felt that they had been able to accomplish something useful with their loans, but they would have liked additional vocational and business skills training. Seventy percent were still in business at the time of the follow up interviews. Almost half (47\%) said that receiving the loan had changed their plans for the future. In regards to her future, one young woman said "I seem to have a bright one".

\section{Changes in sexual and reproductive health behavior among intervention participants (baseline $\rightarrow$ final)}

\begin{tabular}{|l|c|c|c|c|}
\hline SRH variable & \multicolumn{2}{|c|}{ Peer educator } & \multicolumn{2}{c|}{ Micro-finance } \\
& Kanyama & Mtendere & Ngombe & Mtendere \\
\hline $\begin{array}{l}>1 \text { sexual partner in past } \\
3 \text { months }\end{array}$ & $11 \% \rightarrow 7 \%$ & $16 \% \rightarrow 2 \%$ & $6 \% \rightarrow 2 \%$ & $6 \% \rightarrow 2 \%$ \\
\hline $\begin{array}{l}\text { condom use in past 3 } \\
\text { months }\end{array}$ & $50 \% \rightarrow 58 \%$ & $56 \% \rightarrow 81 \%$ & $80 \% \rightarrow 89 \%$ & $83 \% \rightarrow 79 \%$ \\
\hline $\begin{array}{l}\text { pregnancy prevention } \\
\text { used in past 3 months }\end{array}$ & $55 \% \rightarrow 75 \%$ & $50 \% \rightarrow 77 \%$ & $68 \% \rightarrow 90 \%$ & $72 \% \rightarrow 63 \%$ \\
\hline $\begin{array}{l}\text { abstinence over past 3 } \\
\text { months }\end{array}$ & $55 \% \rightarrow 65 \%$ & $49 \% \rightarrow 54 \%$ & $55 \% \rightarrow 67 \%$ & $45 \% \rightarrow 65 \%$ \\
\hline
\end{tabular}

Changes in sexual behavior were more consistent and significant among the peer educator group. In the in-depth interviews conducted with intervention participants, 94\% of peer educators indicated that they were practicing safer sexual behavior, while only $45 \%$ of credit recipients said that they had changed their sexual behavior. The following table shows that there were greater changes in the peer educator compounds for variables such as condom use and pregnancy prevention, while loan recipients were somewhat more likely to have practiced abstinence over the past three months. 


\section{Impact on the community}

There were similar trends found in both the baseline and final community evaluations. Sexual activity starts young and is common among youth. Payment for sex is widespread. Family planning services are not accessible for young people. Contraceptive use is low among adolescents, while knowledge of methods to use to induce abortion is quite high.

It appears that the interventions were not able to delay or stop sexual activity; in the post-intervention period, age of sexual initiation had not increased and levels of sexual activity had not decreased. However, it does seem that adolescents in the intervention compounds were practicing safer sexual and reproductive health behavior. The following evidence supports this conclusion:

- Adolescents in the intervention sites were less likely to have had more than one sexual partner in the past three months as compared with the baseline figures and as compared with the control site. The following figure shows these data for girls.

\section{Proportion of girls who have had more than one sexual partner in the past three months, by compound}

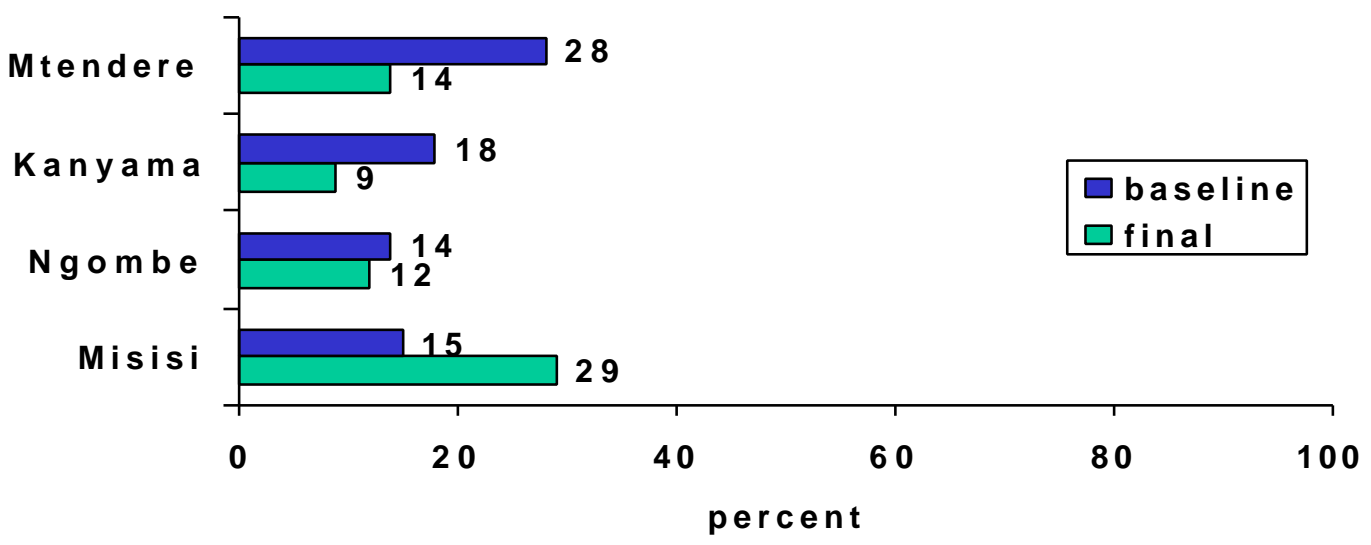

- Condom use seemed to show greater increases in the intervention sites as compared with the control site.

- The control site showed a higher proportion of adolescents reporting that they had had an STI in the previous nine months as compared with the intervention compounds.

- Adolescents who had suffered from an STI in intervention sites were more likely to seek treatment from a clinic as opposed to a nganga (traditional healer) as compared to the control site.

\section{Comparison of the interventions}

The two interventions that were tested were very different, and, not surprisingly, the achievements of the participants were also very different. While changes in sexual 
behavior were more pronounced in the peer educator groups, changes in outlook for the future, the ability to go back to school and feelings of responsibility toward one's self and one's family are also important and came out strongly from the micro-finance participants. Although we focused on sexual and reproductive health, the adolescents themselves viewed the improvements of their lives differently and more broadly. As one of the loan recipients in Mtendere put it to us, "..Instead of relying on parents I have a self reliance to move ahead."

The variation between the compounds and the short study period make it difficult to assess differences in community impact due to the project. However, overall it seems that the peer education program had greater community level impact. This is not surprising since peer educators were trained to go into the community to provide counseling and condoms, while the credit recipients were not expected to actively share their new skills and information with the community beyond their usual social networks.

\section{Recommendations}

Peer education programs:

- Peer educator programs are labor-intensive but they seem to pay off both in communities and among participants themselves in terms of improving sexual and reproductive health

- Peer educators should distribute condoms for free rather than selling them

\section{Micro-finance programs:}

- A successful micro-finance program for youth must have meaningful involvement of households in the groundwork, as family responsibilities have a large impact on adolescents

- A successful micro-finance program for youth must have strong selection criteria

- A micro-finance program that targets female adolescents will do better than one that targets males

\section{General recommendations:}

1. Any interventions that wish to affect the age of sexual initiation need to start in primary schools. Our intervention did not have an impact on the age of sexual initiation because our fourteen to nineteen year-old target group was already several years older than the average age of sexual initiation in these communities.

2. Reproductive health programs must be more proactive about addressing girls' livelihoods. Interventions that have a broader and more integrated approach to development can also have positive reproductive health outcomes.

3. Young people need accurate information on the dangers of self-induced abortion. Access to modern family planning methods is limited for youth and many 
young people have misperceptions about what family planning methods are available and appropriate for their use. Because of this, young people often resort to traditional methods and modern medicines that are probably highly ineffective and potentially dangerous.

4. In order to address the stigma that surrounds condom use, the condom social marketing program should be stronger in their campaign to promote condoms as a family planning method. Adolescents primarily view condoms as a means of protecting themselves from acquiring an infection rather than as a method for preventing pregnancy. Therefore young people who try to negotiate condom use are often stigmatized and thought to have an infection or chastised for considering their partner to be at risk.

5. In order to make condoms more accessible to young people, special condom distribution campaigns should focus on youth and these should utilize a variety of channels and locations. Condoms are the most important family planning and disease prevention method for young people in Zambia. Many young people state they want to use condoms but have problems accessing them, either freely or for sale. Making condoms available to young people in places and manners that are acceptable to them must become a high priority in order to improve youth access to condoms. 


\section{Introduction}

\section{Problem statement}

The world is now sustaining the largest number of youth in human history; today there are nearly 900 million $10-19$ year olds and their health and livelihood issues are becoming increasingly important to policy makers worldwide. Zambia is no exception, the population is youthful, with 26 percent of its nearly 9 million inhabitants aged between 10 and 19 years (1996 Zambia Demographic and Health Survey). Almost $70 \%$ of these young people live in poverty. Most have limited access to jobs, secondary education and health care. Unless things change, more than $25 \%$ of these young people living in Lusaka will become HIV positive (Central Board of Health, 1998). The problems these adolescents face are unique and the messages and programs needed to reach them require innovation and understanding of their lives from their perspectives.

Most Zambian adolescents are sexually active by their mid-teens and many face social and peer pressure to engage in intercourse at an even earlier age. In a national sample of adolescents from the 1996 Zambia Demographic and Health Survey (ZDHS), more than two-thirds of adolescents admitted to being sexually active by age 18 . In a recent UNICEF study of 1100 school age adolescents in Lusaka, 38\% of $10-19$ year old girls and $71 \%$ of boys reported having engaged in sexual activity. When this sample was disaggregated by age, the figures were only slightly lower for $10-14$ year olds, $34 \%$ of girls and $71 \%$ if boys said that they had already had intercourse by the time they were fifteen (Webb, 1997).

In Zambia, pregnancy during adolescence is the norm rather than the exception even though pregnant teenagers have an elevated risk of maternal mortality and complications related to birth. Social, familial and economic pressures weigh heaviest on girls and often result in early marriage or, more often, early pregnancy outside of marriage as boys often shirk responsibility for the births. The 1996 ZDHS stated that by age nineteen almost onequarter of girls are pregnant or mothers. Although there are no reliable data on unwanted pregnancy community based research has shown that knowledge about traditional methods for inducing abortion is widespread amongst adolescents in Lusaka (Kambou et al, 1997). In 1990 at the University Teaching Hospital in Lusaka it is believed that selfinduced abortion accounted for up to $30 \%$ of maternal mortality, and one quarter of these deaths occurred in women under eighteen (Ahmed, unpublished data).

In addition, sexually transmitted infections (STIs), including HIV are a major health problem for adolescents. A 1997 study by UNICEF and the National AIDS Program found that adolescents make up about 40 percent of the STI clients who present to out patient departments in Lusaka (Webb, 1997).

In spite of the fact that nearly all Zambians know that HIV/AIDS is transmitted through sexual intercourse HIV infection rates among 20-29 year olds continue to rise steadily. According to the Central Board of Health $(\mathrm{CBoH})$, the Zambian HIV prevalence rate for adults over the age of 15 is 19.9 percent with the highest prevalence rate in the country in Lusaka where $26.5 \%$ of adults over age 15 are thought to be infected with the HIV virus $(\mathrm{CBoH}, 1997)$. According to a 1994 sentinel site survey of childbearing women ( $\mathrm{N}=11,517$ : aged 14-44) carried out in nine provinces, $20 \%$ of the sample of urban females 15-19 were HIV positive, while $32 \%$ of the $20-24$ year old women were infected 
(Fylkesnes et al, 1994). Young women in the 15 to 19 year old age group are five times as likely to be infected with HIV as boys in that age group.

Despite high risk of unplanned pregnancy, unsafe abortion and STIs, only a small proportion of adolescents take action to protect themselves from pregnancy and STIs. According to the 1996 ZDHS, only 4.7 percent of $15-19$ year old girls in Zambia were using a modern method of contraception. However, there is some evidence suggesting that young people would use condoms if they had increased access to them. In a 1996 KAP study conducted by The Society for Family Health in Lusaka, $27 \%$ of sexually active $15-19$ year old girls and $35 \%$ of boys reported having used a condom at the time of their last intercourse (Agha, 1998). No data on younger adolescents are available but it can be assumed that their use of contraception (including condoms) is much lower.

These numbers clearly indicate the magnitude of the sexual and reproductive health problems among adolescents. In addition, adolescents themselves repeatedly identify teenage pregnancy and STIs as serious health problems. However, there are many barriers to improving this situation. Adolescents encounter considerable opposition by parents and teachers to the use of modern contraceptive methods. Most adults recommend abstinence before marriage. In a qualitative study conducted in 1990, fortysix percent of mothers were in favor of modern methods of contraception for adolescents, but only 18 percent of fathers said they approved. Reasons given for these restrictive attitudes include concern about side effects, that use of family planning leads to prostitution, and beliefs that modern contraception can only be effectively used by educated persons (Nyirenda et al.,1990).

\section{What to do: Going beyond focus group discussions}

During CARE Zambia's four years of programming in the health and education sectors it became clear to us that "traditional" interventions for adolescents may not work in this environment of hopelessness; too many interventions had come and gone without addressing issues of relevance to the target population. In an effort to use a participatory development approach and address adolescents' own concerns, CARE Zambia, the Planned Parenthood Association of Zambia (PPAZ) and Makeni Ecumenical Center (MEC) have implemented a study to test new and innovative ways of reaching adolescents with sexual and reproductive health information. This project has been implemented with technical assistance and funding from the Population Council's Africa Operations Research and Technical Assistance (OR/TA) Project II.

We began the study with Participatory Learning and Action (PLA) ${ }^{1}$ assessments among adolescents in four shanty settlements (commonly referred to as compounds) around peri-urban Lusaka. PLA has been used at CARE Zambia to explore knowledge, attitudes

\footnotetext{
${ }^{1}$ PLA is a growing family of approaches and methods that enable people to share, enhance and analyze their knowledge of life and conditions, to plan and to act. PLA is also known as PRA (Participatory Rural Appraisal) developed by Robert Chambers and colleagues at the Institute of Development Studies in the UK. PLA is based on the principles of learning through visualization. The process is aided by trained facilitators.
} 
and practice regarding sexual behavior and reproductive health, food security and urban livelihoods made increasingly tenuous by stringent structural adjustment policies, the high prevalence of HIV/AIDS and other debilitating diseases in the country. We chose to use a participatory approach for a number of reasons including:

- The sensitivity of the research subject; participatory approaches can mobilize community support and sensitize community leaders.

- Lack of existing qualitative data on adolescent sexual and reproductive health (SRH); PLA data yields definitions, causes, consequences and context necessary to develop appropriate interventions.

- Involving adolescents at the level of project design is a starting point for empowerment and ownership of projects.

- Community participation is philosophically in line with the ongoing Zambian Health Reforms; participatory research encourages communities to take responsibility for their own health.

- PLAs were used to identify a core of support among adolescents for dissemination of results and to begin the self-selection of groups to participate in the interventions.

- PLA results were used to develop a peer counseling curriculum that is culturally sensitive, timely and addresses local misconceptions and needs.

We used participatory methodologies and asked adolescents to discuss and analyze their own health needs and behaviors, thus compiling information from more than 3,500 adolescents. PLA assessments required skilled facilitators and community volunteers to build rapport with the research participants. Good facilitators work adeptly with many different tools and experiment with the use of new tools and topics in their approach. The following chart shows a partial list of tools used during the PLAs in Lusaka.

\section{Selection of tools used during Participatory Learning and Action research}

\begin{tabular}{ll}
\hline PLA tool & Specific uses \\
\hline Social mapping & $\begin{array}{l}\text { Establishing important locations, resources, diversity in } \\
\text { neighborhoods, social clusters and networks }\end{array}$ \\
\hline Body mapping & Finding common terminology \\
\hline Ranking/ scoring & Understanding adolescent prioritization and decision-making \\
\hline Focus group discussions & Exploration of issues and problems regarding adolescent health \\
\hline In-depth interviews & $\begin{array}{l}\text { Compiling case studies on important sexual health issues, adding } \\
\text { depth with personalized data }\end{array}$ \\
\hline Sketch drawing & $\begin{array}{l}\text { Understanding sexual behavior, building rapport, drawing out quiet } \\
\text { participants }\end{array}$ \\
\hline Transect walk & Observing the diversity of resources, orientation \\
\hline
\end{tabular}

Not surprisingly, from these assessments we found adolescents' lack of economic, recreational and educational opportunities to rank highest in their own descriptions of their needs. We were also made aware of the incredible gender disparity in economic relations among adolescents; most adolescents in these areas were sexually active by the age of 13 (some as early as eight years of age) and, for girls, sex for sweets, snacks, 
money or answers to schoolwork was commonplace. In a survey we conducted as part of the assessment more than $80 \%$ of girls' last sex acts were remunerated in some way. Risky sexual behavior like engaging in sex for money with multiple partners was often attributed to economic need or often just boredom. While the connection was not always made explicit by young people themselves when we engaged them in problem-solving exercises they often related their own risky sexual behavior with a lack of educational or employment opportunities and a sense of hopelessness about the future.

The use of PLA methodology clearly had an impact on many different groups during the study. PLA teams were comprised of up to 25 members from within the partner organizations and the communities where we were conducting research. Instead of lengthy training sessions community facilitators are paired with expert facilitators for "on the job" learning. At the end of each day in the field the PLA teams were responsible for recording and reporting back to the groups their results from that day. These community facilitators helped us to analyze, discuss and disseminate the results in their communities. Some facilitators who excelled were kept on and used in other communities, one Neighborhood Health Committee volunteer eventually became a project staff member. At least a dozen other local and international NGOs, research organizations, interns and policymakers also seconded members to take part in the participatory research at some time during the study. All of this has culminated in a strong commitment on the part of donors, organizations and government officials to use participatory approaches to improve their research and programs.

During the final evaluation we also trained peer educators in PLA methods to assist in the data collection; not only were they pleased with the opportunity to be involved, they excelled. They were able to see for themselves the problems articulated by their peers and identify the weaknesses and strengths of their own peer education programs. Including them in the groups also meant that adolescents were able to bring their problems directly to clinicians and community leaders.

Figure 1: Mtendere adolescents participating in a PLA pocket voting exercise led by two peer educators

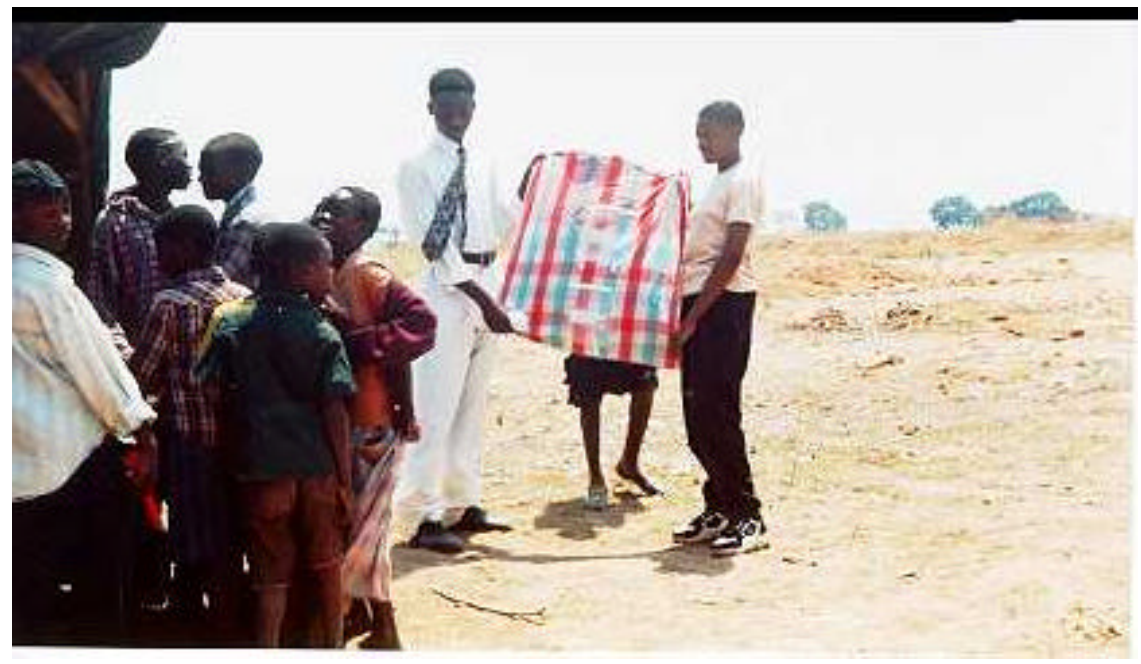


Through this study we were trying to affect sexual behavior change with interventions that not only increased knowledge but also gave the participants a more positive outlook about the future. Our measures of success were to promote consistent and correct condom and contraceptive use and abstinence in these communities but our approach was slightly different than many that have been tried in the past. We tried to respond to adolescent needs and desires and use activities that would promote individual and group responsibility and build self-esteem and self-confidence, and thereby become a vehicle for sexual behavior change. We promoted activities that may not have had direct benefits to the adolescent's livelihood in the long term but would at least provide them with activities that promoted a positive view of one's self and a more optimistic outlook about their own future.

\section{Study design/methodology}

This study and the evaluation of this study used a pre-post test design that broadly followed the three phases outlined below.

\section{- Phase 1: baseline assessments (November 1996 - March 1997) \\ - Phase 2: intervention implementation (April 1997 - November 1998) \\ - Phase 3: evaluation of the interventions (June 1998 - December 1998)}

The baseline PLA assessments were conducted with groups of adolescents aged $10-19$ in order to include a wide range of perspectives and topics related to young people and their sexual and reproductive health behavior. The interventions however included only youth between the ages of 14 and 19. The two interventions that were evaluated and compared were 1) a micro-finance intervention and 2) a training program for adolescent peer educators and condom sales agents. Each of these was tested in one compound, while in a third compound both interventions were implemented together. A fourth shanty compound was selected as a control site where no intervention would be operating.

While many similarities exist in the lifestyles and livelihoods of peri-urban adolescents and their families it is very difficult to establish comparability between four communities in urban Lusaka. The socio-economic situations and compound infrastructure were more similar in Kanyama and Mtendere than they were to Misisi (the control site) and Ngombe. During the baseline fieldwork there were several discussions about the possibility of making the control site (Misisi) the PPAZ intervention site. Unfortunately, though the need was great in Misisi Compound, the implementing agencies felt that it was difficult to work in a compound that had just been legalized because the community infrastructure was not yet developed and the Lusaka City Council was still hesitant to commit resources to the new area. PPAZ also felt that they needed to work in an area where they already had established projects. These differences between the compounds were taken into account during the analysis. The location and implementing agency for the study is illustrated in the following diagram. 


\section{Structure of interventions}

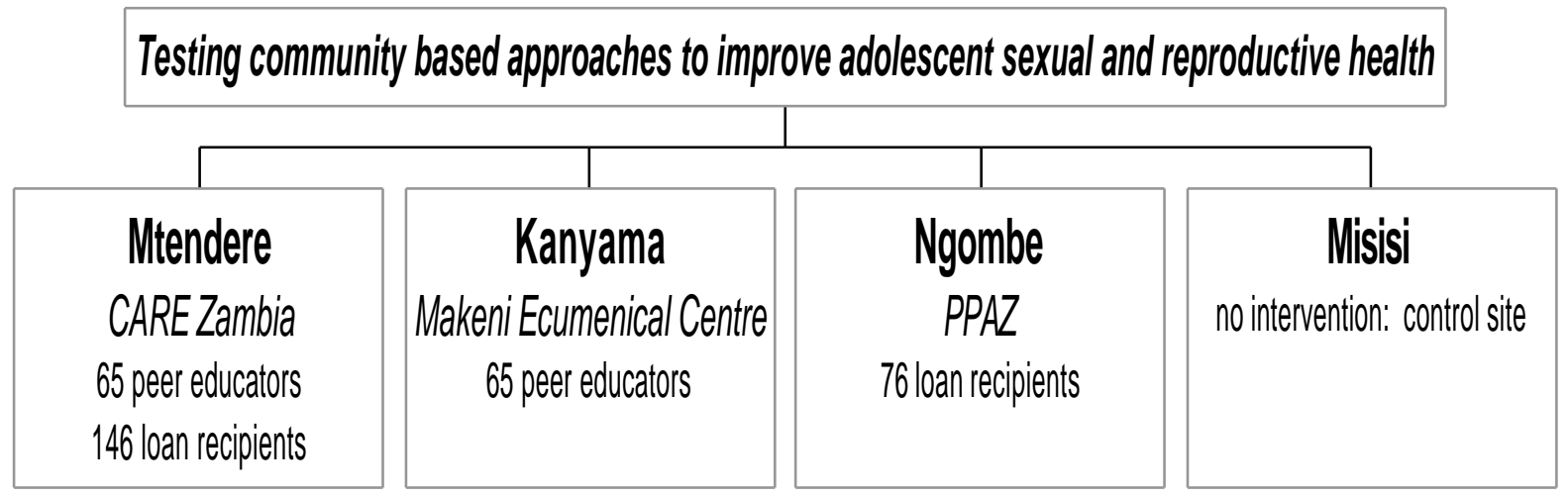

The study was conducted by three organizations, with CARE Zambia playing a lead role and implementing both interventions in one community and two other partner organizations, The Planned Parenthood Association of Zambia and Makeni Ecumenical Centre implementing one intervention each, the micro-finance program and the peer education program respectively.

The interventions selected for the study were aimed at improving these young people's feelings of self worth. In the process of doing this we were trying to fulfill our primary study objective, to increase the motivation for avoiding pregnancy and sexually transmitted disease by building adolescents' selfesteem and sense of responsibility and encouraging safer sex behaviors (primarily consistent and correct condom use) among them.

A number of other secondary programmatic objectives were identified:

- to facilitate peer-driven counseling and accurate information about adolescent sexual and reproductive health

- to work closely with adolescents to promote individual and group responsibility, build self-esteem and self confidence

- to promote leadership skills, civic responsibility and community development for social change

- to build program and research capacity within CARE's health sector programs and partner NGOs

Being committed to participation in development means involving young people in their own choices and programs; it means addressing their concerns and not making false promises. It is unclear whether the interventions implemented as part of this project can sustain improvements to these young people's livelihoods, but we did hope to improve their own sense of optimism about the future by involving them in meaningful activities during the interventions; activities that would ultimately contribute to their own life skills and coping strategies. It was in this manner that we hoped to cause these young people to take more responsibility for their own sexual lives. 


\section{Phase 1: Summary of PLA baseline findings ${ }^{2}$}

PLA research yields relatively quick and low-cost results useful for program design and implementation. During the research we talked to hundreds of adolescents about sexuality and reproductive health and gave them an opportunity to look at their own lives (and the lives of their peers) and identify potential solutions to their own problems. Often we would find adolescents waiting for us at the meeting place wanting to take part and share with us their own thoughts and feelings.

It is clear from this research that environment contributes to poor sexual and reproductive health. In these communities adolescents live in crowded environs where people do not disguise or try to hide their sexual activity. These communities have no recreational facilities and few economic opportunities other than small scale vending and trading for sex in the surrounding taverns. Sexual activity begins as early as eight years of age and can be either forced or consensual. Reliable sources of information on sexual health in the early years are almost nonexistent and sex as a bartering tool is deeply embedded in these adolescents' lives.

Household living situations also play a role in an adolescent's sexual behavior. In these households sexual relations amongst neighbors and relatives (especially cousins and inlaws) are common, maybe even expected. Subsequently, adolescents get most of their "sex education" from observation, film and media, and friends; they are least likely to discuss these problems with parents and clinicians. They often seek information about sexual and reproductive health problems from grandparents and ngangas (healers). All of their sources of information are ripe for the inaccuracies and misperceptions that are common in their communities.

These adolescents prefer to buy (if they have money) traditional or modern contraceptives rather than go to the health center. Regarding contraception, they hold strong beliefs in the efficacy of traditional contraceptive methods, abortifacients and tablets and capsules sold to them by local marketers. Most of the adolescents we spoke with could only name two modern contraceptive methods ("pills" and condoms, although condoms were more often associated with protection from disease rather than pregnancy) and their knowledge of STIs often confused symptoms commonly associated with the diseases. The adolescents had an abundance of information on traditional (and often harmful) methods for inducing an abortion at home, in a private clinic or with the help of a traditional medical practitioner. Adolescents are reluctant to go to a health center for treatment of an STI or for contraception because they insist that there is no confidentiality and they are often chastised for "bad behavior".

Peer pressure, "young love", pornographic film and economics all play a role in increasing sexual activity in this compound. The early ages of sexual initiation put young people at a greater risk of STI both physiologically and because of the increasing number of partners in their lifetime. Most sex in this area is "paid for" with some form of food, gift or cash. Economic needs for school and survival are great, "payment" or exchanges for sex begin early and become commonplace. Schoolchildren often trade sex for pencils, snacks or test answers. Early sexual activity is common amongst in and out of school boys and girls; in school girls have even more economic needs than out of school girls

\footnotetext{
${ }^{2}$ Refer to the baseline report "Youth Talk About Sexuality" for a more detailed description of the baseline PLAs conducted in Lusaka.
} 
but they lack the vending opportunities open to the young school leavers. Although girls occasionally give gifts or money to male sex partners, all of the girls said that they preferred boyfriends who "could pay something".

Adolescents hold a general disdain for condoms even though they are aware that condoms prevent disease and pregnancy. Many boys feel that condoms are too big for them, they prefer "skin-to-skin" sex and do not feel at risk of acquiring STIs or AIDS. Girls rarely initiate condom use for fear a boy will think she is "sick" or because the boys claim that she does not trust or love him. If a girl wants to use a condom, the girls complain that boys will "prick the condoms" to get them pregnant because the girls were arrogant enough to demand condom use. Some young boys and girls believe that a young boy cannot impregnate a girl because his "sperms are not strong enough". Perhaps, in part, because of this belief condom use increases in the mid to late teens except in the case of young female partners with older boys who will not use condoms because they believe they are with "young clean girls".

During the PLA research the suggestions of the adolescents were clear: "invest in us and invest in our communities". They listed improvements in infrastructure (schools, clinics, garbage collection, and recreation facilities) as well as interventions that would affect their own lives (vocational training and starter capital for projects). These adolescents clearly saw their environment as having an effect on their sexual and reproductive health and reaffirm the need for more integrated reproductive health programming that addresses not only health but also economic development and skillbuilding.

\section{Phase 2: Implementation of the two interventions}

Based on the baseline findings and previous CARE work, two interventions were developed and implemented to help improve adolescents lives, as detailed below.

\section{Intervention One: Adolescent peer educators/condom sales agents}

Objective: To promote safer sex behaviors and provide accurate SRH information through adolescent peer educators who also act as condom sales agents. The purpose of this strategy is to reach adolescents with important information regarding their sexual and reproductive health and to improve adolescent access to condoms for protection from disease and pregnancy. Socially marketed Maximum condoms were sold to adolescents at wholesale prices and then the condoms could be sold in their communities for a small mark up. Ultimately the intervention should build individual and group responsibility, self-esteem and self confidence in the participants themselves.

\section{Main activities:}

- Counseling adolescents in the health center and in the community.

- Condom sales or the distribution of free condoms.

- Drama and role play activities in the community, local churches and in compound schools.

- Sexual and reproductive health education for the adolescent loanees, recreation and sports activities and exchanges with the loanees. 


\section{Monitoring of activities:}

- Monitoring forms were collected from the clinic as well as individual counseling contacts for peer counselors counseling outside of the clinic.

- Qualitative reports were turned in monthly by the peer educators to explain in their own words what they felt to be their successes and failures.

\section{Timeline:}

- One hundred adolescents were trained in five 5-10 day courses on sexual and reproductive health and basic business skills necessary for social marketing of condoms between April and September 1997

- Five refresher courses were held during the twelve month period after the first one hundred adolescents were trained. Other activities such as sports exchanges, field days, condom sales competitions and community-based drama also helped maintain enthusiasm and ensure the exchange of accurate information.

- One of the implementing agencies chose to establish a field office for holding meetings and activities; the groups in the other compounds met on the clinic grounds. Generally, the groups met weekly although for some individuals attendance was sporadic.

- In order to combat attrition occurring among the peer educators another 30 peer counselors were trained in a 5 day course on sexual and reproductive health and basic business skills necessary for social marketing of condoms.

- An internal evaluation was conducted in May of 1998. The evaluation included the project implementation team and a random sample of the intervention participants.

\section{Project outputs:}

- PLA results were used to develop a facilitator's guide on adolescent sexual and reproductive health for peer educators and condom sales.

- Over 65,600 condoms were distributed in these two communities; only 5,000 of these condoms were sold while the rest were distributed for free.

- Over 4,000 self-reported SRH counseling sessions were held in the clinics and/or in the two communities.

\section{Intervention Two: Micro-finance for youth}

Objective: To promote safer sex behavior through the introduction of activities that promote a positive view of one's self and one's future by building skills needed for improving the livelihood status of out of school young people.

\section{Main activities:}

- Selection of adolescents for a 14 hour small business skills course for out of school youth. Trained peer educators were used in the business skills courses to facilitate $\mathrm{SRH}$ discussions and training sessions with the perspective loanees.

- After completing the course and a loan interview each successful young person was given a small loan of Kw 100,000 (US $\$ 67$ on average) to begin or to build their business.

- Loanees repay their loans with interest over a six month period while accumulating a small savings. 
- Three credit officers from PPAZ and CARE conducted the training, collected the repayment, supervised the loan recipients and participated in the evaluation of the credit recipients.

\section{Timeline:}

- 221 adolescents participated in business skills courses from August 1997-March 1998.

- 221 adolescents were given loans of Kw100,000 each between October 1997-April 1998.

- $\quad$ The scheduled repayment period was from December 1997 - October 1998.

- An internal evaluation was conducted in May 1998. The evaluation included the project implementation team and a random sample of the intervention participants.

\section{Project outputs:}

- Loan procedures manual for adolescent microcredit recipients

- Basic business skills course for adolescents

- The table below shows the number of loans distributed and the amounts repaid in each of the communities over the life of the project.

\section{Loan distribution and repayment in Mtendere and Ngombe compounds}

\begin{tabular}{|l|c|c|}
\hline & Mtendere & Ngombe \\
\hline Loan recipients & 146 & 75 \\
\hline Young women & $77(53 \%)$ & $36(48 \%)$ \\
\hline Amount disbursed (Kwacha) & $\mathrm{Kw} 14,600,000$ & $\mathrm{Kw} 7,500,000$ \\
\hline Amount repaid (Kwacha) & $\mathrm{Kw} \mathrm{5,166,000(35.4 \% )}$ & $\mathrm{Kw} 860,000(11.5 \%)$ \\
\hline Adolescents paying nothing & $21(14 \%)$ & $20(27 \%)$ \\
\hline Adolescents repaying everything & 7 & 2 \\
\hline
\end{tabular}

\section{Phase 3: Evaluation of the interventions}

This study was designed to allow adolescents and community members to play an active role in all aspects from design to dissemination. Project evaluation took place during each of the three phases at community and individual participant levels. The phases and data sources are illustrated below.

\begin{tabular}{|c|c|}
\hline Phase of study & Sources of data \\
\hline Phase 1: Baseline & $\begin{array}{l}\text { - } \text { Community-based PLA assessments } \\
\text { - SRH surveys in each community } \\
\text { - SRH survey with each intervention participant prior to } \\
\text { training }\end{array}$ \\
\hline Phase 2: Implementation & - $\quad$ Process evaluation with the implementation team \\
\hline Phase 3: Evaluation & $\begin{array}{ll}\text { - } & \text { Final community-based PLA assessments } \\
\text { - } & \text { Final SRH surveys in each community } \\
\text { - } & \text { Final SRH survey with each intervention participant who } \\
& \text { could still be located } \\
\text { - Final questionnaire with a random sample of intervention } \\
\text { participants }\end{array}$ \\
\hline
\end{tabular}

During the baseline PLAs community members were trained in the use of PLA methodology in order to give the communities a sense of ownership as well as allow 
them to disseminate some of the contentious findings about adolescent sexuality. The PLA information was supplemented with a short survey on sexual behavior and knowledge with approximately 400 adolescents in each site. The PLAs also helped us to form groups of adolescents who participated in their own dissemination and action planning and formed the backbone for participant selection.

The same survey instrument on sexual and reproductive health was used prior to the training with each of the intervention participants. Eighteen months after the project started the same survey was conducted with as many of the participants who could still be located. An additional qualitative interview was conducted with a random sample of the participants in both interventions. Consent was obtained from the participants, all of the interviews were conducted by trained researchers, there were no names on the interview forms to ensure confidentiality and the adolescents were encouraged to answer candidly. Unfortunately a few of the questionnaires from the baseline intervention sample were spoiled and have been omitted from the sample. All analyses have been conducted using Epi Info software.

In addition to the research conducted with the intervention participants during the final phase of the study, a process evaluation was conducted with the implementation team and the counterparts in their organizations. The diversity of approaches and the participatory nature of this study gave rise to many useful comments and suggestions for improving each of these interventions and the project in general. In addition, notes from the monthly meetings were analyzed to identify the main issues and lessons from the field.

Finally, during the last two months of the study, final PLAs and surveys were conducted in each of the sites including the Misisi control site. During the final evaluation peer educators participated in the PLAs and discussions were held as a form of selfevaluation of their interventions. This information contributed to our understanding of the project and changes in sexual behavior that had occurred on a community level.

In the end we found it very difficult to compare these two interventions. The skills developed and the lessons learned among the peer educators and among the microfinance participants varied drastically and meant different things to the groups and to the individuals within them. In this report we have chosen to highlight the changes in their sexual behavior because this was, ultimately, our primary objective. However, the report would not be complete without addressing the different comments and perceptions of the micro-finance participants and the peer educators as they felt that the interventions had contributed to their own views of their lives.

\section{Study Find ings}

The findings are presented in three main sections: 1) a description of the implementation of the interventions, including recommendations for improving these types of interventions; 2) the impact of the interventions on the participants, namely the peer educators and the loan recipients; 3 ) the impact on the community. Finally, there is a discussion of a comparison between the two interventions and some of the methodological issues around making this comparison. 


\section{The peer education/condom sales agent intervention}

\section{Condom sales}

Many organizations worldwide have utilized peer educators to disseminate information on safer sex practices although the idea of these peer educators actually distributing contraceptives has often met with resistance. Heeding our baseline results from young people in Lusaka, which encouraged interventions that affected skills and livelihood status of young people, we looked for interventions that might enrich their lives in these areas and cause them to exhibit more protective sexual behavior.

A number of unique cultural characteristics led us to hypothesize that social marketing of condoms that utilizes and targets young people might work in Lusaka.

- The Population Services International (PSI) social marketing program in Zambia is one of the largest and most diverse in Africa, encompassing HIV/AIDS prevention, family planning and child health. The program has sold over 36 million condoms since its inception in 1994 and has made the MAXIMUM condom brand name a household word in Zambia. Because of this program Zambia was number eight in condom sales per capita in Africa in 1998. It seemed that these urban and out of school youth who are a key target population in social marketing programs might also be just the people to reach their more reluctant peers.

- Baseline and prior research conducted in Zambia had shown us that these same young people were extremely reluctant to go to the clinic for condoms claiming that they were "chased" [away] by the nurses if they tried. They also had no confidence in the confidentiality of the services they would receive at the clinic should they choose to use it.

- As in many parts of the developing world with strong social marketing programs, some people believe that the free condoms obtained at the clinic are inferior.

- The Zambia DHS reports high levels of awareness about AIDS as a sexually transmitted disease. This knowledge and awareness about the use of condoms as the primary means for preventing the spread of HIV is increasing demand for condoms.

All of the peer educators were given their first 48 condoms for free after completing their training and were then required to purchase more condoms from their supervisors at wholesale cost. Although participation as a condom sales agent was to be a prerequisite for training participation for these youth, most of the adolescents were not happy with the idea of condom sales. They went so far in their protestations that they asked that "condom sales agent" not be put on their identity badges. We held numerous meetings with them to identify barriers to condom sales and find new ways to support them but most still felt that they could not sell condoms. We tried to recruit adolescents who were already involved in small scale vending thinking that these young people would simply add condoms to their stock. We also held meetings with parents, guardians and 
community leaders to try again to explain the objectives of the project and ask for their support.

In the evaluation conducted with the peer educators, almost one-third of these young people said that the part of the project they liked least was condom sales. One of the two condom distribution sites (65 peer educators) gave up on encouraging sales and began to distribute free condoms that were donated to the project through the International Planned Parenthood Federation in January, 1997. During the final evaluation most of the adolescents interviewed (83\%) indicated that they had given away or sold condoms during the project, as shown in the following figure.

\section{Figure 2: Types of condom distribution by peer educators, as reported in the final evaluation}

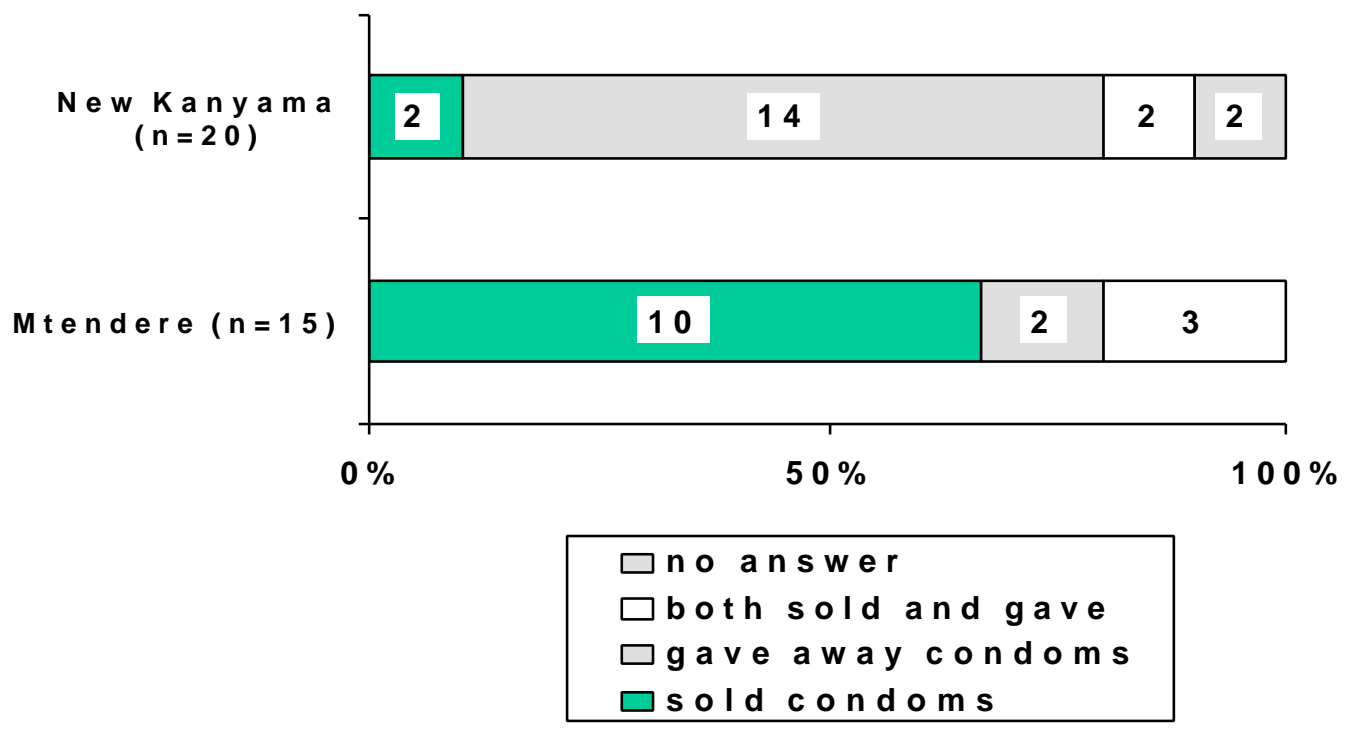

The reasons the young people gave for not liking condom sales were numerous but usually related to issues of conscience rather than profit. One young man felt that he was facing an ethical dilemma and explained why he had sold his condoms at a discount in his monthly report,

I have sold my condoms on such a price (Kw 180) because many teens can't manage to raise Kw250 and my main objective is not to make profit out of the sale of condoms but to encourage as many as I can manage to start using condoms at the moment.

Please, if you don't mind send some condoms to hand to peers who can not manage to buy these condoms because many poor teens are willing to use condoms to reduce the spread of STIs but because condoms seem to be expensive so they decide to have sexual intercourse without a condom as a result many of us peers are STI positive.

Another explained the situation as follows: "I felt shy that the client will not be protected and end up lose his/her life or others. As most clients don't have money but engage in sexual 
activity, it is better to give them free so they are protected." The overwhelming feeling was that "condoms are to protect lives so people should not have to buy them;" condoms should be accessible, available and free and adolescents would use them.

In the Mtendere site the peer educators were much more likely to sell condoms but this was mainly because we never supplied them with free condoms. They were, however, sometimes given Government issued condoms in the clinic to distribute while counseling there. When we used a scale to ask peer educators how comfortable they were giving condoms away, both groups scored in the middle of the scale (averages $=2.83$ for Mtendere and 2.89 for Kanyama) where five is the least comfortable. All but two of the adolescents interviewed felt that it was easier to give condoms away than to sell them; one of these said that it was difficult either way and the other said that, "[Selling them is fine] I had confidence in myself because of the training." The peer educators in Kanyama (where free condoms were being distributed throughout most of the project) were more likely than the ones in Mtendere to say that they were "helping people" because "when they have no money and need condoms it's easier to give free ones". One said, "In counseling it is better to give freely, if not it is better they buy from ntembas (market stalls)".

The Kanyama adolescents were also somewhat more likely to say that they were shy or embarrassed about giving condoms away, especially in front of their elders. A few adolescents in Kanyama (3) also felt that they should not be selling condoms as Christians and that they were encouraging prostitution by doing so. Another woman in this group said that "people looked at me differently for involving myself in condoms." Almost everyone except for a few girls said that they gave/sold most of their condoms to boys because boys are free to discuss sexual issues and ask for condoms. Of the few girls who said that they gave most of their condoms to girls they said that this was because girls are more at risk for contracting diseases. Another girl said that she gave most of her condoms to girls who "use them with sugar daddies who prefer not to carry condoms."

There is always a concern in condom distribution programs that the condoms are not reaching the target population and ours was no exception. We asked this sample of adolescents to estimate the percentage of condoms they had given/sold to adults (people over age 19). Almost all of them replied that some of their condoms had been given to older people but the answers varied widely. The averages were nearly the same in both compounds, they felt that they had distributed just over one-quarter of their condoms $(27 \%$ in Kanyama and 29\% in Mtendere) to people over the age of 19.

Many adolescents (particularly in Kanyama Compound) claimed that there was "too much availability of free condoms" in their communities and people are "used to getting them for free". Their peers chided them that "donors like CARE should have free condoms". In Kanyama Compound there were two other strong peer education programs that do distribute free condoms; the CARE Partnership for Adolescent Sexual and Reproductive Health Project (PALS) as well as a Ministry of Health/UNICEF peer educator project that also operates in Kanyama distributing free condoms in the health center and in the community. After six months of operation in Kanyama Compound the Makeni Ecumenical Centre staff decided to stop trying to encourage the peer educators to sell condoms and see if they would distribute them for free. Over the next year these adolescents distributed more than 60,000 condoms in their community. In comparison, the Mtendere peer educators only sold 5,000 condoms.

Pricing of condoms continued to be a problem throughout the course of the study. The peer educators felt guilty when their peers said that they had no money to pay for 
condoms. This put the peer educators in an awkward situation because they were required to purchase the condoms from their supervisors at wholesale prices and then to sell them at the retail price in order to make a small profit (about US 0.50 profit for selling 12 boxes of four condoms each ). In order to help the adolescents to be able to purchase the condoms we bought "shippers" of condoms in bulk from PSI and then broke them up and sold them as dispensers of 48 condoms to each sales agent. This meant that the return on each dispenser was minimal and it required a good deal of selfdiscipline to be able to save those profits and purchase another dispenser of condoms. The profits were low enough that they rarely remained with the capital for their next dispenser especially if their peers persuaded them to distribute the condoms for free or at reduced prices.

The general opinion of these sales agents (which is called into question in the community impact section) was that adolescents are unlikely to spend money on condoms because their earning potential is so low. As one peer educator said, "Kw150 is fetching for a bun." We asked if adolescents will ever pay for condoms and one supervisor responded, "Adolescents buy Maximum in a situation where there are no free condoms, especially at night in a bar."

\section{Project Management}

The flexibility given to the community counselor supervisors and the different styles of leadership between the partners made the project more dynamic in terms of the peer education activities. Twice monthly partnership meetings ensured communication and facilitated the flow of new ideas between the intervention sites. Having a field office based in one of the intervention sites also gave rise to more activities in this site; adolescents were able to use this site for sports and drop-in counseling and to arrange weekly meetings.

Animosity grew between some of the intervention participants because of what was seen as a lack of commitment or involvement on the part of their group members. Conversely some of the peer educators were so committed that we had to fight hard to temper their enthusiasm, enthusiasm that usually led to demand for incentives that we were not willing to pay. Many of the peer educators came and went over the course of the study period, and as a group we struggled with how to define "active" in a way that would satisfy everyone. The nature of this age group meant that many of the group members left because they had moved out of the area, were sent for courses or to relatives, or became employed. After one year we organized an extra training session to raise the knowledge level of some of the peer counselors who had been volunteering as well as provide encouragement to the first groups. This training also served as a refresher course for the first groups when twenty of the most active peer educators sat in on two days of the training.

The adolescents were adamant about the need for Identification badges and t-shirts. They were proud to be affiliated with CARE and felt that it was easier to introduce SRH topics to people if they had something "official". This debate followed us throughout the life of the project in terms of the definition of counseling. Some of the peer educators felt that they were only counseling if they were in the clinic Youth Friendly Corner. These adolescents felt that the privacy afforded them by the clinic Youth Friendly Corner was essential to their work. It was difficult for them to see the more casual dissemination of information that they impart on their friends as "counseling". It was a debate that came up monthly during collection of peer counseling contact forms. 
Peer educators were asked to keep track of their "community contacts" in the clinic as well as at home. They were given small cards to turn in monthly with their reported contacts in the community. Many of them also turned in "monthly reports". These were usually notes about meaningful events or suggestions they had for improving the intervention.

Special activities like sports exchanges, discussions about SRH topics as well as "Open Days" with drama contests and quiz shows were used as informal review or refresher sessions. These activities also helped keep up morale and encouraged the adolescents to review their course handouts in order to prepare role plays. The groups were also invited to facilitate special sessions at local churches and schools as well as to conduct trainings with the loan participants.

After completing the community counselor/commercial sales agent training, the adolescents received certificates for successfully completing the course. Many of these young people have no high school diploma or skill certification so, in a couple of cases, these adolescents have used the certificates to apply for piecework or entry-level jobs. The project staff are currently negotiating with CARE's micro-finance project to allow the certificates to be used as a form of recommendation for adolescents applying for small business loans.

We are continuing to pursue ways to improve project sustainability. Many of the adolescents, even almost two years after the training are still very active and committed to the project. We have taken every opportunity to introduce and integrate these young people into existing projects around Lusaka but the difficulties of communication and transport make it difficult for them. The adolescents themselves have tried to organize a Youth Advisory Board to sustain their counseling and SRH activities and have begun to develop their own proposals for activities with the assistance of members of the Operations Research Unit.

\section{Christianity}

Zambia is a Christian Nation, the only nation in Africa with Christianity written into the Constitution. Christianity ended up playing a major role in the peer counseling intervention. One of the peer educator supervisors is a church elder and the other a pastor so it was clearly important for them to bring these values into the group. Most of the adolescents also belong to church youth groups and they became very active in making presentations to different church youth groups in their communities. Two of the peer educators have become active in a youth coalition that has put together an inter-faith facilitator's guide for peer educators. The projects often used Bible verses, especially in Kanyama, to justify their programs in condom distribution and encourage abstinence. Still, a few of the adolescents continued to feel uncomfortable with their own views of Christianity and condom distribution. A few of them, especially in Kanyama, expressed these opinions in the final evaluation.

Many of the community-based churches were interested and supportive of our activities and none were actively resistant. There is clearly a need to utilize these institutions and expand support to them while being careful not to become pedantic and alienate other young people who may not be affiliated with a church. 


\section{Recommendations for improving the peer education/condom sales agent intervention}

Field office: The field supervisor in Mtendere felt that he could have been more effective if he had a field office in the compound (as they had in Kanyama) rather than meeting at the health center. The peer educators never actually complained that this was a problem and continued to meet regularly on their own at the group leader's home although not as frequently as the group in Kanyama that had scheduled meetings three times per week with their supervisors. Certainly supervising a peer education intervention is laborintensive and having supervisors based in the field and in close communication with the peer educators sustains the momentum, allows for flexibility in project management and eases demands for incentives.

Incentives: Not surprisingly this was the most common complaint and suggestion of the peer educators themselves. As in most peer education programs we tried to encourage participation in many other ways and alleviate the demand for remuneration. We organized refresher meetings, field days, sports exchanges, discussions, gave tshirts, badges, musical and sports equipment, included peer educators in district-wide workshops and included them in selected research activities. However, this is time consuming and worrisome to the supervisors of the peer educators. Without their daily presence in the field listening to concerns and developing new and creative ideas to sustain enthusiasm our attrition would have been much higher.

Condom distribution: While selling condoms was very unpopular, many of these adolescents were willing to distribute them for free and over 65,000 condoms were distributed in these two communities. Many of the youth, their friends and families seemed to have changed their attitudes about distributing condoms since the project began. It is also unclear to us whether or not the Maximum condoms would have been sold if they were donated to the adolescents for free rather than making them pay for them. It was a joint decision between PSI and CARE not to provide these socially marketed condoms to the young people for free but to provide them at wholesale prices to encourage sales rather than free distribution. At least two of these adolescents wanted to see the project expanded to include other products like the female condom and oral contraceptives.

Sustainability: Many of the peer educators indicated in their final questionnaires that they would like to see the project continue and even expand to new geographic areas. However, as in all peer education efforts this is difficult to sustain after the project ends. We have tried to encourage these youth by introducing them to other youth projects in Lusaka (as well as the PALS adolescent SRH project at CARE), by involving them in selected research projects and by encouraging them to plan and implement their own activities. To date the Mtendere group has written and submitted two small proposals for Lusaka-wide training activities. Many of the group members in Kanyama suggested the project expand into micro-finance or vocational and technical training.

\section{The micro-finance intervention}

Inherent in this intervention is a good deal of trial and error; the lessons we have learned in this component should prove to be extremely valuable to other organizations interested in income generating activities or micro-finance targeting youth. This type of intervention 
is increasingly popular in Zambia even though, to our knowledge, no existing youthfocused organization has had more than relative success in this area.

\section{Implementation}

CARE and PPAZ hired a total of four credit officers to run this intervention in May 1997. Two of these officers were based at PPAZ with an established field office in Ngombe Compound. The other two credit officers ran the program in Mtendere from the health center although one of these found another position during the project and was never replaced. All of the credit officers completed a training and orientation program on microfinance with CARE's PULSE Project ${ }^{3}$, a micro-finance project established in 1994 that targets men and women with small businesses for small enterprise development.

Adolescents began to form themselves into credit and savings groups during the PLA dissemination process. Those who were interested and fit the eligibility criteria of 14-19 years of age and out of school were asked to form credit cells of five members with their own friends and neighbors. We encouraged them to try and recruit young people with some business skills and this proved not to be difficult. The informal economy is so strong in Zambia that most (approximately 65\%) of these young people had some sales experience. Those who were selected also required approval from a parent or guardian and needed someone to pledge household items as collateral for the loan.

These five member cells were put together into a larger credit group to facilitate the business skills training. The credit groups drew up constitutions to define their own roles and responsibilities and began a fourteen hour business skills course covering topics including the identification of business opportunities, market research, marketing, stock control, record keeping, costing and pricing, cash management, savings, salesmanship and budgeting. Sessions on sexual and reproductive health were also included in the training. The reproductive health sessions were taught either with the aid of videos, by outside facilitators from PPAZ or CARE, or in presentations by our trained peer educators. The business skills courses were taught by the credit officers. Only adolescents who completed the course satisfactorily and had prepared a six month cash flow worksheet and business plan for their proposed business or expansion of their existing business could sit for an interview with the Credit Review Board. Business plans were reviewed in interviews conducted by the Credit Review Board and approved business plans were eligible to receive $\mathrm{Kw} 100,000$ loans (US $\$ 67$ on average) to invest in their business. The loan recipients worked closely with the credit officers to prepare their business plans and while many of the credit recipients were given comments and suggestions on their work plans fewer than ten individuals were actually disqualified if they reached this stage. More often they were sent back to incorporate changes with a credit officer before they could receive the loan.

\footnotetext{
${ }^{3}$ The CARE PULSE project has been in existence in Lusaka since 1995. Over that time period they have given more than 3,000 loans to men and women already in business. They do not target adolescents. The PULSE project is recognized as the foremost micro-finance organization in Zambia.
} 


\section{Figure 3: A Mtendere credit recipient at his ntemba (market stall)}

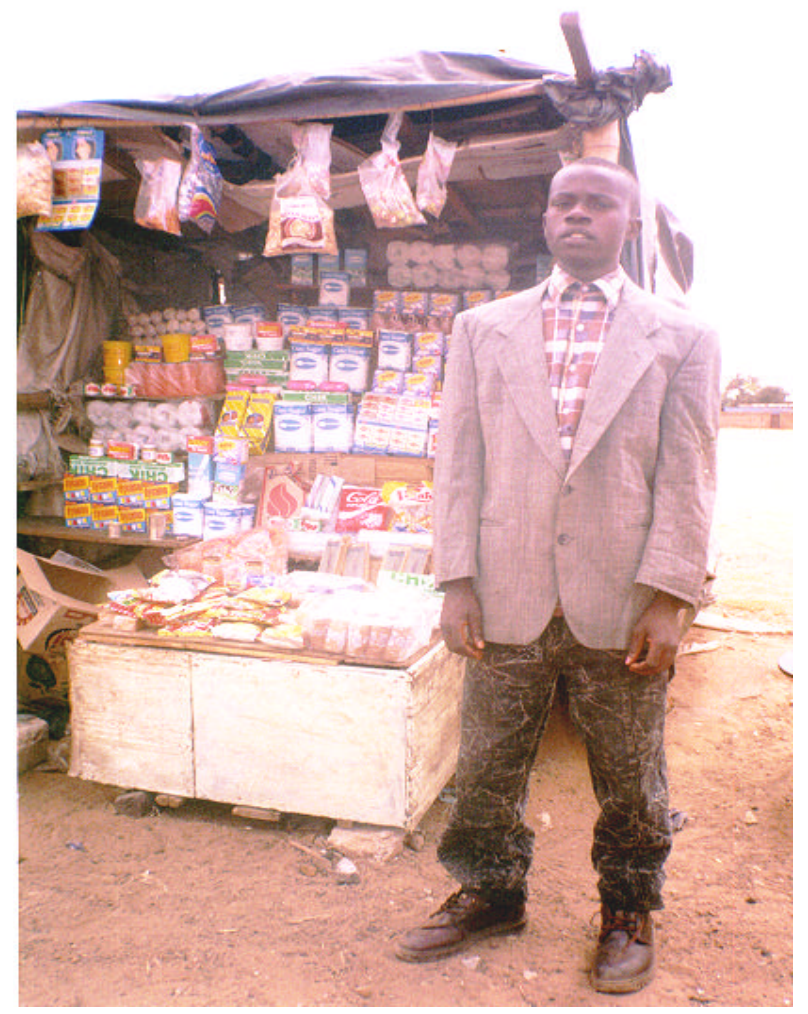

The small size of the loans and an ever-expanding informal sector in Lusaka meant that nearly $95 \%$ of the adolescents chose to engage in small scale vending activities. Most of them chose to sell sweets and snacks near the school, cooking oil, eggs, used clothing, or simple household groceries that could be sold from makeshift stands near their homes or in the markets around town. This created a debate within the implementation team about whether or not we had created too much local competition in their communities. Although market research was a part of all of the business skills trainings we were unsuccessful in encouraging diversification or collaboration in business activities. Some of the groups received presentations from small enterprise groups such as the Yenga sunflower press association or from CARE-affiliated business people socially marketing condoms but they were very reluctant to collaborate or innovate. They seemed to have a deep-seated mistrust of cooperation and even people in the same business would not pool their resources to buy goods. Perhaps living in very dense communities where people don't dare show others that they own a television or radio for fear of burglary has already jaded these young people. It certainly was true that default was often due to theft or fraud common even among relatives and household members.

\section{Encouraging savings}

Through the development of the group constitutions adolescents were taught about the repayment schedule, the interest rates set at $8 \%$ and the Loan Insurance Fund (LIF). The LIF is actually a proportion of each loan installment that was set aside as individual savings or collateral should other members in the group's cell default. In the end each loanee was given a loan of K100,000 and was asked to repay K120,000. From the extra K20,000, K8,000 was the interest payment and the other K12,000 Loan Insurance Fund 
was placed in an interest-bearing account to encourage their capacity to save. However, the LIF could only be collected after the principle loan amount and interest for the entire cell $(\mathrm{Kw} 540,000)$ had been repaid.

The interest rate for the loanees was set at $8 \%$. We were encouraged to charge interest to alleviate the idea of these loans being given as "free donor money" and certainly we heard this idea espoused anyway among some of the loan recipients who never bothered to repay anything. The interest payments were to be used to offset funds lost to loan defaulters. Ultimately, each adolescent was to repay:

\section{Kw 100,000 (principle) \\ Kw 8,000 (interest) \\ Kw 12,000 (Loan Insurance Fund/LIF) Kw 120,000 TOTAL}

The LIF was the most difficult concept for these adolescents to grasp. The concept of LIF as cell insurance and savings promotion has been used by CARE in other micro-finance projects with a good deal of success. The LIF was to be returned (with interest) to each individual if all of the five cell members completed repayment. Unfortunately it became clear to the adolescents quite early that they would not receive their LIF because too many of their fellow group members were not repaying. This led to bickering among the cell members and many who were repaying rebelled and said that they would only pay their principle and interest on the loan.

\section{Loan repayment}

Prior to disbursing loans a number of procedures were put into place to help ensure repayment. Parents and guardians were given letters explaining the project. Pledge forms to pledge items of furniture as collateral were collected from guardians for use by our organizations should the young people fail to repay the loan. If these guardians were illiterate or had questions they were visited in their homes by a credit officer. Group constitutions included the loanee obligations and the legality of the group should there be a need to repossess items pledged as collateral.

Repayment was always very slow and discouraged the credit officers as well as the adolescents who were repaying when they saw their peers fall into arrears. Nearly all of the loanees went into default but many adolescents continued to promise to repay (and did make efforts, especially in Mtendere) when they were given a longer repayment time than the initial six month repayment schedule. The poor repayment rates look somewhat different when you exclude $14 \%$ and $20 \%$ of the adolescents in Mtendere and Ngombe who have paid nothing. If we disregarded these adolescents the proportional repayment would be higher, $41 \%$ for adolescents who paid something rather than $35 \%$ in Mtendere and $17 \%$ rather than $11 \%$ in Ngombe as shown in the graph below. 
Figure 4: Local currency distributed and collected

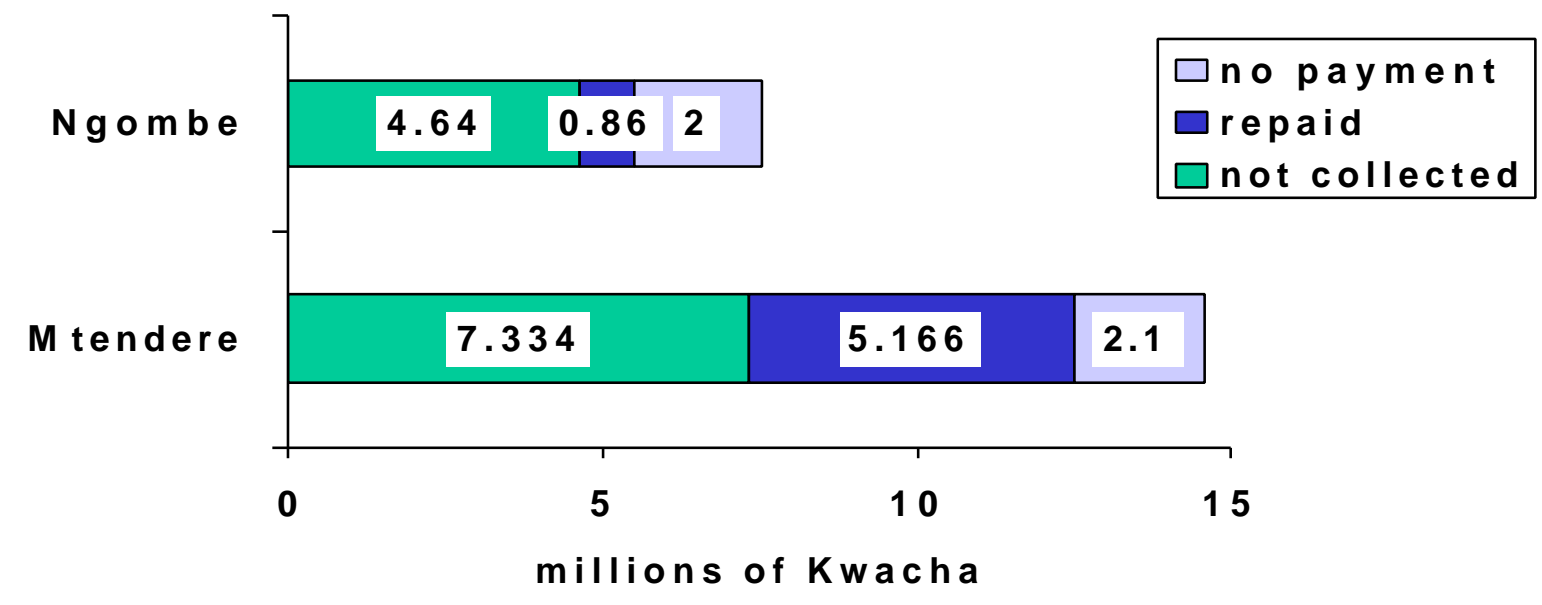

A few of the adolescents have even finished paying off the loans with interest. Ultimately, the team felt that with stronger and more appropriate selection criteria these repayment rates could probably be improved. Some of the possible criteria suggested included limiting the program to young women, those who are already doing business or those who are willing to start a savings account.

The repayment pattern for girls was consistently higher than that of boys. The credit officers felt that the girls took the project and their responsibilities more seriously and were "more afraid of the consequences". Figure 5 shows the number of boys versus girls who repaid proportions of their loans. For example, there were 15 boys who paid nothing as compared with only six girls.

Figure 5: Repayment in Mtendere, girls vs. boys $(n=146)$

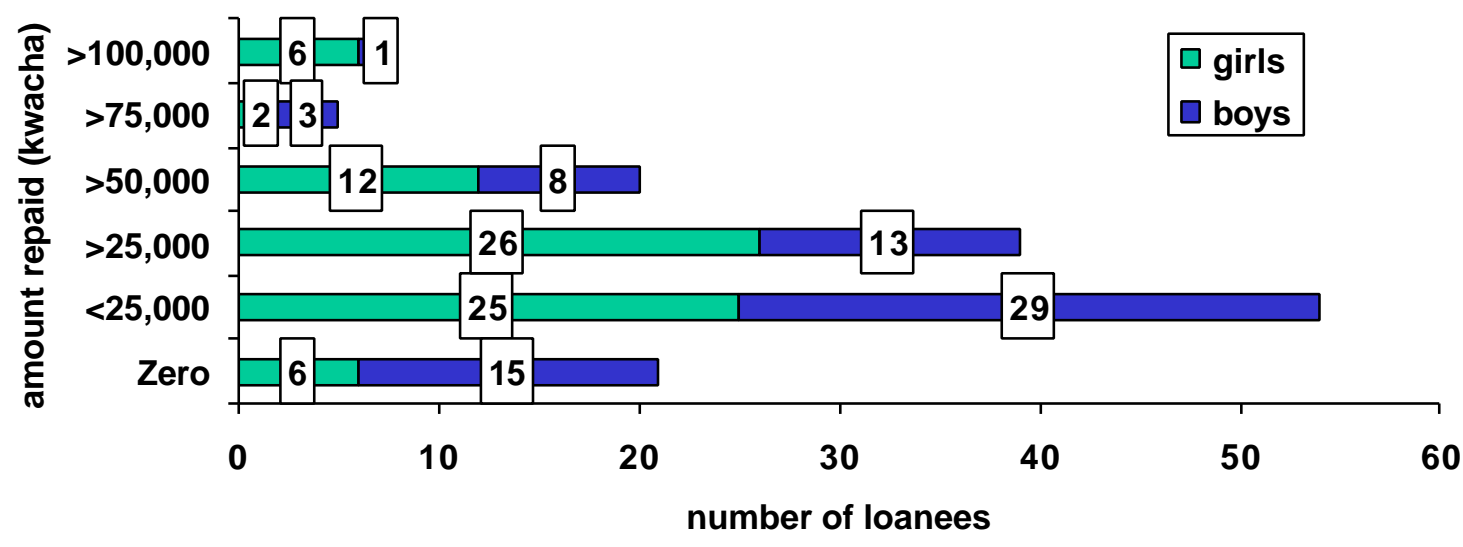

In Ngombe (the PPAZ intervention site) the situation was always much worse than in Mtendere. The credit officers in Ngombe have complained that they overheard one of their loanees chiding his friends for repaying the loans because "it was only donor money." These credit officers also felt that the socio-economic situation in Ngombe is 
worse than that of the young people in Mtendere. ${ }^{4}$ They felt that many of the households of these adolescents "had never seen Kw 100,000 at one time" and that their families were unable to come to the aid of these young people in the same way that the households in Mtendere could. Even the baseline SRH indicators indicate that sexual activity is somewhat higher and that girls were more likely to be remunerated and more likely to have an STI than in the other compounds.

Initially the grace period for making a payment on the loan was to be two months until the credit officers realized that motivation to repay was slipping as time passed. The grace period was shortened to one month and then to two weeks for the last three groups and the repayment rates improved tremendously in these last groups. The grace period was shortened. There was general debate about the improved repayment in the last three groups and no consensus was reached about whether this could also be attributed to better training and experience on our part. The credit officers also emphasized that they had learned to enforce a routine for repayment in order to cut down on field visits and encourage adolescents to come in to pay on certain mornings of the week.

\section{The environment}

The first loans were disbursed late in the year in 1997 and the repayment rates were very poor. Unfortunately, these adolescents faced seasonal pressures of the Christmas holidays, school fees and torrential rains that kept people off the streets and out of shops for two months. While most of these adolescents were not heading their own households they told us that it was difficult to deny assisting with the extra household obligations during these months. During the evaluation of a random sample of all of the loan recipients we noted that many of the adolescents who paid nothing were victims of serious hardship like a death in the family, theft or demands that they pay school fees for a sibling. A significant number were forced to hand over the loan to a household member with a promise that it was to be returned that never materialized. This is a case where the adolescent credit recipient cannot be seen as only an individual but as a member of a marginalized household. The added responsibility of the loan and income means that they are also expected to contribute although they probably have less power and ability to negotiate conditions in their favor.

Unfortunately, after two years of a stable currency market the Zambian economy began to stagger during this study period. These fluctuations have certainly affected adolescent businesses as well as repayment; the cost of goods has risen around the country and the value of all of the loans decreased dramatically after they were given. When the first loan group received funds in December 1997, the US dollar was worth 1,397 Zambian Kwacha; in October 1998, the exchange rate had increased to Kw 2,010.

\section{Logistics}

A labor-intensive project like this one requires motivated and self-directed staff willing to follow up clients on off duty hours. Fortunately for this project the small number of project staff (6) meant that people became highly invested in their interventions and well known by the participants. Three out of six field staff lived in the areas where they were working and two of the compounds had field offices for operating day to day activities.

\footnotetext{
${ }^{4}$ See the baseline report, Youth Talk About Sexuality, for a more lengthy discussion of the selection and comparability between the intervention sites.
} 
Because of the different agencies implementing the project the credit officer from CARE had a motorcycle but the two from PPAZ were only given bicycles. The mobility of these adolescents, the rough roads and maintenance on the cycles meant that transport in the field continued to be a problem for all of them. Many of the adolescents were selling in informal markets in other parts of the city and on-site supervision (and debt collection) was always difficult. Also, the transient nature of peri-urban Lusaka as well as a strong extended family network made supervising and tracking defaulting adolescents very difficult. People in this age group seem even more transient and often have little say in these moves; intervention participants were often sent for courses, sent to help or stay with an extended family member or encouraged to move in with friends, siblings or sexual partners.

\section{Conclusions}

There is an ongoing debate within the implementation team about how best to make this intervention work and what kind of "success" we would have had if we had done things differently. Throughout this project we have learned many lessons about the livelihoods of these young people and what is important to them. We have met regularly with our local partners involved in vocational training programs and small enterprise development and have begun to make regional and international contacts in this field. We started this project with a literature review that produced little in the area of adolescent micro-finance and instead drew heavily on local partners doing related work. Most of the literature that we did find on micro-finance led us away from this target group of young people as they were said to be too much of a financial risk and the loans too much of a burden on them at this early stage in their lives. Even though our objectives were health-related we hoped that the results would also touch the lives of these adolescents in other ways and improve their outlooks for the future. Certainly we have learned that "success" can be looked at in many different ways.

\section{Recommendations for improving the micro-finance intervention}

Throughout the project we spent a great deal of time trying new approaches and reflecting on what we had accomplished (or not). Even as we have focused much of our critique on the difficulties we have encountered while implementing this intervention there was still optimism among the project staff. Everyone felt that there had been significant steps toward changing SRH behavior among the intervention participants and that, given the opportunity, loan repayment could be improved with the lessons learned. After developing the initial training modules for the program the costs were not excessive relative to other interventions that focus on behavior change. The trainings are all done on-site on odd mornings of the week and the supervision is done by the credit officers from their field offices. On average each of the credit recipients received US\$67 and part of this investment has been recovered in repayment. The following suggestions are ones made collectively based on our experiences during this project.

- Length of repayment. The repayment time for the adolescents was set at six months giving the adolescents a weekly payment of 6,500 Zambian Kwacha. Looking back the credit officers think this repayment time may have been too long. Repayments tended to drop off after the first two months. The credit officers also experimented with different grace periods for repayment. They found that the two week grace period was more appropriate and greatly improved their repayment 
patterns. They also felt that repayment was better when collection was standardized on regular days and hours for each of the groups. In conclusion people felt that the grace period should remain at the initial two weeks after loan disbursement but that the repayment time should be minimized to three months thus doubling the weekly repayment to 13,000 Zambian Kwacha.

- Involvement of the parents and guardians. The project credit officers realized that they needed to encourage more involvement from the guardians in the initial stages of the project. In the first three groups they found some cases of fraud, where adolescents had forged parents' signatures on the "pledge" forms or the guardians simply did not understand the project and were never informed when the young people received their loans. After this was discovered the officers made sure to visit each of the households, explain the project again and confirm the signatures on the pledge forms.

Throughout the project much of the fraud occurred in the household where a downward spiral of arrears led to the adolescent's defaulting. In some cases it was the parent her/himself who demanded or borrowed the money and never repaid it. It is clear that the support and commitment of the young people is not enough to insure that their family members repaid money that had been borrowed from the loanees. Unfortunately these young people are not able to protest against the familial pressures in their households and are often expected to give up a portion of their loans to meet familial obligations even when this harms their chances for repayment.

In order to halt some of this fraud the credit officers encouraged better screening of loanees. They said there was a need to look more closely at household composition and familial relationships that might hinder these young people's chances for successful repayment. They also suggested meaningful involvement of parents and guardians in the training and early phases of the project to ensure that family members were well aware of all project activities and the repayment obligations.

- Goods versus cash. As the network of adolescent micro-finance groups has grown throughout Lusaka, our group's own ideas have also shifted and we have begun to look toward other projects for new strategies. One adolescent project run by the YWCA also trains young people in business skills, however, instead of giving cash the project arranges to deliver goods to these adolescents. The adolescents are expected to repay the equivalent amount in cash. Internally our debate centered around our objective of building a sense of responsibility and confidence in these young people, would this be considered a sign of mistrust in them if we chose this approach? Are we still building confidence or is this seen as even more of a donor handout? One member of the implementation team commented that, 'this is not protecting them but safeguarding the first steps to insure that they start out on the right path". Stealing goods is certainly not as desirable as cash and it was thought that this approach could alleviate the familial demands, fraud and theft that occurred when they first received the loans.

- Organizing training by trade. Another idea that has come from the staff is to organize the training groups by trade or goods being sold to make their training experience more directed and meaningful. Although this was never suggested by the adolescent participants, organizing the groups in this manner could also enable them to create buying groups for buying and transporting goods in bulk and offer them some additional cost savings and peer support. In our groups almost everyone 
chose to do some type of small scale vending so those groups might have to be organized by product or market location.

- Reasonable goals within reasonable time periods. One generally agreed upon problem was that the targets for intervention participants were too ambitious to allow for proper supervision and monitoring during this short study period. Contracts had to be signed, funds secured, staff hired and trained and the proper systems put in place to train intervention participants and insure financial accountability, all of this took the better part of one year and significantly cut into the time allowed for implementing the intervention.

Certainly the strategy most affected was the credit intervention. The credit officers were sent to CARE's PULSE micro-finance project for a month of training and then asked to develop their own implementation plans for this unique target group. Each group of 15 - 40 adolescents then had to be recruited and participate in a fourteen hour (3-4 week) business skills training. After completing training each adolescent was required to sit before the Credit Review Board to review their cash flow analysis and their own business plan for the loan. Checks had to be requested and approved and payments made to each of the loan recipients.

The process was so lengthy that the loan distribution by cell member could not be staggered if we were to meet the study targets (a total of 300 loanees in the two compounds) within the time frame. Ideally we would have used CARE Zambia's micro-finance model that gives payment to the first five members of five five-person "cells" and then requires those people to repay a significant proportion before the second members of the five cells can receive a loan. This model allows for more peer pressure on the individual cell members and encourages repayment. Instead, each of the 25 trained cell members was given a loan at the same time. We knew that we would not be exerting the same amount of group pressure to repay the loans if we chose this manner of implementation but the two year time period of the study left us with few options. We feel that the ideal implementation time (using the CARE model) would require fifteen months to distribute loans and support two groups of twenty-five people through the process after the systems have been put in place. However, new groups of twenty-five people could begin training while the first groups were completing repayment.

- Better screening of loanees. In micro-finance literature this is often cited as the point where a project is made or broken. We used a self-selection process begun in our PLAs hoping to allow adolescents to form cohesive groups of their peers that they could cooperate with. We needed stronger criteria for selection. These criteria need not be based on friendship or socio-economic status but rather on individual characteristics that are intrinsic to successful enterprising behavior. It is critical to the success of projects like these that these characteristics be culturally-bound, welltested and utilized if they are to succeed amongst high risk populations like youth with low earning power. Some of the criteria that were suggested included loaning only to young women, looking more carefully at household composition or employment of parents and guardians, having an established business, civic or community involvement or successfully completing individual interviews with the credit officers.

- Encouraging repayment. All members of the implementation team felt that there was too much fraud in the project which affected the morale of the participants and the staff. One loan recipient commented, 'there are some who haven't paid anything 
and they are having a negative effect on their friends". A debate has recently broken out among us about whether to repossess items put up for collateral by parents and guardians on individual pledge forms. This is routinely done by CARE PULSE and is even initiated by cell and group members to encourage repayment by defaulters. The idea would be to set an example of one or two persons who have not made a payment and encourage repayment in some members who have stalled. The items could then be "purchased" again by repaying the adolescent's debt. According to the PULSE Project setting an example in the community could be all that is required to stimulate better repayment. While this practice could certainly improve repayment levels some of the project staff were reluctant to initiate this practice for fear we could cause violence in these households and because we intended to test this strategy and not to cause more hardship in these already impoverished households. Some other suggestions for improving repayment have been to give certificates for completion of repayment and to establish linkages with other credit programs that might be more willing to give these successful adolescents second loans. The PULSE Project has already indicated an interest in providing second loans to those adolescents who have completed repayment.

- Savings. The implementation team felt that we ought to do more to encourage savings than to just maintain the Loan Insurance Fund. One way to encourage savings might be to institutionalize chilimba groups, a culturally accepted savings circle where members take turns paying into the fund and then receive their returns as one lump sum. Another possibility might be to require savings accounts or savings contributions from prospective loanees before they are given a loan.

- Stronger cell and group formation. In order to maximize the benefits of the LIF money stronger five person cells and twenty-five member groups need to be built to encourage true cooperation and group responsibility.

- Sexual and reproductive health education. Another aspect of the project that could have been improved was that the project never standardized the sexual and reproductive health $(\mathrm{SRH})$ activities into the adolescent loan groups. Instead, a variety of methods were used; $\mathrm{SRH}$ role plays and discussions led by the trained peer educators, video presentations, discussions led by the credit officers, sports exchanges with trained peer educators, and sessions led by CARE-trained business people also involved in the commercial sales agent program socially marketing condoms. The methods used usually depended on the implementing agency and the resources available to them. Most of us felt that the interventions would have been more comparable if we had united and standardized one SRH curriculum.

- Timing of sexual and reproductive health education. The credit officers quickly learned that, whatever the activity, it was easier to encourage the $\mathrm{SRH}$ sessions before the loans were distributed and the adolescents were busy with their business.

- Situational learning for business supervision. One of the team members suggested a situational learning technique for supervision of adolescent loanees at least on the initial visit. They suggested a form of self or skills evaluation that could be produced with the adolescents themselves. Currently, there are so many loanees and their needs and skill levels so diverse that supervisory needs are left up to the three credit officers, one of whom is supervising 146 loanees. Initially it was hoped that some of this supervision might be taken over by cell or group leaders but they became so involved in their businesses that they quickly became disinterested. It is 
necessary to set up a more structured type of supervision that could include regular group meetings during the evenings or checklists on business operations. Over the course of the study period the supervisory visits should be calculated in order to determine the expense of each defaulter and whether this is a cost effective means of supervision.

- Encouraging diversity. Even when given opportunities to learn about new opportunities like the Yenga Sunflower Oil Press the youth were very slow to become interested. They seemed to be very reluctant to trust even their own family members so attempts to encourage them to collaborate were unsuccessful. Instead they all fell back on trading, often insisting on selling the same goods as their friends and neighbors. Some of the implementation team members felt that a greater emphasis on hands-on learning opportunities or short apprenticeships during the training may have encouraged some of the adolescents to try and invest in new opportunities.

\section{Impact on intervention participants}

The following section explains the impact of the two interventions on the participants, including both the general impact on their life as well as the impact on their sexual and reproductive health. The main socio-demographic characteristics of the intervention participants are outlined below.

\section{Socio-demographic characteristics of the intervention participants at the beginning of the project}

\begin{tabular}{|l|c|c|}
\hline & $\begin{array}{c}\text { Peer educators } \\
(\mathbf{n = 1 3 0 )}\end{array}$ & $\begin{array}{c}\text { Loan recipients } \\
(\mathbf{n}=\mathbf{2 2 1})\end{array}$ \\
\hline Average age & 17 years & 17.6 years \\
\hline Proportion female & $52 \%$ & $51 \%$ \\
\hline In school & $20 \%$ & 0 \\
\hline Married at baseline & $2 \%$ & $18 \%$ \\
\hline Proportion with prior sales experience & $\mathrm{N} / \mathrm{A}$ & $65 \%$ \\
\hline Proportion with children & $9 \%$ & $22 \%$ \\
\hline
\end{tabular}

\section{Peer education/condom sales agent intervention participants}

From 4-16 months after the adolescent peer educator/condom sales agent trainings were held (trainings were phased in over a year-long period) in-depth interviews were conducted with a random sample of $27 \%(35 / 130)$ of the peer educator/condom sales agents from the two intervention sites. Due to the high mobility and the attrition of these young people replacement sampling was used when a former peer educator had moved out of the compound. In addition, a sexual and reproductive health survey was conducted with participants both in the baseline period and final evaluation. The following table shows the sample size for this survey. Findings from both of these sources are presented in this section. 


\section{Sample sizes for the sexual and reproductive health behavior surveys}

\begin{tabular}{|l|c|c|c|}
\hline & $\begin{array}{c}\text { Total } \\
\text { participants }\end{array}$ & Baseline sample & Final sample \\
\hline Kanyama peer educators & 65 & $55(85 \%)$ & $42(65 \%)$ \\
\hline Mtendere peer educators & 65 & $53(82 \%)$ & $41(63 \%)$ \\
\hline
\end{tabular}

A small number of the peer educators ( $6 \%$ of the final sample) were married or married during the project. These people have been removed from the analyses on the sexual and reproductive health behavior variables but have been included in the questions on the intervention, knowledge and the impact on their lives. Eighteen months after we began this project the average age of the participants wa on the older side of our $14-19$ year old target group. The average age was just under 19 years for those sampled during the final sexual and reproductive health behavior survey.

\section{General impact}

Those who said that they were still involved with the project were asked why they had continued. The overwhelming sentiment was that these young people enjoyed the learning that enabled them to counsel and "help" others. Even as much as eighteen months after the first training the majority of the young people interviewed said that they had counseled peers in the clinic during the past month. When we asked if they felt differently about themselves since joining the project their answers centered around their changed sexual behavior and the self confidence they had gained through counseling and training. One girl commented, "I am sexual strong. I avoid sex. I can scream if a boy wants to abuse me."

We were concerned over the course of the study that the peers and families of these young people would see them differently and in a negative way, but most said that their participation had a positive effect on their relationships. A surprising number of these adolescents said that their parents supported their efforts to distribute condoms. A few of the adolescents interviewed said that their parents were uncomfortable at first but gradually began to accept the idea and even encourage them. Very few of the respondents said that they had spoken to any adults about sexuality before this study. At the time of these interviews, however, nearly all of them had. They were viewed with respect by their friends and family members and were able to discuss sexuality more freely both in and outside the home. Surprisingly almost half of these young people interviewed said that they preferred to counsel members of the opposite sex or either sex. Many boys said that they counseled girls more often "because they were the ones who needed help and lacked information." Some girls said that they found themselves counseling boys because "the girls were too shy to approach them."

Among the adolescents who were not active in the project only two commented on the content of the intervention, saying the young people were not serious and that there were no [financial] incentives for the work so they had quit. Incentives came up again when we asked what they disliked about the project. Many said that they disliked selling condoms (particularly in Kanyama where they refused to sell them) and several others felt that they should have been paid for their work. One disgruntled adolescent said, "Working without benefits, see my shoes are even finished in walking around!" When we asked what changes they would like to make in the program these young people wanted wages for 
their activities but they also wanted vocational or technical training, research experience and scholarships for finishing school.

Throughout the training course we tried to emphasize the need to view counseling broadly and the need to view oneself as a non-expert who should be referring others to facilities and individuals they had learned about. Still the facilitators were concerned that these young people viewed counseling as something that took place only in the health center's Youth Friendly Corner ${ }^{5}$. However, these adolescents were evenly split between those saying that most of their counseling took place in the clinic ("it is private and there are lots of clients') and those who did most of their counseling in the community because "..adolescents don't go to the clinic, those who need help stay in the community."

Even though condom sales for adolescents was met with reluctance among these adolescents all of them felt that condom use among young people in their communities had increased due to the project whether condoms were sold or given away. They also seemed to have no problem distributing condoms for free and many even "felt proud" about their work.

\section{Impact on sexual and reproductive health}

The vast majority of the peer educator/condom sales agents interviewed (94\%) said that they themselves were now practicing safer sex behavior. Two peer educators said that they had not changed their behavior because they had practiced abstinence before the training. The graph below categorizes the answers as to how they had changed their sexual behavior.

Figure 6: Change in sexual behavior among peer educators

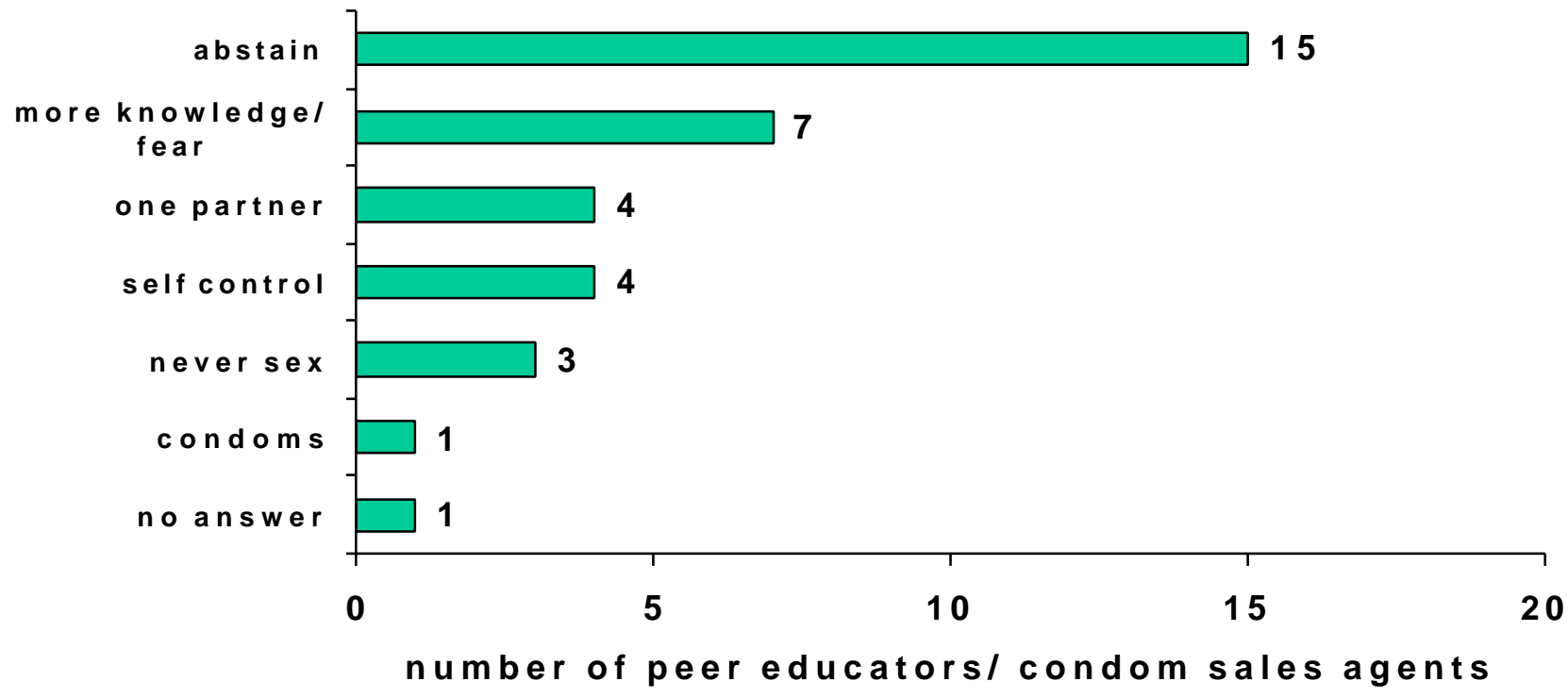

While every one of these participants said that they had changed their sexual behavior in a positive way since the intervention began (or that they had no sexual behavior to change) only one of them stated explicitly that this "change" included more condom use. By far the

\footnotetext{
${ }^{5}$ An initiative encouraged by the CARE PALS Project as a safe and confidential place in a health center where young people can meet with trained peer educators.
} 
most popular answer was abstinence. Many others stated that they now knew more about the dangers of sex and feared STIs, early pregnancy, or even death, but they did not mention any specific behavior change. Two of these peer educators also stated that they choose to control their own sexual behavior because now, "I am a teacher, I choose to lead by example as a counselor."

Figure 7: Proportion of participants with more than one sexual partner in the past three months

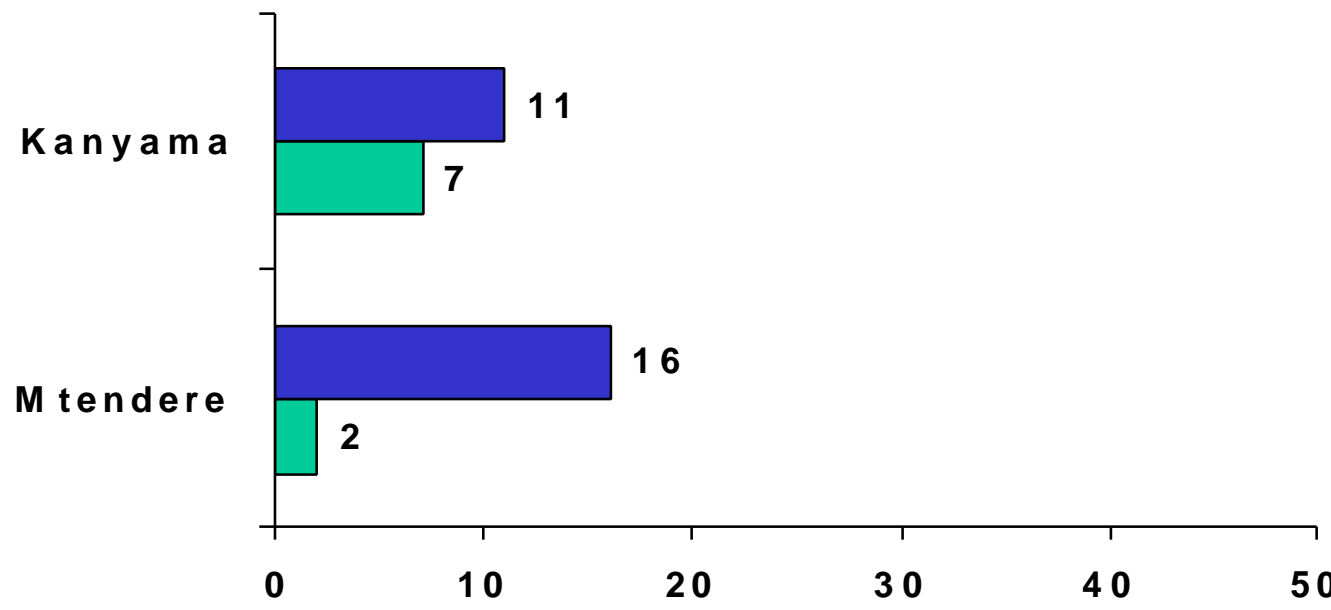

Our data suggest that the average number of sex partners in three months declined for both groups of peer educators and that fewer adolescents had more than one sexual partner after participating in the intervention than they did before the project started. For example, in Mtendere, while $16 \%$ of adolescents had more than one sexual partner in the previous three months in the baseline interview, this dropped to only $2 \%$ in the final evaluation.

These young people also reported that they were more likely to use something to prevent a pregnancy after the intervention than before the project began. The increases were similar in both compounds, as shown in the table below.

\section{Proportion of adolescents having sex in the past three months who used something to prevent pregnancy}

\begin{tabular}{|l|c|c|}
\hline & $\begin{array}{c}\text { Baseline sample } \\
(\mathrm{n}=20,16)\end{array}$ & $\begin{array}{c}\text { Final sample } \\
(\mathrm{n}=12,17)\end{array}$ \\
\hline Kanyama peer educators & $55 \%$ & $75 \%$ \\
\hline Mtendere peer educators & $50 \%$ & $77 \%$ \\
\hline
\end{tabular}

In this analysis we excluded the married participants because they may have been trying to become pregnant. Our sample sizes were further limited by including only those adolescents who have had been sexually active in the past three months. In both compounds the unmarried intervention participants were more likely to report using something to prevent a pregnancy at the close of the intervention than before the intervention began. 
Ever use of condoms among intervention participants

\begin{tabular}{|l|c|c|}
\hline & $\begin{array}{c}\text { Baseline sample } \\
(\mathrm{n}=42,37)\end{array}$ & $\begin{array}{c}\text { Final sample } \\
(\mathrm{n}=37,37)\end{array}$ \\
\hline Kanyama peer educators & $52 \%$ & $38 \%$ \\
\hline Mtendere peer educators & $62 \%$ & $68 \%$ \\
\hline
\end{tabular}

In this analysis we included all of the sexually active adolescents. While the Mtendere peer educators consistently improved on the reproductive health indicators the Kanyama peer educators (as a whole) did not report that they were more likely to have used a condom by the time the project had finished. However, the graph below does show increases in both compounds of adolescents reporting to have used a condom in the past three months.

Figure 8: Condom use among intervention participants in the past three months, Kanyama and Mtendere compounds

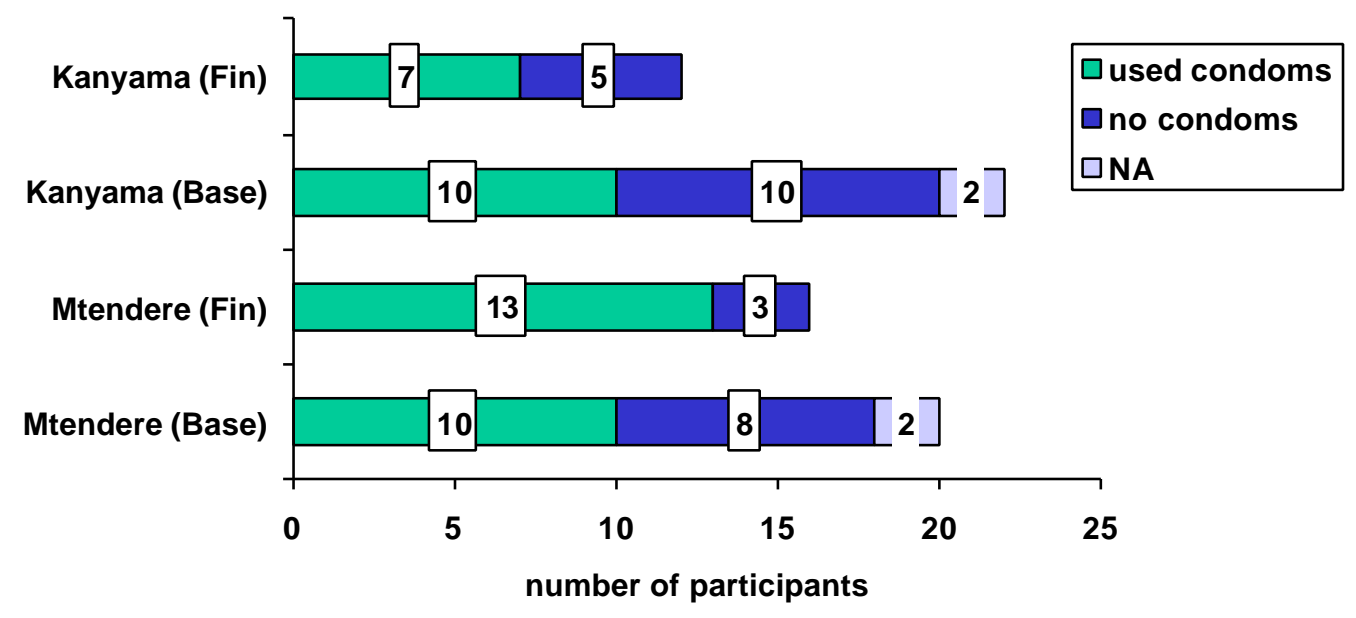

In this analysis we excluded the married participants because they may have been trying to become pregnant and limited our respondents to those who were unmarried and sexually active in the past three months. Following on the earlier question we were more interested in whether these adolescents' recent sexual activity occurring after the intervention began) was more likely to have been protected. In both of the compounds less of the peer educators were reporting to be sexually active but a higher proportion of those who were sexually active reported using a condom in the three months prior to the end of the intervention. The next table shows the results on consistency of condom use among the peer educators. 


\section{Frequency of condom use among sexually active adolescents}

\begin{tabular}{|l|c|c|c|c|c|c|}
\hline & \multicolumn{3}{|c|}{ Baseline sample } & \multicolumn{3}{c|}{ Final sample } \\
\hline & never & always & sometimes & never & always & sometimes \\
\hline $\begin{array}{l}\text { Kanyama peer educators } \\
(\mathrm{n}=40,37)\end{array}$ & $50 \%$ & $20 \%$ & $30 \%$ & $62 \%$ & $16 \%$ & $22 \%$ \\
\hline $\begin{array}{l}\text { Mtendere peer educators } \\
(\mathrm{n}=34,35)\end{array}$ & $41 \%$ & $32 \%$ & $27 \%$ & $34 \%$ & $43 \%$ & $23 \%$ \\
\hline
\end{tabular}

This question showed inconsistent results. The Kanyama peer educators included in the final sample indicated that they were less likely to use of condoms occasionally or consistently as well as being less likely to have ever used them. The Mtendere group did improve and reported to be more likely to have used a condom and more likely to always use them than the baseline group.

While promoting abstinence was not a primary objective of this project many of the adolescents felt more comfortable promoting abstinence to their peers than promoting condom use. Abstinence was also reported by the participants as the safer sexual behavior that they themselves were most commonly practicing. All of the adolescents included in these analyses and reporting abstinence over the past three months did report that they were sexually active at one time. The table below gives the percentage of adolescents who were sexually active but reported that they had abstained from sex over the past three months.

\section{Sexually active peer educators reporting to have abstained from sex for the past three months}

\begin{tabular}{|l|c|c|}
\hline & $\begin{array}{c}\text { Baseline sample } \\
(\mathrm{n}=42,37)\end{array}$ & $\begin{array}{c}\text { Final sample } \\
(\mathrm{n}=34,35)\end{array}$ \\
\hline Kanyama peer educators & $55 \%$ & $65 \%$ \\
\hline Mtendere peer educators & $49 \%$ & $54 \%$ \\
\hline
\end{tabular}

These analyses were limited to the sexually active unmarried peer educators. There was an increase in periodic abstinence reported in both of the compounds from the participants included in the final samples. While all of this abstinence may not have been intentional, it may indicate that these young people are acting more selectively about entering relationships and is reinforced by the findings on the decreased numbers of adolescents reporting more than one sexual partner. The table below also supports this information, during the final survey none of the adolescents in the peer education groups reported suffering from and STI in the past nine months.

\section{Proportion of peer educators reporting having had an STI}

\begin{tabular}{|l|c|c|}
\hline & $\begin{array}{c}\text { Baseline sample } \\
\text { Have you ever had an } \\
\text { STI? }\end{array}$ & $\begin{array}{c}\text { Final sample } \\
\text { Have you had an STI in } \\
\text { the past nine months? }\end{array}$ \\
\hline Kanyama peer educators & $9 \%(\mathrm{n}=34)$ & $0 \%(\mathrm{n}=37)$ \\
\hline Mtendere peer educators & $8 \%(\mathrm{n}=37)$ & $0 \%(\mathrm{n}=37)$ \\
\hline
\end{tabular}


Although the sample sizes are small and the time period is short these young peer educators seem to be less likely to have suffered from a sexually transmitted infection while they were participating in the intervention than they were prior to the intervention. This information provides further support for their reported increases in condom use in the past three months. The table below addresses knowledge of the peer educators regarding ways to prevent the transmission of HIV/AIDS both before and after the intervention.

\section{Percentage of peer educators reporting ways to prevent acquiring HIV/AIDS}

\begin{tabular}{|l|c|c|}
\hline Method & $\begin{array}{c}\text { Peer educators } \\
\text { Baseline (N = 108) }\end{array}$ & $\begin{array}{c}\text { Peer educators } \\
\text { Final (N = 83) }\end{array}$ \\
\hline Condom Use & $46 \%$ & $95 \%$ \\
\hline Abstinence & $45 \%$ & $86 \%$ \\
\hline Other & $4 \%$ & $11 \%$ \\
\hline Do not know & $19 \%$ & $1 \%$ \\
\hline
\end{tabular}

${ }^{*}$ multiple responses were encouraged so the figures do not total $100 \%$

As can be seen from the table above, condom use and abstinence were the most important methods reported for protecting one's self from HIV in both the baseline and final surveys. However, the final survey data also show that there was a significant increase in adolescents reporting condom use and abstinence over the responses given in the baseline survey. This is particularly significant in this society where young people are inundated with media misinformation and rumors on the inefficacy of condoms.

When we asked the counselor supervisors if they felt that the program had an impact one responded, "Yes, at first they didn't even want to talk freely about condoms but now they are moving around with them with pride, even the girls." Amongst the peer educators the most common sentiments expressed about the project centered around the following three themes.

- Learned the dangers of unprotected sex.

- I have acquired knowledge and confidence about myself.

- I never used to know anything about diseases.

\section{Micro-finance intervention participants}

Three to seven months after the initial loans were distributed (group trainings were conducted over a period of one year) in-depth interviews were conducted with a random sample of $20 \%(47 / 221)$ of the intervention participants. Sexual and reproductive health questionnaires were to have been collected from all participants at baseline and from all of the loan recipients who could still be located during the final evaluation. Unfortunately some of the questionnaires from the baseline intervention sample were lost when the CARE offices were moved so the sample for Mtendere is incomplete. The sample sizes for the SRH survey are shown below. 


\section{Sample sizes for the sexual and reproductive health behavior surveys}

\begin{tabular}{|l|c|c|c|}
\hline & $\begin{array}{c}\text { Total } \\
\text { participants }\end{array}$ & Baseline sample $^{6}$ & Final sample \\
\hline Mtendere credit recipients & 146 & $79(54 \%)$ & $59(40 \%)$ \\
\hline Ngombe credit recipients & 76 & $68(90 \%)$ & $44(58 \%)$ \\
\hline
\end{tabular}

Eighteen months after we began this project the average age of the participants is on the older side of our 14-19 year old target group. The average age is just under 19 years in all of the groups. Sixty percent of the young people interviewed were female and only four were in school at the time of the interview. We initially tried to exclude married and in school young people from the intervention group but some married and started course work after they joined their groups. While we did not intend to allow married youth into the project the ambiguous status of relationships (especially at these ages) in Zambia meant that some people were already trained or had been given a loan by the time it was discovered. Others used the proceeds from their businesses to formalize their relationships by renting a house together or paying for the church ceremony. Among the entire participant group 7 participants in Ngombe and 42 in Mtendere were married or married during the intervention. These people have been removed from the analyses on the sexual and reproductive health behavior variables but have been included in the questions on the intervention, knowledge and the impact on their lives.

\section{General impact}

Of the participants interviewed just under half of these young people had their own business at the time they received the loan and $78 \%$ felt that they had been able to accomplish something "useful" with their loan. Most of them felt that the business skills training that was developed for the intervention was the right length of time and they could name something useful that they had learned as a result of the course. In fact more of them felt that the training was too short rather than too long. When we asked them what was most useful about the training most cited different lessons in the business training. Three participants said that it was actually the $\mathrm{SRH}$ courses that they preferred, one of these said that in particular it was "how and why to use a condom". More of the young people in Ngombe asked for vocational training in addition to the loans. The following graph shows the additional training and skills that they requested.

\footnotetext{
${ }^{6}$ These samples have missing data. There is no way of being certain that this is a representative sample.
} 


\section{Figure 9: Additional skills/training requested by loan recipients}

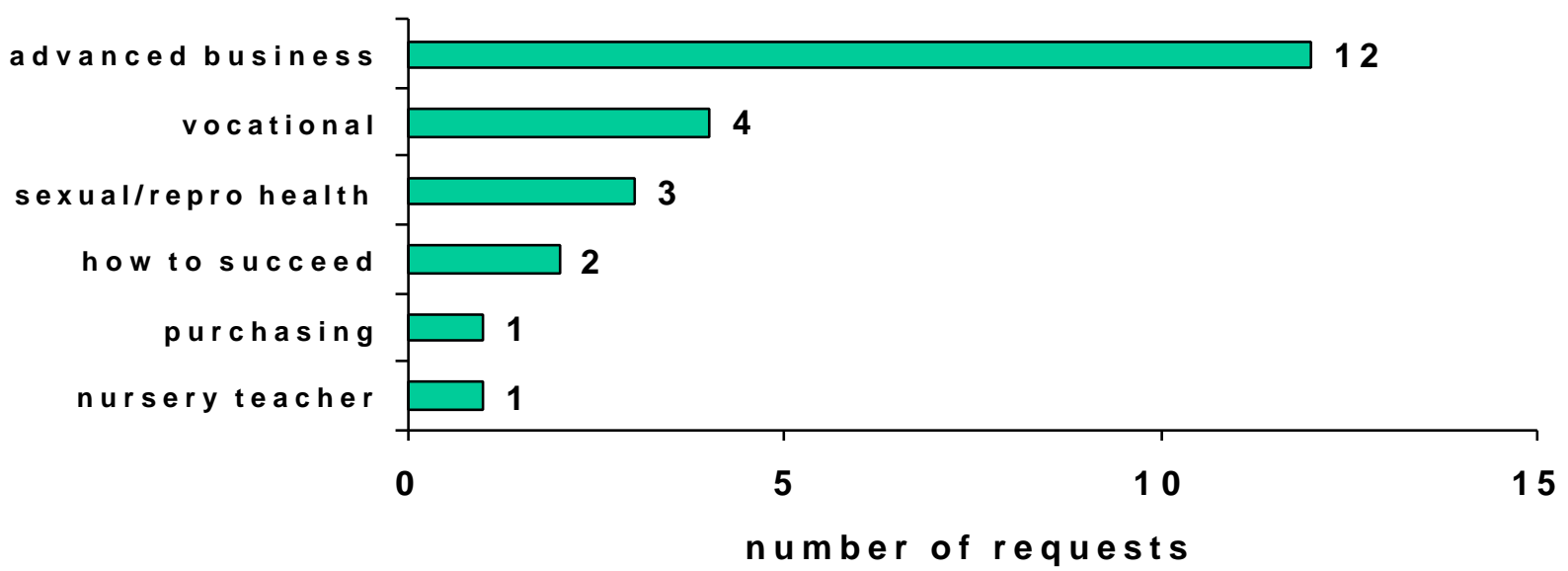

Many micro-finance projects have been criticized for giving people debt rather than loans and we were equally worried that we were doing this. However, most $(63 \%)$ of the adolescents interviewed said that the loan satisfied their business requirements and the majority also said that the six month repayment period was acceptable to them. Still, more than one-third of these adolescents said that they were very worried about being able to pay back the loan. Those that were afraid of not paying mainly said that they feared the police, that their parents would be "troubled" or they felt a responsibility toward PPAZ or CARE and did not "want to disappoint them". Many others said they were "confident that they could pay it back because they were working hard" or they were paying because they wanted a second loan, a few said that they were not worried because they knew that their fathers or other relatives would pay. More than half $(53 \%)$ of these adolescents said that receiving the loan did not mean having more money to spend on themselves. For those that did have more money most of this was spent meeting basic needs (food, health, medical, school, rent) for themselves and their families.

While livelihood objectives were not explicitly written into this project there was certainly a hope that these inputs would lead to more opportunities for the future of these adolescents. Some of these adolescents said that they did not accomplish anything with their loans, most cited illness, death of a family member or theft/swindling of their money as causes. Nearly three-quarters $(70 \%)$ of the participants interviewed indicated that they were still in business at the time of this interview and $94 \%$ said that their business was earning money. More of the respondents from Ngombe than those from Mtendere said that their business was not earning money or had already "gone broke". We asked if there were things that they had been able to accomplish (business or otherwise) because of the loan they had received and their responses are worth noting. Unfortunately, for some of the responses it is difficult to be certain whether these accomplishments were achieved due to misuse of the initial capital or because of profits earned when the business was successful. We have grouped these accomplishments into the following categories: 
Figure 10: Accomplishments of the loanees due to project participation

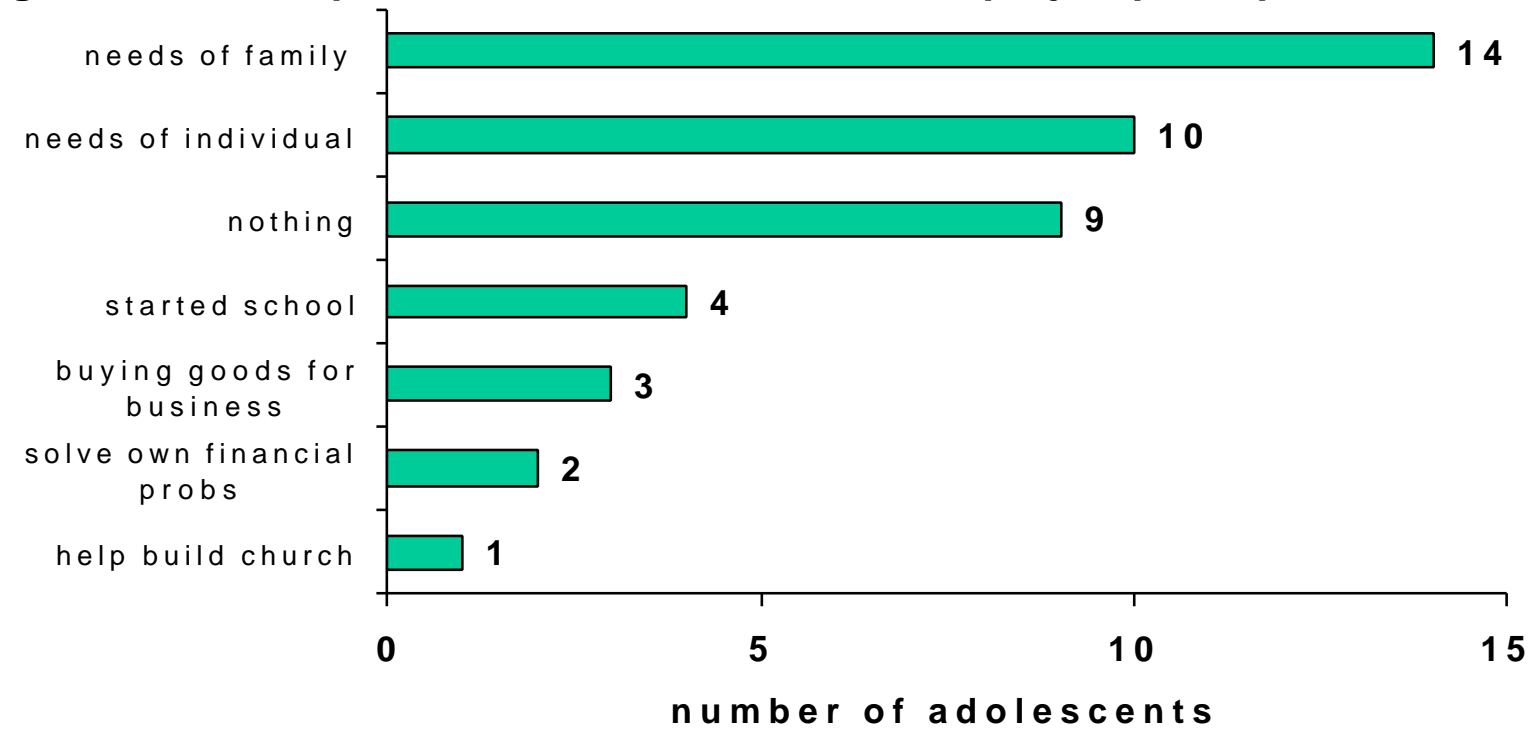

Many of the participants interviewed said that they were able to contribute to their households by paying for a relative or sibling's school fees or buying food. Others said that they were now able to buy food, clothes or shoes for themselves. On a more individual level almost half of this group (47\%) said that receiving the loan had changed their own plans for the future in some way. Two said that they themselves had been able to start school and two others said that they had plans to start. More importantly to our specific objectives may be several comments from individuals who said that "I never knew I could do business before receiving this loan" or, in regards to her future one young woman responded, "I seem to have a bright one".

We were concerned that the loans might actually contribute to stress in these young peoples' lives so we asked about their relationships. Most of the families were pleased that their offspring could contribute something in the household and the young people were proud enough to take note of this. A few articulated having problems with family members or friends who wanted money or credit or friends who were jealous of their opportunity to get a loan. One said, "We no longer have the same ideas and their doings contrast what I am doing."

We asked these young people what kinds of things had prevented them from achieving the business goals they had set for themselves. The answers reveal the complexities of their lives and environments.

\section{Barriers to achieving business goals}

\begin{tabular}{|l|c|}
\hline Barrier & Number of adolescents \\
\hline Funerals & 6 \\
\hline Sickness/pregnant & 5 \\
\hline Friend/relatives/thieves took money or goods & 5 \\
\hline No profit/loan too small & 3 \\
\hline Gave credit that was not repaid & 3 \\
\hline No storage facilities for goods & 2 \\
\hline Family responsibility is too great & 2 \\
\hline
\end{tabular}




\section{Impact on sexual and reproductive health}

All of the loan recipients were aware that our primary project objectives were related to $\mathrm{SRH}$. During their business skills courses the young people were exposed to SRH videos, role plays conducted by the peer educators, or short lessons facilitated by local experts. During this evaluation we asked open-ended questions about their own sexual behavior during the past nine months. Slightly less than half of the total interviewed (45\%) said that they had changed their sexual behavior in some way since their training. Most of these adolescents said they were abstaining from sex or being faithful to one partner because they needed to be serious about their business but none of them explicitly stated that they were using condoms more consistently (as they did in the following SRH questionnaire). Some of the adolescents (particularly in Mtendere) used their loans to improve their social standing and marry. Many said that they reduced the amount of sexual activity or partners because this type of behavior was not conducive to good business and they "feared misusing money". One young man explained this as follows, "My previous thoughts were that if I had money I would have many girlfriends but this thought has since changed." Many others said that the training had given them more knowledge (and fear) about the dangers of STls. One young woman, when asked how she had changed her sexual behavior, stated, "Now I have my own money instead of asking from men."

Through the quantitative surveys we explored changes in sexual behavior that might have occurred as a result of the micro-finance intervention.

\section{Proportion of participants with more than one sexual partner in the past three months}

\begin{tabular}{|l|c|c|}
\hline & $\begin{array}{c}\text { Baseline sample } \\
(\mathrm{n}=64,65)\end{array}$ & $\begin{array}{c}\text { Final sample } \\
(\mathrm{n}=59,44)\end{array}$ \\
\hline Mtendere credit recipients & $6 \%$ & $2 \%$ \\
\hline Ngombe credit recipients & $6 \%$ & $2 \%$ \\
\hline
\end{tabular}

Our data suggest that the average number of sex partners in three months declined for both groups of loan recipients and that fewer adolescents had more than one sexual partner after participating in the intervention than they did before the project started. Even though the proportion of adolescents who had engaged in sex was higher in both of the final samples there is still a decrease in the number of adolescents who had more than one sexual partner. These analyses include married and single loan recipients. In the following table we asked adolescents if they had used "something" to prevent a pregnancy in the past three months.

\section{Proportion of adolescents having sex in the past three months who used something to prevent pregnancy}

\begin{tabular}{|l|c|c|}
\hline & $\begin{array}{c}\text { Baseline sample } \\
(\mathrm{n}=25,22)\end{array}$ & $\begin{array}{c}\text { Final sample } \\
(\mathrm{n}=16,10)\end{array}$ \\
\hline Mtendere credit recipients & $72 \%$ & $63 \%$ \\
\hline Ngombe credit recipients & $68 \%$ & $90 \%$ \\
\hline
\end{tabular}


In this analysis we excluded the married participants because they may have been trying to become pregnant. Our sample sizes were further limited by including only those adolescents who have had sex in the past three months. In Ngombe Compound the unmarried intervention participants were more likely to report using something to prevent a pregnancy at the close of the intervention than before the intervention began. The Mtendere credit recipients were somewhat less likely to report having used something to prevent a pregnancy after participation in the intervention.

\section{Ever use of condoms among intervention participants}

\begin{tabular}{|l|c|c|}
\hline & $\begin{array}{c}\text { Baseline sample } \\
(\mathrm{n}=58,42)\end{array}$ & $\begin{array}{c}\text { Final sample } \\
(\mathrm{n}=49,34)\end{array}$ \\
\hline Mtendere credit recipients & $66 \%$ & $74 \%$ \\
\hline Ngombe credit recipients & $76 \%$ & $56 \%$ \\
\hline
\end{tabular}

In this analysis we included all of the sexually active adolescents. There was no clear and consistent trend in these analyses. The proportion of these adolescents who had ever tried a condom increased in Mtendere but actually decreased in Ngombe.

Figure 11: Condom use among intervention participants in the past three months, Mtendere and Ngombe compounds

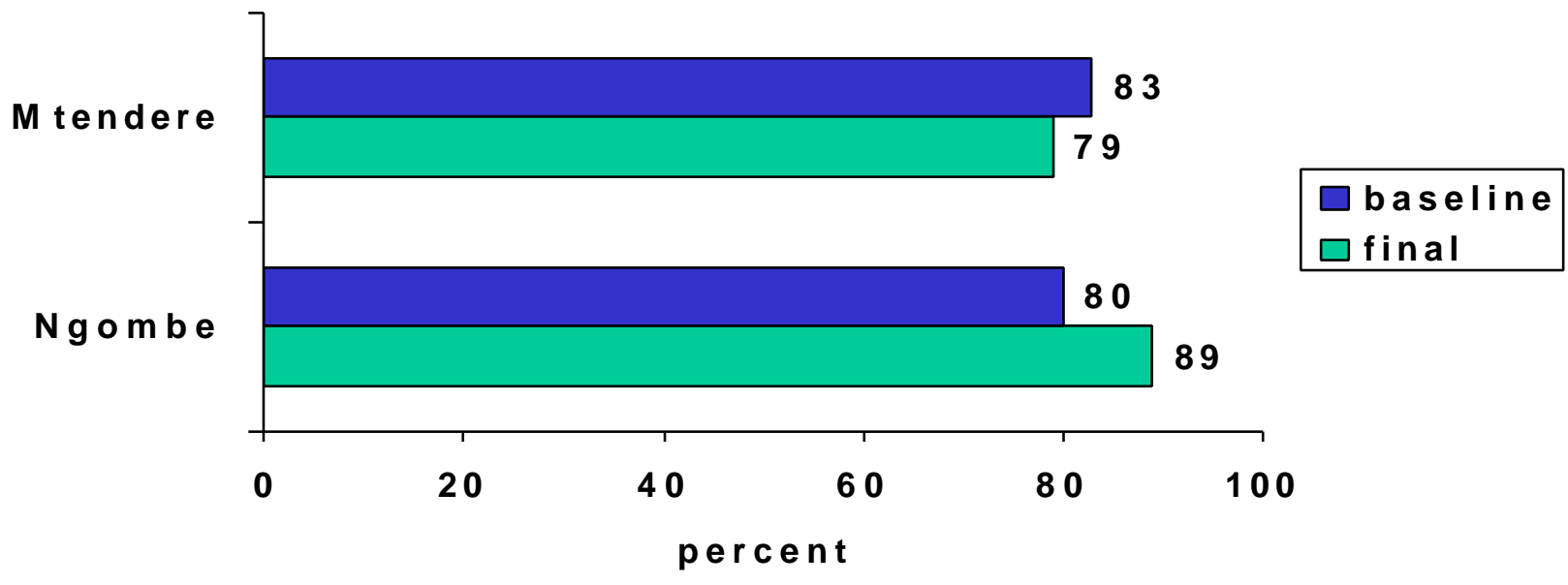

In this analysis we excluded the married participants because they may have been trying to become pregnant and limited our respondents to those who were unmarried and sexually active in the past three months. The adolescents who participated in the intervention were quite likely to have used a condom in the three months prior to participation in the intervention. During the final survey the Ngombe participants reported to have been slightly more likely to have used a condom but the Mtendere participants were slightly less likely to have used a condom in the past three months. Unfortunately the sample sizes for this question make it difficult to state a change with any kind of certainty. It appears that condom use was highly likely and condoms continued to be used among these adolescents. The following table gives the results of our questions on consistency of condom use among the peer educators. 


\section{Frequency of condom use among adolescents who have ever had sex}

\begin{tabular}{|l|c|c|c|c|c|c|}
\hline & \multicolumn{3}{|c|}{ Baseline sample } & \multicolumn{3}{c|}{ Final sample } \\
\hline & never & always & sometimes & never & always & sometimes \\
\hline $\begin{array}{l}\text { Mtendere credit recipients } \\
(\mathrm{n}=61,47)\end{array}$ & $33 \%$ & $33 \%$ & $34 \%$ & $28 \%$ & $34 \%$ & $38 \%$ \\
\hline $\begin{array}{l}\text { Ngombe credit recipients } \\
(\mathrm{n}=42,34)\end{array}$ & $24 \%$ & $48 \%$ & $29 \%$ & $44 \%$ & $21 \%$ & $35 \%$ \\
\hline
\end{tabular}

This question showed inconsistent results. Two-thirds of the baseline group reported to be using condoms either all the time or some of the time. These proportions remained constant during the final surveys but the proportion of sexually active people who reported never trying a condom decreased somewhat from $33 \%$ to $28 \%$. The inverse occurred in Ngombe and more people said that they had never used a condom during the final survey. The proportion of people who reportedly always used a condom also decreased by more than half but the number of people reporting inconsistent use did increase in this compound.

Because many of the young people were reporting that they had changed their behavior by abstaining from sex due to the intervention we looked at the difference in sexual activity reported three months prior to the beginning of the intervention and three months prior to the end of the project.

\section{Sexually active credit recipients reporting to have abstained from sex in the past three months}

\begin{tabular}{|l|c|c|}
\hline & $\begin{array}{c}\text { Baseline sample } \\
(\mathrm{n}=44,44)\end{array}$ & $\begin{array}{c}\text { Final sample } \\
(\mathrm{n}=37,27)\end{array}$ \\
\hline Mtendere credit recipients & $45 \%$ & $65 \%$ \\
\hline Ngombe credit recipients & $55 \%$ & $67 \%$ \\
\hline
\end{tabular}

These analyses were limited to the sexually active unmarried micro-finance participants. There was an increase in periodic abstinence reported in both of the compounds from the participants included in the final samples. Again, some of this abstinence may not have been intentional but it was reported in the qualitative interviews as a common form of behavior change among these young people.

\section{Proportion of credit recipients reporting having had an STI}

\begin{tabular}{|l|c|c|}
\hline & $\begin{array}{c}\text { Baseline sample } \\
\text { Have you ever had an } \\
\text { STI? }\end{array}$ & $\begin{array}{c}\text { Final sample } \\
\text { Have you had an STI in } \\
\text { the past nine months? }\end{array}$ \\
\hline Mtendere credit recipients & $6 \%(\mathrm{n}=53)$ & $8 \%(\mathrm{n}=49)$ \\
\hline Ngombe credit recipients & $5 \%(\mathrm{n}=42)$ & $0 \%(\mathrm{n}=34)$ \\
\hline
\end{tabular}

This question on sexually transmitted infections produced mixed results. In Mtendere more young people reported to have suffered from an STI in the past nine months than 
reported to have ever suffered from an STI prior to the intervention. However, none of the Ngombe credit recipients reported having suffered from an STI in the nine months prior to the close of the study. Because of the small sample size and the even smaller proportion of young people reporting to have suffered from STIs these data (both producing positive and negative results) may not be very accurate.

Because of the livelihood aspects of the project we were also interested in looking at sex for exchange of money or gifts.

\section{Proportion of credit recipients receiving a payment or gift the last time they had sex}

\begin{tabular}{|l|c|c|}
\hline & Baseline sample & Final sample \\
\hline Mtendere credit recipients & $21 \%(n=56)$ & $8 \%(n=50)$ \\
\hline Ngombe credit recipients & $43 \%(n=42)$ & $53 \%(n=34)$ \\
\hline
\end{tabular}

Sex for exchange decreased significantly during the final evaluation among the Mtendere loan recipients. However, more people reported receiving a payment or gift in exchange for sex in the Ngombe credit group during the final evaluation.

\section{Percentage of loan recipients reporting ways to prevent acquiring HIV/AIDS}

\begin{tabular}{|l|c|c|}
\hline Method & $\begin{array}{c}\text { Loan recipients } \\
\text { Baseline (N =147) }\end{array}$ & $\begin{array}{c}\text { Loan recipients } \\
\text { Final (N =103) }\end{array}$ \\
\hline Condom Use & $65 \%$ & $94 \%$ \\
\hline Abstinence & $21 \%$ & $64 \%$ \\
\hline Other & $9 \%$ & $22 \%$ \\
\hline Do not know & $12 \%$ & $2 \%$ \\
\hline \multicolumn{2}{|c|}{${ }^{*}$ multiple responses were encouraged so the figures do not total $100 \%$}
\end{tabular}

As can be seen from the table above, condom use and abstinence were the most important ways reported for protecting one's self from HIV indicated in both the baseline and final surveys. The final survey data also show that there was a significant increase in adolescents mentioning condom use and abstinence over those mentioning these methods for protection from HIV during the baseline. There was also a decrease in the number of adolescents reporting not to know even one way to protect themselves from HIV/AIDS. This seems to provide sufficient evidence to conclude that the intervention had been effective in increasing knowledge of methods for preventing HIV transmission.

\section{Community impact}

\section{Final community based PLA assessments and survey results}

This study utilized a pre-post test design to assess the impact of the project amongst a random sample of individual intervention participants (described previously) as well as in the community by using PLA assessments. The baseline and final PLAs combined community-based qualitative and quantitative data on key variables. An $\mathrm{SRH}$ questionnaire was also administered during the baseline and final evaluations. During both assessments research teams were in the field for one week per compound, three 
days collecting PLA data and two days conducting surveys. The surveys were administered by a group of trained researchers from the implementation team and the community, to a purposive sample of $400-500$ adolescents in each of the four areas. During the final PLAs we also tried to determine the level of knowledge about the project and list any other community based organizations and resources in the field of reproductive health. The similarities and differences between the first and final evaluations are highlighted in this section of the report.

\section{Characteristics of the baseline and final samples}

\begin{tabular}{|l|c|c|}
\hline Characteristic & $\begin{array}{c}\text { Baseline sample } \\
(\mathbf{n = 1 6 3 4 )}\end{array}$ & $\begin{array}{c}\text { Final sample } \\
(\mathbf{n = 1 7 2 0})\end{array}$ \\
\hline Age (boys) & 15.8 years & 15.6 years \\
\hline Age (girls) & 15.3 years & 14.9 years \\
\hline Proportion female & $48 \%$ & $49 \%$ \\
\hline In school & $51 \%$ & $56 \%$ \\
\hline Married & $3 \%$ & excluded \\
\hline Have children & $8 \%$ & $5 \%$ \\
\hline $\begin{array}{l}\text { Proportion who have ever } \\
\text { engaged in sex }\end{array}$ & $68 \%$ & $71 \%$ \\
\hline
\end{tabular}

The mean age of the adolescents included in the final evaluation was slightly different than that of the baseline participants. The adolescents sampled during the final survey were slightly younger than those included in the baseline. For the baseline sample the mean age of boys was 15.8 compared to 15.6 in the final survey. For girls the average age was 15.3 but dropped to 14.9 in the final survey. There were no significant differences in average age between the compounds. We also found that our final evaluation sample included more adolescents who were presently in school. More adolescents in Mtendere (13\%) and Misisi Compounds (10\%) were likely to have no education but the young people in Ngombe and Misisi spent fewer years in school (5.7 versus 6.4) when compared with their peers in the other two compounds.

\section{Sexual behavior among youth in Lusaka: To make love grow}

As in many African cultures, boys in Zambia are socialized to equate sexuality with manhood. The pressures to engage in sexual relations come early and are often ignored by families as topics of discussion. Sex is everywhere and boys and girls are exposed to it early. They see it in local video shows that can be viewed in exchange for a bottle with a deposit on it; in homes crowded with extended family members; and in their communities where children spy on adults engaging in sex around taverns or other wellknown meeting spots. The common belief that abortifacients are effective and locally available for "contraception" also adds to the easy acceptance of unprotected sex by both boys and girls

Of the sample of $10-19$ year olds included in the final questionnaire, $8-12 \%$ of the girls interviewed stated that they were single mothers (the lowest percentage reported in Mtendere). This is similar to the baseline results except in Mtendere where we only

\footnotetext{
${ }^{7}$ The response of a young girl in Ngombe Compound when asked about her reasons for engaging in sexual activity.
} 
asked whether or not they had been pregnant and received a positive response from more than one-fifth of the girls who said that they had previously engaged in sex. Many girls see pregnancy as a positive step or a way out; in some cases where parents have died girls consider marriage as their only option for livelihood. Instead girls often find themselves faced with becoming single mothers. Boys involved in our PLAs felt that the repercussions of accepting a pregnancy were too great and knew that they could get out of the marriage by claiming that the girl had many partners. If they were forced to marry it could mean a large sum of money would have to be paid to the girl's parents for "damaging" their daughter.

The samples collected during the baseline and the final evaluation show the two data sets to differ with respect to level of sexual activity. The survey shows that the sample of adolescents included in the final evaluation were more likely to have engaged in sex than those included in the baseline assessments except in the control site where the highest levels of sexual activity declined during the period between the baseline and final evaluation.

Proportion of 10-19 year olds who report ever having had intercourse

\begin{tabular}{|l|c|c|c|c|c|c|c|c|c|c|}
\hline & \multicolumn{2}{|c|}{ Mtendere } & \multicolumn{2}{c|}{ Kanyama } & \multicolumn{2}{c|}{ Ngombe } & \multicolumn{2}{c|}{ Misisi } & \multicolumn{2}{c|}{ TOTAL } \\
\hline & $\mathbf{M}$ & $\mathbf{F}$ & $\mathbf{M}$ & $\mathbf{F}$ & $\mathbf{M}$ & $\mathbf{F}$ & $\mathbf{M}$ & $\mathbf{F}$ & $\mathbf{M}$ & $\mathbf{F}$ \\
\hline & $\mathrm{N}=208$ & $\mathrm{~N}=191$ & $\mathrm{~N}=214$ & $\mathrm{~N}=201$ & $\mathrm{~N}=208$ & $\mathrm{~N}=195$ & $\mathrm{~N}=255$ & $\mathrm{~N}=192$ & $\mathrm{~N}=885$ & $\mathrm{~N}=779$ \\
\hline Baseline & $\mathbf{6 8 \%}$ & $\mathbf{4 1} \%$ & $\mathbf{7 9} \%$ & $\mathbf{5 6} \%$ & $\mathbf{7 6} \%$ & $\mathbf{5 6 \%}$ & $\mathbf{8 4} \%$ & $\mathbf{7 2} \%$ & $\mathbf{7 7} \%$ & $\mathbf{5 6} \%$ \\
\hline & $\mathrm{N}=245$ & $\mathrm{~N}=207$ & $\mathrm{~N}=203$ & $\mathrm{~N}=217$ & $\mathrm{~N}=214$ & $\mathrm{~N}=209$ & $\mathrm{~N}=217$ & $\mathrm{~N}=208$ & $\mathrm{~N}=879$ & $\mathrm{~N}=841$ \\
\hline Final & $\mathbf{8 3} \%$ & $\mathbf{5 4 \%}$ & $\mathbf{8 6} \%$ & $\mathbf{5 8} \%$ & $\mathbf{8 3} \%$ & $\mathbf{5 3} \%$ & $\mathbf{8 0} \%$ & $\mathbf{6 0} \%$ & $\mathbf{8 3} \%$ & $\mathbf{5 8} \%$ \\
\hline
\end{tabular}

The proportion of sexually active adolescents is higher for boys than for girls; this holds true for both the baseline data and for the final evaluation. Zambian adolescents start having sexual relationships early in their lives. The comparison of the baseline and endof-project data provides sufficient evidence at the $5 \%$ level of significance to conclude that the mean age of sexual initiation for the baseline is different from that for the final evaluation. The adolescents in the final evaluation reported having sex at slightly younger ages than those included in the baseline sample. This trend was most pronounced among girls. These data, from both the baseline and the final evaluation, also suggest that the male adolescents initiate sex at a younger age than their female counterparts.

\section{Age at first sex, by compound}

\begin{tabular}{|l|c|c|c|c|c|c|c|c|c|c|}
\hline & \multicolumn{2}{|c|}{ Mtendere } & \multicolumn{2}{c|}{ Kanyama } & \multicolumn{2}{c|}{ Ngombe } & \multicolumn{2}{c|}{ Misisi } & \multicolumn{2}{c|}{ TOTAL } \\
\hline & $\mathrm{M}$ & $\mathrm{F}$ & $\mathrm{M}$ & $\mathrm{F}$ & $\mathrm{M}$ & $\mathrm{F}$ & $\mathrm{M}$ & $\mathrm{F}$ & $\mathrm{M}$ & $\mathrm{F}$ \\
\hline $\begin{array}{l}\text { Baseline } \\
\text { (years) }\end{array}$ & 11.8 & 13.9 & 11.3 & 13.4 & 12.2 & 12.7 & 12.1 & 13.2 & 11.9 & 13.3 \\
\hline $\begin{array}{l}\text { Final } \\
\text { (years) }\end{array}$ & 11.7 & 13.3 & 11.2 & 12.6 & 11.8 & 12.3 & 11.6 & 12.5 & 11.6 & 12.7 \\
\hline
\end{tabular}

Generally during PLAs boys and girls were likely to say that school-going girls were less likely to engage in early sexual activity than their peers who were school leavers because school leavers were more likely to trade sex for money. Girls commonly listed their sources of livelihood as vending, prostitution or stealing. These two girls from Ngombe gave us their methods for earning money: 
- Prostitution

- Stealing

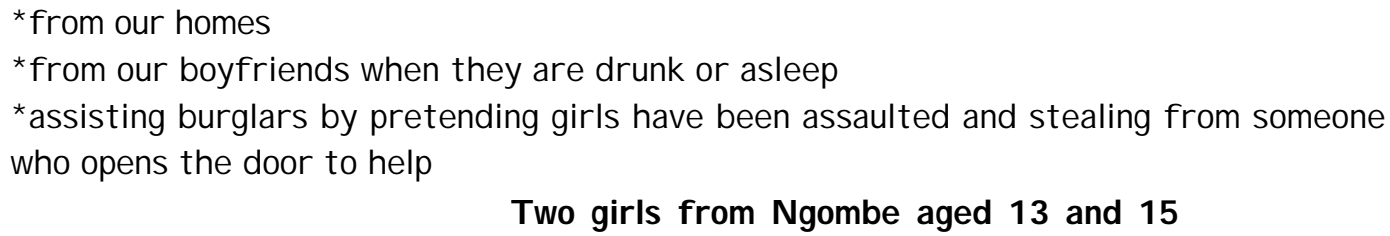

By and large, sex payments are often used as sources of livelihood, particularly for girls. It was stated over and over during the assessments that one of girls' primary reasons for engaging in sex was poverty or simply, for money and material goods that they had no access to. One girl in Misisi Compound spoke about girls in her community:

When parents die there is no one to lean on for support. As a result the only means of survival is to get married.

During the PLAs, the adolescents gave a number of other reasons supporting their perception that schoolgirls resist engaging in sexual activity. They felt that girls in school fear having to quit school. They are usually taught the dangers of sex in classes and are more occupied than those girls who have already stopped schooling. Out of school girls were thought to start having sex earlier than all other groups because they need money, want stable partnerships, have more free time, and often exhibit "bad behavior".

Contrary to the belief that being out of school increases levels of sexual activity and decreases age of sexual initiation, quantitative data show that most young people are initiating sex before they finish primary school and school does not seem to influence this decision. In a few situations girls would say that they did not believe that there was a difference. These girls from Ngombe Compound voiced their opinion:

There is no change in the behavior between in and out of school. It is even worse for those in school because they want more money for many things. They are even picked in boyfriends' cars.

\section{8 girls 13-14 years old, Ngombe Compound}

Baseline and final survey data also present contradictory results about these assumptions of decreased sexual activity and school attendance. During the final survey we asked adolescents to recall the first time they had sex and tell us if they were in school at that time. The results are shown below. 
Figure 12: Proportion of adolescents reporting that they were in school when they first had sex (final survey ${ }^{8}$ )

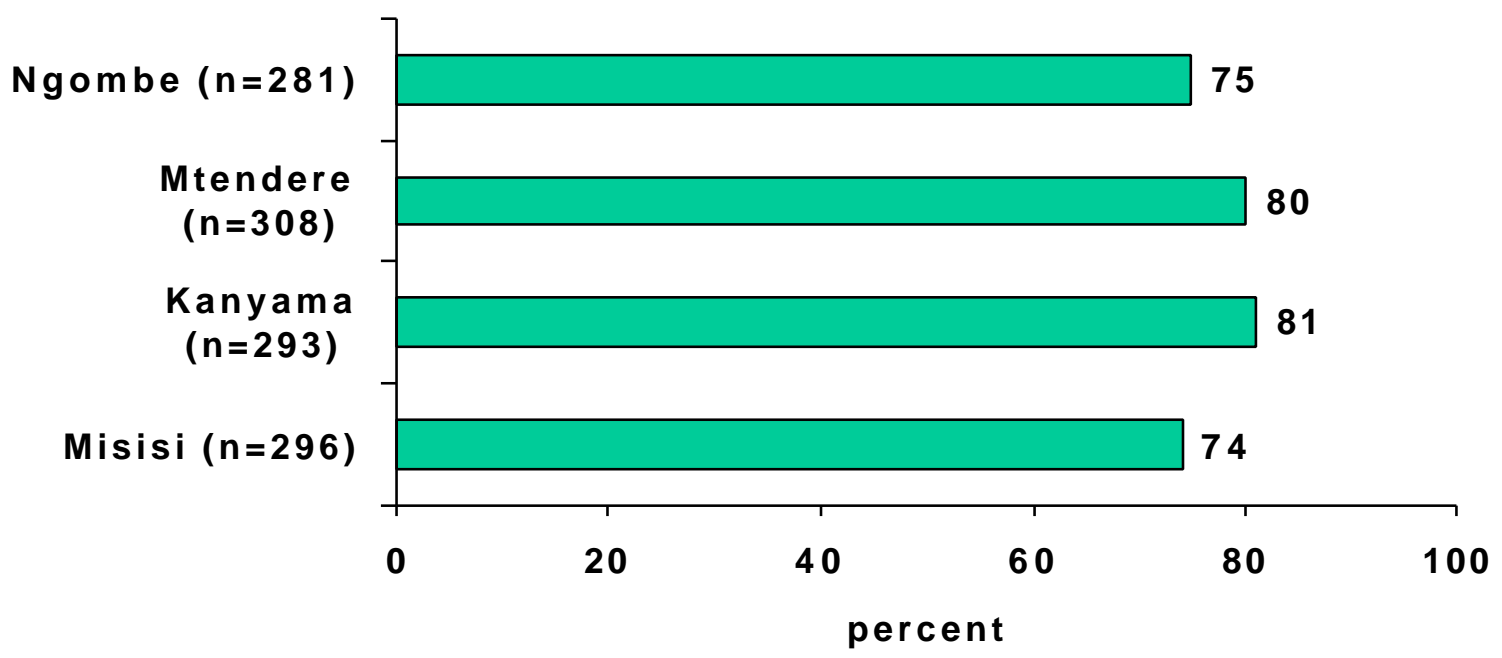

Overall, $78 \%$ of the adolescents were in school at the time they initiated sex (figure 12). The proportions are highest in Mtendere and Kanyama compounds where there are more school-going youth who go to school for more years on average than the young people who live in the other two compounds. While school may not cause people to engage in sexual activity, these data indicate that school may not act as a deterrent to early sexual activity as both adolescents and policymakers often claim.

Even though youth in the final survey were more likely to have been sexually active in the past three months than those in the baseline sample, the number reporting to have had more than one sexual partner in the past three months decreased significantly for both boys and girls. In Mtendere amongst boys and girls and amongst Kanyama girls these groups were twice as likely to have had only one sexual partner in the past three months than the ones surveyed during the baseline. The only groups that did not report fewer sexual partners were those sampled in the control site, Misisi Compound. The table below gives these results for both the baseline and final samples.

\section{Proportion of adolescents who have had more than one sexual partner in the past three months}

\begin{tabular}{|l|c|c|c|c|c|c|c|c|c|c|}
\cline { 2 - 11 } \multicolumn{1}{c|}{} & \multicolumn{2}{c|}{ Mtendere } & \multicolumn{2}{c|}{ Kanyama } & \multicolumn{2}{c|}{ Ngombe } & \multicolumn{2}{c|}{ Misisi } & \multicolumn{2}{c|}{ TOTAL } \\
\cline { 2 - 11 } \multicolumn{1}{c|}{} & $\mathbf{M}$ & $\mathbf{F}$ & $\mathbf{M}$ & $\mathbf{F}$ & $\mathbf{M}$ & $\mathbf{F}$ & $\mathbf{M}$ & $\mathbf{F}$ & $\mathbf{M}$ & $\mathbf{F}$ \\
\hline Baseline & $54 \%$ & $28 \%$ & $57 \%$ & $18 \%$ & $47 \%$ & $14 \%$ & $62 \%$ & $15 \%$ & $55 \%$ & $40 \%$ \\
\hline Final & $24 \%$ & $14 \%$ & $32 \%$ & $9 \%$ & $26 \%$ & $12 \%$ & $71 \%$ & $29 \%$ & $30 \%$ & $14 \%$ \\
\hline
\end{tabular}

While reports of "rape" are rarely read in the Zambian newspapers or discussed with outsiders, when we used the words "forced sex" many young boys and girls had a lot to say. One young boy in Ngombe said that "...rape is common because girls wear mini-

\footnotetext{
${ }^{8}$ During the baseline SRH survey we asked if they were in school now and how old they were when they initiated sexual activity but we neglected to ask if they were in school when they first had sex.
} 
skirts." Girls in Kanyama believed that even if sex is forced, if it is with a husband or boyfriend, it is not rape. They felt that rape only occurs between strangers and, in most cases, the girl's vagina is torn. Forced sex was thought to be very common and boys are socialized to believe that it is not wrong to force themselves on their wives or other women. Boys will speak with chilling indifference about their steps to win a girl, with flirtatiousness, gifts or force.

The most common way to "win girls" is through exchange, sometimes this exchange is made in appreciation for sex, at other times as a way of convincing someone to have sex. Exchange (or remuneration) for sex and partnership is deeply embedded in the lives of these adolescents. It starts early and is certainly not thought of as prostitution, it is even sometimes from girls to boys. In fact very few women who receive sex for money in these communities are considered to be prostitutes. Exchange for sex is equally as likely among young people to be for scones, snacks, pencils or small amounts of money. Usually boys give voluntarily but the exchange, usually benefiting the girl, seems embedded in the culture because of the inherent power and economic disadvantage of girls. In some households girls are even indirectly encouraged to engage in sex (or to find a boyfriend) to help feed and support the household. The table below from a PLA exercise in Ngombe Compound gives girls' reasons for engaging in sex with certain partners and shows how deeply embedded the ideas of exchange are in their culture.

\section{Preferred sex partners and reasons, from a group of 20 adolescent girls in Ngombe compound (final PLA)}

\begin{tabular}{|l|l|c|}
\hline Preferred sex partner & Reasons & $\begin{array}{c}\text { Preference } \\
\text { ranking }\end{array}$ \\
\hline Driver & Give starter money & 1 \\
\hline Office workers & Help by providing transport at funerals & 2 \\
\hline Doctors & Good medicine; the medicine which you \\
& can't find & 3 \\
\hline Police officers & Defend you & 3 \\
\hline Pilot & Buydresses and perfume & 3 \\
\hline Cooks & Good leftovers & 4 \\
\hline Teachers & Places in school & 5 \\
\hline Busconductors & Free transport & 5 \\
\hline Gardener & Give plants/flowers & 6 \\
\hline Water tap attendants & Give free water & 7 \\
\hline Yo/gangstas (trendy rich 6oys) & Nice dressers & $7-8$ \\
\hline Zamcab (piecework hauling) & Nothing & 8 \\
\hline Guards & Sleep alone & 10 \\
\hline Tavernoperators & Free beer & 15 \\
\hline Kawalala (thieves) & Give dollars and nice pots & 16 \\
\hline
\end{tabular}

One young girl from Kanyama stated it this way:

We cannot stop having sex with our boyfriends because they give us money and whatever we need in our lives. Parents cannot reach our demands. 
During the survey we asked the sexually active adolescents if they received a payment or gift the last time they had sex.

\section{Proportion of adolescents who gave/ received a payment the last time they had sex}

\begin{tabular}{|l|c|c|c|c|c|c|c|c|c|c|}
\cline { 2 - 11 } \multicolumn{1}{c|}{} & \multicolumn{2}{c|}{ Mtendere } & \multicolumn{2}{c|}{ Kanyama } & \multicolumn{2}{c|}{ Ngombe } & \multicolumn{2}{c|}{ Misisi } & \multicolumn{2}{c|}{ TOTAL } \\
\cline { 2 - 11 } \multicolumn{1}{c|}{} & $\mathbf{M}$ & $\mathbf{F}$ & $\mathbf{M}$ & $\mathbf{F}$ & $\mathbf{M}$ & $\mathbf{F}$ & $\mathbf{M}$ & $\mathbf{F}$ & $\mathbf{M}$ & $\mathbf{F}$ \\
\hline Baseline & $40 \%$ & $66 \%$ & $11 \%$ & $53 \%$ & $36 \%$ & $70 \%$ & $58 \%$ & $69 \%$ & $37 \%$ & $65 \%$ \\
\hline Final & $35 \%$ & $67 \%$ & $3 \%$ & $53 \%$ & $43 \%$ & $46 \%$ & $72 \%$ & $77 \%$ & $42 \%$ & $58 \%$ \\
\hline
\end{tabular}

The same proportions of girls reported receiving money or gifts during the baseline when compared with the final survey except in Ngombe where there has been a significant decline. There is also a significant increase in girls receiving payment or gifts for sex in Misisi compound. More boys (as one might expect) also reported giving something for sex in Misisi. They also were more likely to give something for sex in Ngombe where fewer girls said that they had received anything. In the other two intervention compounds, Mtendere and Kanyama, boys were less likely to pay for sex the last the last time they had it than they were at baseline. Even though the economy in Zambia has taken a severe downturn over the eighteen months since the project began there is not sufficient evidence at the $5 \%$ level of significance to conclude that there is less (or more) remunerated sex now than at the beginning of the project. Misisi compound youth reported the highest level of sex for money both during the baseline and the final evaluation where both young men and women reported to be more likely to have given or received something after engaging in sexual activity.

We asked girls in Misisi compound what they would do to stop prostitution in their community and they drew us the following list.

\section{How to stop prostitution according to a group of girls aged 12-18 years from Misisi compound}

- Employment e arning at le ast 225,000 each

- Improve water situation. Drawing water at all hours of the night adds to rape and bad sexual befiavior.

- Give loans to do business

- Abolish some of the bars that have brothels

- If parents could find ways to keep children in school

- Teach reproductive health

- Forming more clubs for young people

\section{Pregnancy Prevention}

Condom use and abstinence were the most frequently cited ways to prevent pregnancy known and used by these young people, although more than two-thirds of those who are sexually active have still never used anything to prevent a pregnancy or protect themselves from an STI. The table below lists the answers from the adolescents during 
the baseline and final evaluation when we asked if they had ever used anything to prevent a pregnancy.

\section{Proportion of adolescents who have had sex who use something to prevent pregnancy}

\begin{tabular}{|l|c|c|c|c|}
\hline & Mtendere & Kanyama & Ngombe & Misisi \\
\hline $\begin{array}{l}\text { Baseline: } \\
\text { Never }\end{array}$ & $75 \%$ & $74 \%$ & $85 \%$ & $85 \%$ \\
\hline \hline $\begin{array}{l}\text { Final: } \\
\text { Never }\end{array}$ & $64 \%$ & $71 \%$ & $71.5 \%$ & $71 \%$ \\
\hline Always & $11 \%$ & $9 \%$ & $11 \%$ & $10 \%$ \\
\hline Sometimes & $25 \%$ & $20 \%$ & $17.5 \%$ & $20 \%$ \\
\hline
\end{tabular}

Using something to prevent pregnancy appears to have become more common in all of the compounds when compared to the baseline data. This change is least pronounced in Kanyama. One-quarter to one-third of the adolescents we sampled in the final survey have used something to prevent a pregnancy and almost $10 \%$ of them in each of the compounds (including the control site) said that they always use something to protect themselves from pregnancy.

The most important method used by these adolescents to prevent pregnancy was a condom reportedly used at least occasionally by $26 \%$ of the adolescents who had engaged in sex over in the past three months. The table below lists the family planning methods used by adolescents in these communities during the three months prior to the close of the intervention.

\section{Methods used to prevent pregnancy among adolescents who used something in the past three months (final survey)}

\begin{tabular}{|l|c|c|c|c|c|}
\hline & $\begin{array}{c}\text { Mtender } \\
\mathbf{e}\end{array}$ & Kanyama & Ngombe & Misisi & Total \\
\hline Condoms & $42(71 \%)$ & $49(93 \%)$ & $62(94 \%)$ & $50(78 \%)$ & $\mathbf{2 0 3 ( 8 4 \% )}$ \\
\hline OCs/Injectable & 12 & 2 & 4 & 11 & $\mathbf{2 9}(\mathbf{1 2} \%)$ \\
\hline Other & 5 & 2 & 0 & 3 & $\mathbf{1 0 ~ ( 4 \% )}$ \\
\hline
\end{tabular}

As might be expected, condoms were the most popular method for preventing a pregnancy in all of these compounds, $84 \%$ of young people who used something to prevent a pregnancy, chose condoms. Hormonal contraception (oral contraceptives or injectables) ranked second, the selection of $12 \%$ of adolescent contraceptors. During the PLAs we found a common perception that oral contraceptives are only acceptable for women who have already given birth, and this is probably one reason that they are not a popular choice among young women and men. Perhaps because of the way the question was stated we did not receive many answers other than common medical family planning methods. When exploring these young people's perception of family planning during PLA discussions they came up with less mainstream answers, as shown in the example below from a group of girls in New Kanyama. 
Family Planning methods, according a group of 21 girls in Kanyama aged $10-20$ years old

\begin{tabular}{|l|c|}
\hline Family planning method & Amount \\
\hline Tembusha, muleza, lunzonga herbs and roots & $\begin{array}{c}\text { Per instructions from } \\
\text { marketeers or relatives }\end{array}$ \\
\hline Panadol & 4 tablets after sex \\
\hline Cafenol & 4 tablets after sex \\
\hline Chloroquine & 4 tablets after sex \\
\hline Ampicillin & 6 tablets per day \\
\hline Abortion & $\mathcal{N} / \mathcal{A}$ \\
\hline
\end{tabular}

The adolescents were asked to name three ways to prevent pregnancy but many of them could not complete this task. Forty percent named condom use as a contraceptive method. Abstinence and oral contraception ranked second and third, with $23.5 \%$ and $18.5 \%$, respectively. A small number of the adolescents in every compound thought Panadol (a local analgesic) or chloroquine (for treatment of malaria) could prevent pregnancy. Both of these drugs are often cited in PLAs as abortifacients when taken in larger than normal quantities after unprotected intercourse. Almost $6 \%$ of the adolescents could not name a single method for preventing pregnancy. The only significant difference in these data between the control and intervention sites was the predominance of adolescents naming traditional family planning methods in Misisi compound. The table below summarizes the most common methods mentioned by these adolescents as ways to prevent pregnancy.

\section{Methods known by adolescents as ways to prevent pregnancy (final survey)}

\begin{tabular}{|l|c|c|c|c|c|}
\hline Method & Mtendere & Kanyama & Ngombe & Misisi & Total \\
\hline Condoms & $38 \%$ & $42 \%$ & $40 \%$ & $39 \%$ & 40 \\
\hline Abstinence & $24 \%$ & $23 \%$ & $25 \%$ & $21 \%$ & 23 \\
\hline OCs & $19 \%$ & $18 \%$ & $21 \%$ & $19 \%$ & 19 \\
\hline Other & $9 \%$ & $6 \%$ & $5 \%$ & $7 \%$ & 7 \\
\hline Traditional & $4 \%$ & $2 \%$ & $2 \%$ & $6 \%$ & 4 \\
\hline Don't Know & $5 \%$ & $9 \%$ & $6 \%$ & $9 \%$ & 7 \\
\hline
\end{tabular}

${ }^{*}$ multiple answers were possible

Although we did not ask specific questions relating to abortion in the survey, again our PLA results indicated that knowledge of traditional abortifacients is high among these young people. Most of their methods are attempts to overdose on a substance either considered "strong" or even toxic. Both boys and girls in all of the communities listed chloroquine (five or "as many as you could swallow"), washing powder, ashes made into a type of baking soda, "red and black capsules" (these are usually thought to be nonprescription antibiotics), and many types of traditional herbs and roots commonly found in Zambian markets as abortifacients. The widespread knowledge that these abortifacients are effective and readily available may be contributing to high levels of unprotected sex among these youth. 
When we designed the survey questionnaire we were careful to include questions on condoms and contraception. Perhaps because of the strong social marketing program in Zambia when we asked young people to list methods of "contraception", the adolescents rarely listed condoms as a method for preventing pregnancy but clearly thought of it almost exclusively as protection from STIs and HIV/AIDS. Perhaps because of their control of the method boys in Mtendere felt that condoms were the most common method used to prevent pregnancy but girls felt that vachiboyi (traditional methods like those listed earlier in the Kanyama output) were more common. In Misisi Compound one group of girls said that family planning pills are favored by girls for three main reasons: 1) they are available, 2) they are cheap, 3) the girl who decides to use the pill is actually the one taking the pill. Girls could also name several different traditional methods including locally bought herbs to drink or tie around the waist and tattoos engraved by local ngangas (healers) as well as many non-prescription drugs which they felt could be taken in large quantities to cause a miscarriage. Another girl in Mtendere described her classmates' experience with vachiboyi.

One girl narrated that in her class of twelve 10 to 16 year-old girls six became pregnant. Of these six, four aborted and one of these died of an overdose of black and red capsules. The other three girls used vachiboyi and succeeded in aborting but they dropped out of school.

Extract from Mtendere field notes

In this case in Mtendere a group of girls 10-18 years of age felt that unplanned pregnancies had increased among young people, as described below.

One girl cited an example of her friends. She said that out of eleven friends six had become pregnant and only two decided to keep the pregnancy. The four who decided to abort used Surf detergent, an ash solution (chidulo), matembusha herbs and chloroquine. The girls said that most boyfriends don't allow them to use condoms because they believe that if a girl falls pregnant they can easily abort.

From the field notes of Gladys Nkhama, Mtendere Compound

During the PLA in Kanyama Compound eleven boys ages 14 to 18 shared their thoughts about condom use. They told us that condom use in their community had increased this year because there are now more STIs and many of them had now experienced relatives dying of AIDS.

The baseline survey attempted to establish information that would build a foundation for our programs thus we asked if these young people had ever used a condom or contraception to establish the figures in the table below. During the final evaluation we were more interested in recent changes in sexual behavior so we asked about the past nine months. The final survey results below show that nearly one-third of the adolescents who had sex at least once over the past three months told us that they had used a condom (a slightly higher proportion than those who said that had used condoms as "something to prevent a pregnancy"). 


\section{Condom use among adolescents, by compound}

\begin{tabular}{|l|c|c|c|c|}
\hline & Mtendere & Kanyama & Ngombe & Misisi \\
\hline $\begin{array}{l}\text { Ever used a condom } \\
\text { (baseline) }\end{array}$ & $28 \%$ & $29 \%$ & $30 \%$ & $36 \%$ \\
\hline $\begin{array}{l}\text { Used a condom in } \\
\text { past 3 months (final) }\end{array}$ & $29 \%$ & $29 \%$ & $33 \%$ & $33 \%$ \\
\hline
\end{tabular}

These data suggest that a larger proportion of the sexually active youth are using condoms. Even when we asked whether they had used any method in the past three months the proportion of users is similar or greater than when we asked if they had ever used a condom. While this seems to be a higher proportion than those reporting ever having used a condom in the baseline sample it is still alarming when one considers that HIV infection among adults aged 15 or more in Lusaka is around $26.5 \%(\mathrm{CBoH}, 1997)$. There was also general agreement in the PLA exercises that unprotected ("skin to skin") sex is more expensive for the male paying for sex. The Misisi control sample is the only compound that showed a slight decrease (to 33\%) when we asked if they had used a condom in the past nine months.

PLA data have shown us that male adolescents view condoms as something to be used to protect them against an infection particularly when sleeping with "bad girls". This perception is so strong that girls who try to negotiate condom use are often regarded as having an infection or being unfaithful. Other negative perceptions are still heard in these communities (although seemingly less frequently than 18 months ago) that the lubricant used on condoms causes cancer and that condoms have holes in them. The belief that condoms are "not 100\% safe" (and therefore not necessary) is often used as a rationalization for not using condoms. Some adolescents claim that there are boys who do not use condoms because they are bitter about being infected and intend to infect others. The table below gives the adolescents' survey answers regarding consistency in condom use.

\section{Consistency of condom use among ever users, by compound}

\begin{tabular}{|l|c|c|c|c|c|}
\hline & Mtendere & Kanyama & Ngombe & Misisi & $\begin{array}{c}\text { TOTAL } \\
(\mathrm{n}=321)\end{array}$ \\
\hline Always & $27 \%$ & $23 \%$ & $39 \%$ & $30 \%$ & $29 \%$ \\
\hline Sometimes & $73 \%$ & $77 \%$ & $61 \%$ & $70 \%$ & $71 \%$ \\
\hline
\end{tabular}

In the final survey we tried to determine whether these adolescents who reported having used condoms before were using them consistently or only occasionally. Almost onethird of the sexually active adolescents who had ever used a condom said that they always used them. The vast majority used them only occasionally.

\section{HIV/AIDS and sexually transmitted infections}

Awareness about the risks of HIV/AIDS transmission is usually considered to be high in Zambia; the Zambia DHS indicates that awareness about AIDS is almost universal among adults. However, it is interesting to note that only half of the young people that we asked for two ways to prevent HIV and AIDS named condom use. There were also a significant number of young people $(6 \%)$ who were unable to name even one way to 
prevent HIV/AIDS transmission. The pattern of answers was similar across all four compounds, with no significant difference in responses between the intervention sites and the control site. The following figure shows a composite of all of the answers.

Figure 13: Adolescent responses from all compounds about ways to prevent HIV/AIDS transmission ( $n=2506$ responses from 1664 respondents)

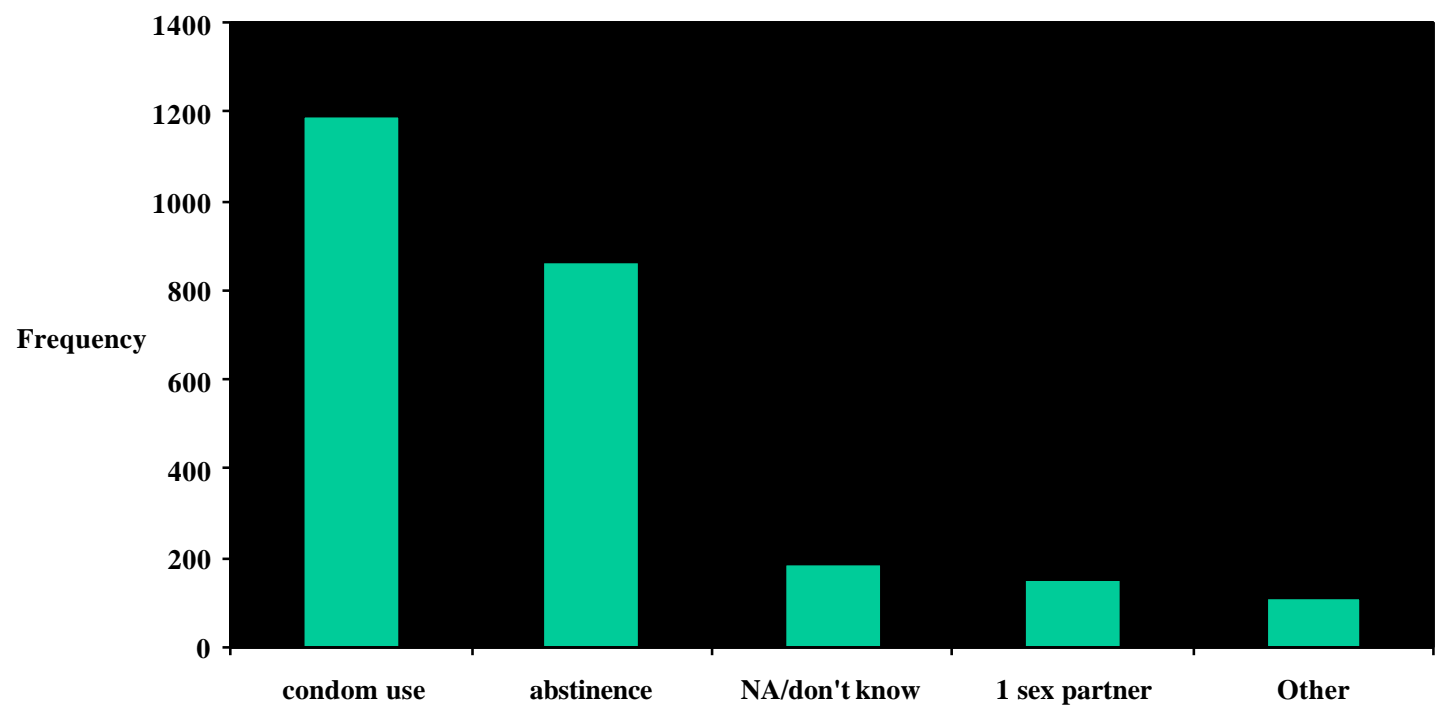

When we looked at the same data in a different way we found an interesting trend. More of the adolescents in Mtendere could name two ways to prevent HIV/AIDS transmission than in the other three compounds. Also, fewer adolescents in Kanyama and Mtendere were unable to mention a single way to protect themselves from HIV/AIDS. The results of this analysis is shown below.

\section{Proportion of adolescents in the final survey who could name two ways or zero ways to prevent the spread of HIV/AIDS}

\begin{tabular}{|l|c|c|c|c|}
\hline & Mtendere & Kanyama & Ngombe & Misisi \\
\hline Two ways & $62 \%$ & $50 \%$ & $45 \%$ & $37 \%$ \\
\hline Zero ways & $1 \%$ & $0 \%$ & $10 \%$ & $8 \%$ \\
\hline
\end{tabular}

In general these young people knew a good deal about HIV/AIDS, how it is transmitted and how to protect one's self. Knowledge about ways to prevent AIDS appears to be higher in the peer education intervention sites and lowest in Misisi and Ngombe Compounds. In one group of ten boys involved in the PLA in Ngombe each one of them knew someone who had died of AIDS. This has been identified as being one of the key factors in success in behavior change interventions. In the same compound girls estimated that three out of ten adults in their community were infected with HIV/AIDS. They were all aware of the dangers of casual unprotected sex yet they admitted that adolescents (including they themselves) infrequently use condoms.

There was clearly a strong belief that only certain "types" of people get AIDS, particularly those who are promiscuous and those who frequent bars and taverns. Some young 
men said that HIV/AIDS was a disease that commonly affected "rich" people. A few PLA participants thought that sharing utensils could infect someone with HIV. Some of the adolescents named "getting married" as one way to protect yourself from HIV/AIDS.

Reducing the incidence of unplanned pregnancy and sexually transmitted infections within the participant groups and their communities were two of the primary objectives of the study. Hence, information on the incidence, prevention and treatment of sexually transmitted infections was sought during the baseline and final PLAs and surveys. The question to elicit this information from the respondents was changed slightly in the final questionnaire to make it time-bound to the project. We asked if they had suffered from an STI in the past nine months. Thus a direct comparison is impossible but it is still useful to make some inferences regarding these figures.

\section{Percentage of youth reporting having had an STI}

\begin{tabular}{|l|c|c|c|c|c|c|c|c|c|c|}
\cline { 2 - 10 } \multicolumn{1}{c|}{} & \multicolumn{2}{c|}{ Mtendere } & \multicolumn{2}{c|}{ Kanyama } & \multicolumn{2}{c|}{ Ngombe } & \multicolumn{2}{c|}{ Misisi } & \multicolumn{2}{c|}{ TOTAL } \\
\cline { 2 - 10 } \multicolumn{1}{c|}{} & $\mathbf{M}$ & $\mathbf{F}$ & $\mathbf{M}$ & $\mathbf{F}$ & $\mathbf{M}$ & $\mathbf{F}$ & $\mathbf{M}$ & $\mathbf{F}$ & $\mathbf{M}$ & $\mathbf{F}$ \\
\hline $\begin{array}{l}\text { Baseline : } \\
\text { Percentage of } \\
\text { sexually active } \\
\text { adolescents who } \\
\text { EVER had an STI }\end{array}$ & $4 \%$ & 0 & $9 \%$ & $7 \%$ & $10 \%$ & $2 \%$ & $8 \%$ & $7 \%$ & $7.8 \%$ & $4.0 \%$ \\
\hline $\begin{array}{l}\text { Final : Percentage } \\
\text { of sexually active } \\
\text { adolescents who } \\
\text { have had an STI } \\
\text { in the past 9 } \\
\text { months }\end{array}$ & $2 \%$ & $2 \%$ & $3 \%$ & $6 \%$ & $3 \%$ & 0 & $9 \%$ & $8 \%$ & $4.8 \%$ & $4.3 \%$ \\
\hline
\end{tabular}

As would be expected, when the length of time for reporting suffering from an STI is shortened most of the percentages decreased when compared with those who reported that they had sometime in their lives suffered from an STI. This is true even though in our final samples we included a larger population with a higher proportion of sexually active adolescents. Although the observed frequencies are too small for this analysis to be of any statistical significance there is a trend worth noting. The exception to the decreasing incidence of STIs is in the control site where even more young people reported having an STI in the past nine months than reported ever having one two years ago. The other reported increase was among a small number of Mtendere girls. None of those included in our baseline sample reported having suffered from an STI but $2 \%$ of those included in the final survey reported having one in the past nine months.

As we found in the baseline PLAs, young people continue to prefer not to go to the health center for treatment of an STI. One boy in Mtendere narrated his story of self-treatment to one of the researchers.

A 17 year-old boy had leaking. After three days he notices a strange feeling in his penis. He had difficulties urinating, later pus developed. He bought thirty red and black capsules for $K 3,000$. He took five in the morning and five in the evening, two days later he felt better.

Extract from Mtendere field notes 
During the Mtendere PLA another group of four boys made the following output on their feelings about STI treatment in their community.

\begin{tabular}{|l|c|c|c|c|}
\hline Best treatment & AIDS & syphilis & bola-bola $^{9}$ & gonorrhea \\
\hline nganga & No cure & $\mathrm{X}$ & $\mathrm{X}$ & $\mathrm{X}$ \\
\hline health center & No cure & & & \\
\hline
\end{tabular}

Mtendere boys 15-19, Final PLA

We asked the adolescents included in the survey where they went for treatment of the STI they had been suffering from. We were not surprised to find that in all three of the intervention sites, most of these youth said that they went to the clinic for treatment of the STI, although more than one-third said that they went to a nganga. However, in the control site the adolescents were more likely to go to a nganga for treatment. The chart below shows the summary of the preferences for STI treatment among the infected adolescents in all four compounds.

Figure 14: Where adolescents with an STI sought help and/or treatment $(n=54)$

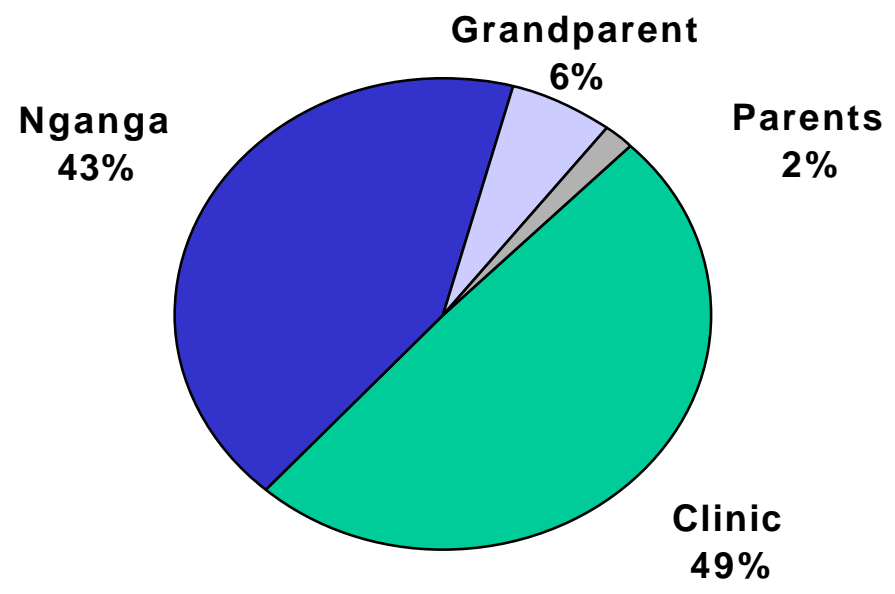

The adolescents repeatedly identified STls as a problem during the PLAs in these communities and were knowledgeable about the symptoms of STIs. On the contrary, the quantitative data showed a fairly low incidence of STIs.

In an effort to find out more about the incidence of STIs in these communities we conducted a clinic record review as part of our final evaluation. In a nine month review from January - September, 1998, the antenatal syphilis results in three clinics (Ngombe does not have a health facility and Kamwala clinic encompasses Misisi Compound) we discovered an alarming number of young women screened for syphilis had positive test results using the Rapid Plasma Reagin test (RPR). Unfortunately we do not have baseline data to compare these records but the information provides some context about the lives and risks these young people face. The following graph shows the proportion of women that had reactive syphilis screening that were $10-19$ year-old girls, these results ranged from a low of $17 \%$ at Kamwala clinic to a high of $37 \%$ at Mtendere.

\footnotetext{
${ }^{9}$ Adolescents commonly consider this to be any STI with ulcers or swelling in the groin that causes the individual to walk with legs apart.
} 


\section{Figure 15: Proportion of positive syphilis tests belonging to adolescent girls during routine ANC exams, 1998}

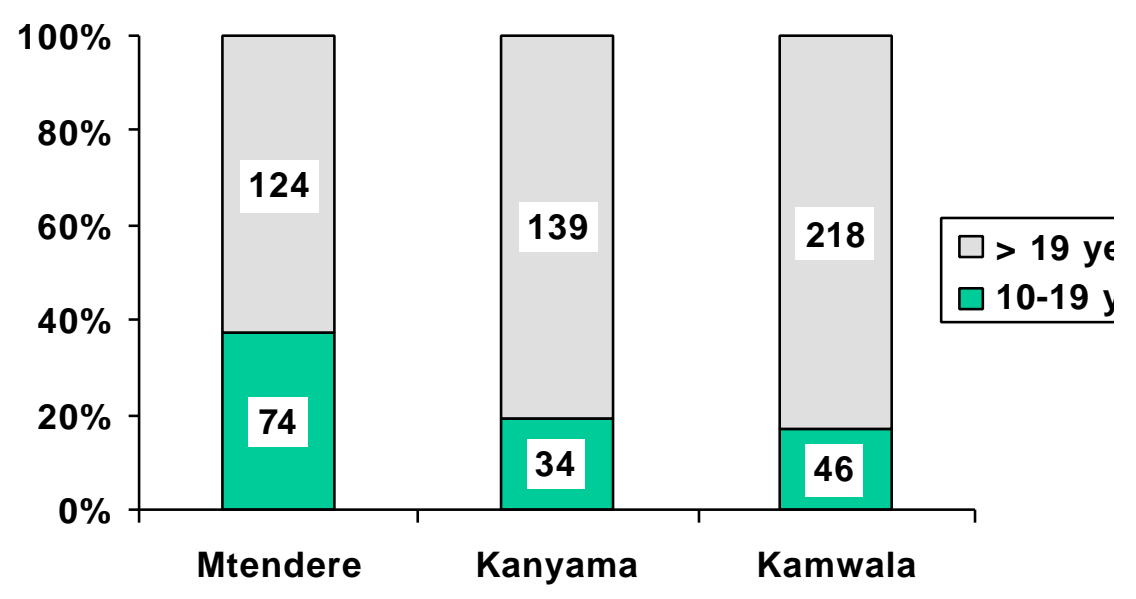

After September of 1998 the number of women screened for syphilis in the ANC clinic decreased dramatically because of shortages of essential supplies and commodities. Most supplies were reserved for symptomatic cases. One issue that came out during the Mtendere PLA was that of payment for STI treatment. We conducted exit interviews with adolescents leaving the out-patient department and found that everyone was made to pay into the "medical scheme" (the Lusaka Urban District health insurance) even though essential services like treatment for STIs are meant to be excluded from the costsharing plan. One 18 year old boy we interviewed reported that he had been diagnosed with syphilis. He had tried treating himself at home with the help of his parents and then had gone to a nganga but nothing helped. On this day he had paid Kw 2,500 to update his health insurance and was given a prescription for his drugs. He was told that if he brought his partner back he would be treated for free but he told the peer educator that he did not intend to do this. Another group of six adolescents expressed their discontent with the Mtendere health center:

People are frustrated. They have resorted to traditional medicine because of medical fees and the attitude of medical personnel. Even when you go there are no drugs for treatment.

\section{Program coverage}

Peer education has long been a favorite strategy for public health practitioners around the globe but often these strategies go on without evaluation and data on the costs of starting and maintaining the project. We also used a peer education model in an attempt to increase the provision of reproductive health information and services through these adolescent community counselors and commercial sales agents. The purpose of this strategy was to reach as many adolescents as possible with important information relating to their sexual and reproductive health and to improve adolescent access to condoms for protection from HIV/AIDS, STIs and unplanned pregnancy. In both Kanyama and Mtendere the peer educators were allowed to use small rooms for counseling in the health center (that they deemed a Youth Friendly Corner) as well as counseling youth in the community. In Ngombe Compound two other reproductive health 
projects had adolescent components including two active peer educators, one run by the YWCA and the other by PPAZ. During PLAs many groups of young people told us that they knew that condoms were available to them through peer educators. This was the case in both of our peer educator sites as well as in Ngombe where other projects for youth were ongoing.

In our survey of adolescents in these two communities, $15 \%$ of boys and girls in Mtendere and $8 \%$ of boys but only $4 \%$ of girls in Kanyama said that they had spoken with one of our peer educators. This information is illustrated in the graph below.

Figure 16: Proportion of adolescents who had spoken with a peer educator $(n=814)$

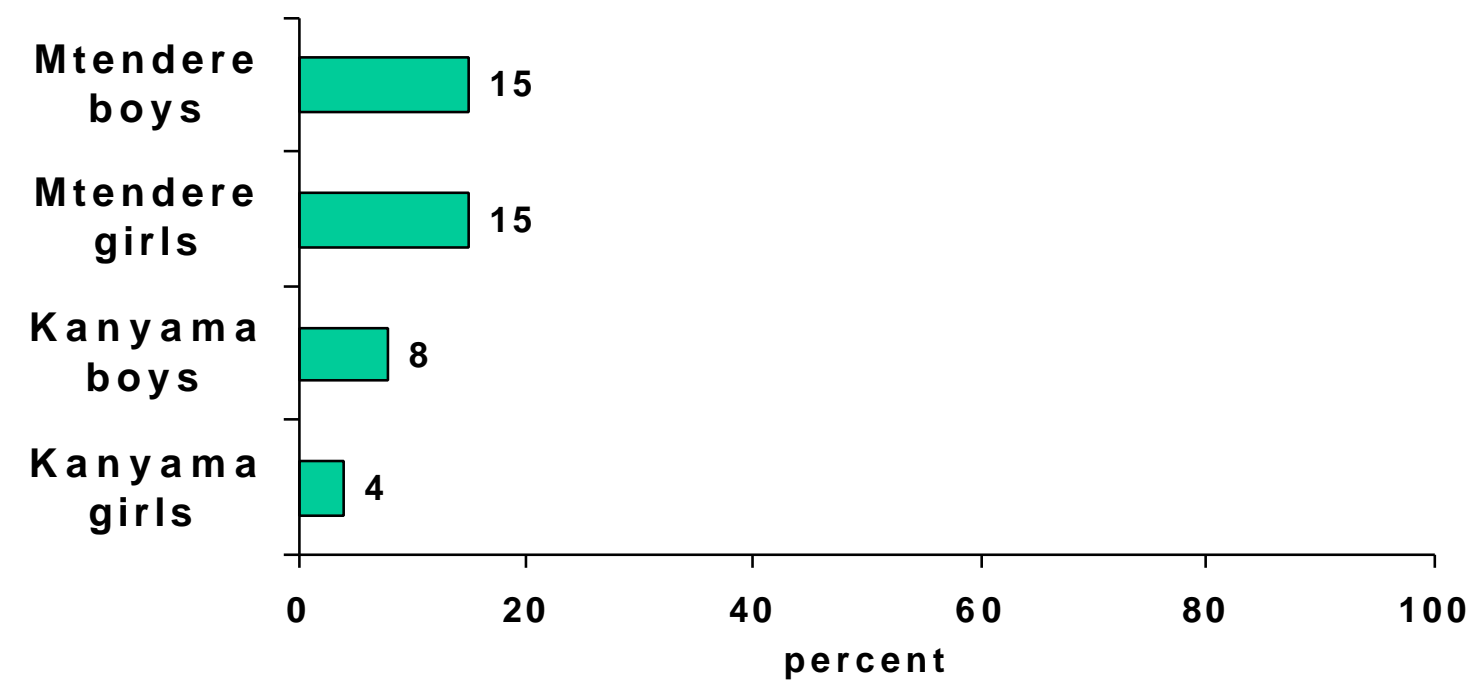

In Kanyama there was general knowledge that peer educators existed and many people could name the two groups, our project (known as the Kanyama Youth Project) and the Ministry of Health peer educators. However, there was general disagreement about whom these projects catered for. Many adolescents said that both projects only gave condoms to older people and that they preferred the Ministry peer educators because they were active in the community, doing drama, music and skits for AIDS prevention.

We were equally curious to know what the peer educators were discussing with the young people in their communities. The pie chart below lists the topics discussed with the peer educators as they were interpreted by their young "clients". 
Figure 17: Clients reporting of topics discussed by peer educators in Mtendere and Kanyama $(n=80)$

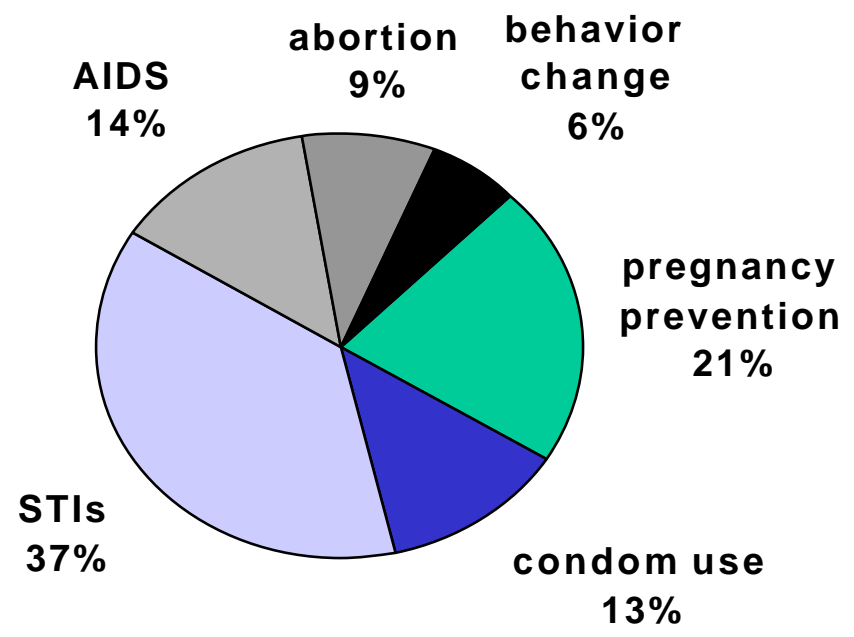

While the peer educators maintained that adolescents were not willing to pay for condoms, these data seem to suggest the opposite is true. Most of these adolescents bought condoms for their use and only rarely did they get them free of charge from their relatives, peer educators and/or friends. The major condom sources they identified were the market, the tuntembas (small stands for household goods), shops, and groceries.

Source of condoms for those who have used in past three months

\begin{tabular}{|l|c|c|c|c|c|}
\hline & $\begin{array}{c}\text { Mtendere } \\
\mathrm{n}=61\end{array}$ & $\begin{array}{c}\text { Kanyama } \\
\mathrm{n}=54\end{array}$ & $\begin{array}{c}\text { Ngombe } \\
\mathrm{n}=66\end{array}$ & $\begin{array}{c}\text { Misisi } \\
\mathrm{n}=69\end{array}$ & TOTAL \\
\hline $\begin{array}{l}\text { Market/Shops/ } \\
\text { Grocery/Ntemba }\end{array}$ & 41 & 34 & 49 & 64 & $188(75 \%)$ \\
\hline Peer educators & 3 & $14^{10}$ & 2 & 0 & $19(8 \%)$ \\
\hline Clinics & 10 & 3 & 4 & 3 & $20(8 \%)$ \\
\hline Chemist & 5 & 0 & 6 & 2 & $13(5 \%)$ \\
\hline Friend/relative & 2 & 3 & 5 & 0 & $10(4 \%)$ \\
\hline
\end{tabular}

Clinics and peer educators did supply a significant number of these condom users with condoms. In the condom distribution sites for the project, Kanyama youth were more likely to receive condoms from their community based peer educators who were distributing free condoms than were the youth in Mtendere where the peer educators were predominately selling condoms. This is interesting when compared with the responses to the questions described above; Mtendere boys were almost twice as likely and the girls were almost four times as likely to say that they had spoken to a peer educator about SRH topics. Peer educators are under-represented in Ngombe and Misisi because there are none in Misisi Compound and only a small group of PPAZ outreach workers in Ngombe Compound. Mtendere youth were somewhat more likely to get their condoms at the health center than were young people in the other three compounds.

\footnotetext{
${ }^{10}$ Half of these stated explicitly that they received their condoms from a CARE/Makeni/Kanyama Youth Project peer educator, the others did not specify the type of peer educator.
} 


\section{Community impact conclusions}

It appears that the interventions were not able to delay or stop sexual activity; in the postintervention period, age of sexual initiation had not increased and levels of sexual activity had not decreased. However, it does seem that adolescents in the intervention compounds were practicing safer sexual and reproductive health behavior, our primary objective. The following evidence supports this conclusion:

- Adolescents in the intervention sites were less likely to have had more than one sexual partner in the past three months as compared with the baseline figures and as compared with the control site

- Condom use seemed to show greater increases in the intervention sites as compared with the control site

- The control site showed a higher proportion of adolescents reporting that they had had an STI in the previous nine months as compared with the intervention compounds

- Adolescents who had had an STI in intervention sites were more likely to seek treatment from a clinic as opposed to a nganga as compared to the control site.

\section{Comparison of the interventions: Measuring success}

In comparing the interventions, first it is important to consider the comparability of the intervention participants and of the four compounds where the study took place. The school leavers who participated in this project were all fairly well educated by National standards. On average, the peer educators tended to be better educated than the participants in the micro-finance intervention (8.75 years versus 8 years of education) and the young people in Mtendere tended to be better educated than their peers in the other compounds. In Kanyama the peer educators who continued with the project were among the better educated in the group.

A small proportion of the peer educators were married ( $3 \%$ at baseline) and several more were married during the intervention. Many more of the credit recipients married during the project and some even said that the stability that they had gained after receiving their loan allowed them to make these changes in their lives. Almost one-quarter of all of the participants sampled had children. More of the Mtendere credit recipients were married and/or had children than any of the other intervention groups. Interestingly the lowest numbers of the same occurred among the Mtendere peer educators. The young ages of sexual initiation, child bearing and marriage in these communities make it difficult to control for these factors when working with this target population.

Evaluation results confirm that both groups of intervention participants are practicing safer sexual behavior. Both groups seem to be having fewer sexual partners and are more likely to have used condoms in the past three months. More than $75 \%$ of the adolescents in each intervention group who reported having sexual intercourse in the last three months, had only one sexual partner. However, the changes in sexual behavior were most pronounced in the peer educator groups and particularly the Mtendere group. Conversely, changes in outlook for the future, the ability to go back to school and feelings of responsibility toward one's self and one's family are also important and came out 
strongly from the micro-finance participants. Making a choice between one or the other intervention becomes difficult and requires a difficult judgement call. These interventions are very different and it makes sense to us that the achievements of the participants are also very different. In this project we focused on sexual and reproductive health but, as we knew from the design and baseline information gathered during this project, the adolescents themselves viewed the improvements of their lives differently and more broadly.

The variation between the compounds and the short study period make it difficult to rule out broader changes taking place in the urban environment and assess differences in these communities that might be due to the project. We selected these sites because they had few or no adolescent sexual and reproductive health programs but that has also changed over the two year study period especially in Ngombe and Kanyama. Most notably though we were struck by the severity of the situation in Misisi Compound. We asked young people in Misisi if they thought their environment was more difficult than other parts of Lusaka and they pointed to the lack of infrastructure; no schools, a nearby health center but not one located in the community, an abundance of brothels and the lack of recognition given by the local government. One girl said, "We are a condemned community, bakawalala (thieves) and prostitutes find it very comfortable here. Girls who live in Libala, Kabwata and Longacres (nearby communities) come here to rent small rooms and be independent. Outsiders coming from the Copperbelt get stranded here and begin business at the Zambia-Zaire complex".

Thus impact at the community level was difficult to measure. We looked most specifically for knowledge of the interventions and it was clear that many young people in each of the sites knew of the existence of the project. In the compounds with peer educators we found a significant number of young people who received either information or condoms from the peer educators/condom sales agents. Young people reporting condom use as the primary way to prevent HIV/AIDS was more common in the peer education intervention sites. While many of the micro-finance recipients reported that they themselves were practicing safer sexual behavior these participants were not given additional skills training in counseling nor were they expected to disseminate the $\mathrm{SRH}$ information beyond their usual social networks. In terms of community impact and our implementation of these interventions one would have to say that a peer education program has greater community level impact.

\section{Policy and programmatic recommendations}

Results from this project were disseminated in various meetings, conferences and workshops. A national dissemination was held in Lusaka in February 1999. The following recommendations are based on the study findings, as well as discussions and suggestions arising from these meetings.

Peer education programs:

- Peer educator programs are labor intensive but they seem to pay off both in communities and among participants themselves in terms of improving sexual and reproductive health.

- Peer educators should distribute condoms for free rather than selling them. 
Micro-finance programs:

- A successful micro-finance program for youth must have meaningful involvement of households in the groudwork, as family responsibilities have a large impact on adolescents.

- A successful micro-finance program for youth must have strong selection criteria.

- A micro-finance program that targets female adolescents will do better than one that targets males.

General recommendations:

1. Any interventions that wish to affect the age of sexual initiation need to start in primary schools. Our intervention did not have an impact on the age of sexual initiation because our fourteen to nineteen year-old target group was already several years older than the average age of sexual initiation in these communities.

2. Reproductive health programs must be more proactive about addressing girls' livelihoods. Interventions that have a broader and more integrated approach to development can also have positive reproductive health outcomes. It is clear that sex for money, early ages of sexual initiation and lack of condom use are often tied to girls' limited employment opportunities and earning power.

3. Young people need accurate information on the dangers of self-induced abortion. Access to modern family planning methods is limited for youth and many young people have misperceptions about what family planning methods are available and appropriate for their use. Taking overdoses of toxic substances to induce miscarriages is common and thought to be effective. Because of these limitations and beliefs young people often resort to traditional methods and modern medicines that are probably highly ineffective and sometimes dangerous.

4. In order to address the stigma that surrounds condom use, the condom social marketing program should be stronger in their campaign to promote condoms as a family planning method. Adolescents primarily view condoms as a means of protecting themselves from acquiring an infection rather than as a method for preventing pregnancy. Therefore young people who try to negotiate condom use are often stigmatized and thought to have an infection or chastised for considering their partner to be at risk.

5. In order to make condoms more accessible to young people, special condom distribution campaigns should focus on youth and these should utilize a variety of channels and locations. Condoms are the most important family planning and disease prevention method for young people in Zambia. Many young people state they want to use condoms but have problems accessing them, either freely or for sale. Making condoms available to young people in places and manners that are acceptable to them must become a high priority in order to improve youth access to condoms. 


\section{Appendices}

\section{A listing of project outputs and presentations}

Fetters T, Mupela E, Rutenberg N. Youth Talk about Sexuality: A Participatory Assessment of Adolescent Sexual and Reproductive Health in Lusaka, Zambia, 1998.

A Facilitator's Guide for Training Adolescent Peer Educators and Condom Sales Agents in Zambia. Available through CARE Zambia.

Daka J, Ndelefa, J. A Loan Procedures Manual for Adolescent Micro-finance. Available through CARE Zambia.

Fetters T, Ndelefa J. Using Participatory Learning and Action Methodology to Assess Youth Livelihoods in Sub-Saharan Africa. Paper presented to the Youth Livelihoods Knowledge Network in Mangochi, Malawi, 1998.

Fetters T. Using PLA methods in the Testing Community-Based Approaches for Improving Adolescent Reproductive and Sexual Health Operations Research Study. Paper submitted to CARE USA for publication in the PLA Guidelines, 1998.

Fetters T. Opening Different Doors: Using Quantitative Surveys to Complement PLA Findings. Paper submitted to CARE USA for publication in the PLA Guidelines, 1999.

Mupela E, Fetters T. Testing Community Based Approaches for Improving Adolescent Sexual and Reproductive Health: PLA Household Survey Results from New Kanyama and Mtendere Compounds. Paper presented to the $3^{\text {d }}$ Reproductive Health Priorities Conference, Republic of South Africa, 1997.

Ndelefa J, Fetters T. Meeting Adolescent Reproductive Health Needs through Economic Empowerment. Poster presentation at the 4th Reproductive Health Priorities Conference, Republic of South Africa, 1998.

Nkonde M, Fetters, T. An Evaluation of a Condom Social Marketing Project for Adolescents. Poster presentation at the 4th Reproductive Health Priorities Conference, Republic of South Africa, 1998.

Fetters T, Siachitema K. "Reproduction Health"; Adolescents appraise their own reproductive health problems in Peri-urban Lusaka, Zambia. Poster presented at the American Public Health Association Annual meeting, 1997.

Teenagers at Risk: Community-based Adolescent Reproductive Health Interventions: A Dissemination Meeting; The Pamodzi Hotel, 25 June 1997.

First working group of the Zambia micro-finance network for youth held at CARE Zambia in September 1998.

Using Micro-credit and peer educators to reach Youth in Zambia: Nairobi Hilton Hotel, Africa Operations Research and Technical Assistance Project II End of Project Conference, November 1998.

Investing in Youth : A Dissemination meeting. The Pamodzi Hotel, Lusaka, Zambia, 26 February 1999. 
Investing in Youth: A Dissemination meeting. USAID Washington, March 1999. 